\title{
Achievements obtained within ATLLAS-II on Aero-Thermal Loaded Material Investigations for High-Speed Vehicles
}

\author{
Johan Steelant ${ }^{1}$, \\ ESA-ESTEC, European Space Agency, Keplerlaan 1, 2200 AZ Noordwijk, the Netherlands \\ Mats Dalenbring 2 , \\ FOI, Swedish Defence Research Agency, 16490 Stockholm, \\ Markus Kuhn ${ }^{3}$, \\ German Aerospace Center (DLR), 70569 Stuttgart, Germany \\ Marc Bouchez ${ }^{4}$, \\ MBDA, rond point Hanriot, 18020 Bourges, France \\ Jens von Wolfersdorf ${ }^{5}$, \\ USTUTT, University of Stuttgart, Germany
}

\begin{abstract}
The co-founded FP7 EC project ATLLAS-II had as objectives the identification and assessment of advanced lightweight and high-temperature resistant materials for high-speed vehicles up to Mach 6.

The material requirements were defined through an in-depth feasibility study of a Mach 5-6 vehicle. The consortium could build upon a set of validated tools, material databases and valuable experience acquired during ATLLAS-I. Starting with a preliminary aero-thermal-structural high-speed vehicle design process, a multi-disciplinary optimization and experimental testing resulted into a detailed layout of a high-speed vehicle. Special attention was given to alleviate sonic boom and emissions at high altitudes.

Throughout the design process, the aero-thermal loads defined the requirements for the proposed materials and cooling techniques needed for both the airframe and propulsion components. The former focused on sharp leading edges, intakes and skin materials each coping with different external aero-thermal loads. The latter were exposed to internal combustion driven loads. Both metallic (Titanium Matrix Composites and Ni-based Hollow Sphere Stackings) and non-metallic materials (Ceramic Matrix Composites and Ultra High Temperature Ceramics) were evaluated.

Combined aero-thermal-structural experiments tested various materials at extreme conditions representative for high flight Mach numbers. Both static and cyclic tests at low and high temperatures were performed including the evaluation of their durability in terms of long duration exposure to the harsh flight conditions. The materials assigned to dedicated engine components were exposed to realistic combustion environments. These were combined with passive or active cooling technologies developed in ATLLAS-I.
\end{abstract}

\section{Nomenclature}

AoA: Angle of attack

AoS: Angle of sideslip

BoC: Beginning of Cruise

CMC: Ceramic matrix composites

DF: Digital Filter

EoC: End of Cruise

FE: Finite Element

FSI: Fluid Structure Interaction

HSS: Hollow sphere structures

MDO: Multi-Disciplinary Optimization

PAX: Passengers

PBL: Planetary Boundary Layer

RSM: Reynolds Stress Model
RTM: Resin Transfer Moulding

SDI: Stochastic Design Improvement

SPS: Spark Plasma Sintering

ST: $\quad$ Synthetic Turbulence

SWBLI: Shock Wave Boundary Layer Interaction

TGMF: Thermal Gradient Mechanical Fatigue

TMC: Titanium Matrix Composites

TPS: Thermal Protection System

TSS: Tube stacking structures

UHTC: Ultra-High Temperature Ceramics

$\begin{array}{ll}b: & \text { wing span } \\ C_{D}: & \text { drag force coefficient }\end{array}$

\footnotetext{
${ }^{1}$ Ph. D., Senior Research Engineer, ESA-ESTEC, P.O. Box 299, Noordwijk, Netherlands, Johan.Steelant@esa.int,

2 Ph. D., Senior Research Engineer,

${ }^{3}$ Research Scientist, Space Systems Integration, Institute of Structures and Design

${ }^{4}$ Aerospace Engineer, AAAF Senior Fellow, AIAA Member

${ }^{5}$ Professor, Institute of Aerospace Thermodynamics (ITLR), Universität Stuttgart, Pfaffenwaldring 31, D-70569, Germany
} 


\section{Introduction}

$F^{\circ}$ or high-speed aircraft, material and cooling issues for both airframe and engine are one of the key elements which force the designer to limit the flight Mach number. The expected benefits of economical, highperformance and high-speed civil-aircraft designs that are being considered for the future will strongly depend through the development of light-weight, high-temperature composite materials for structure and engine applications to reduce weight, fuel consumption, and direct operating costs [1][2][3].

When aircraft fly fast for long periods of time, friction heats up the outer surfaces of the fuselage and wings. For example, an aircraft flying at Mach 3 will experience a temperature increase of $-300^{\circ} \mathrm{C}$ from this kinetic heating. At higher speeds, the outer surface temperature would still increase but would start to level off as heat radiation reduces the wall heat load. This depends strongly on the emissivity of the used materials.

The extremely severe combination of component stress levels and high temperature operating conditions, as well as the requirement for an extended 25,000-cycle service-life, challenge the correct implementation of advanced materials without incurring excessive weight and cost penalties. Such materials' behaviour and related manufacturing processes are beyond current commercial experience and only little information is available. Polymer matrix composites (PMC), advanced aluminium and titanium alloys, metal/intermetallic and ceramic matrix composites (MMC, IMC, CMC) are generally examined in order to establish their long-term performance and reliability under SST conditions, as well as their production cost levels.

Propulsion engineers are mainly confronted with increasing difficulties arising from high engine temperatures. The structural total-life requirements for the HST propulsion system are the same 30,000 hours as in subsonic commercial engines. Nevertheless, subsonic aircraft engines spend less than $10 \%$ of their mission time at the most severe engine conditions. On the contrary, HST engines will spend about $60 \%$ of the mission time under the most severe combination of component stress levels and high temperature conditions. The challenge is to utilize advanced materials to cope with the high temperatures without incurring excessive weight and cost penalties.

It brings the engine designer new problems because of the higher operating temperatures required to produce the higher thrust. At Mach 2 air will enter the intake at about $-60^{\circ} \mathrm{C}$, will be compressed in the intake and be at about $130{ }^{\circ} \mathrm{C}$ when it reaches the face of the engine, and will leave the high-pressure compressor at 550 ${ }^{\circ} \mathrm{C}$. At Mach 3, this rises exponentially to respectively $325^{\circ} \mathrm{C}$ and $986^{\circ} \mathrm{C}$. For Mach 5 , one gets to $750{ }^{\circ} \mathrm{C}$ at the ramjet combustor inlet (no compressor required).

Viable combustors concepts, having a long life goal of 18,000 hours, depend on the development and demonstration of a new class of high temperature ceramic matrix composites (CMC) for which no previous commercial practice exists. At the same time, lightweight, high strength and high stiffness metallic, intermetallic and ceramic composite materials are being examined for the exhaust nozzle design in order to meet engine noise and weight requirements. These include gamma titanium aluminides and thin wall castings of super alloys. In general, large complex configurations must be manufactured economically and demonstrate long life under adverse operating conditions.

However, such materials' behaviour and related manufacturing processes are beyond current operating experience and only little information is available (Barbaux 1994 [4], Stephens et al. 1993 [5]). Through intensive testing and analysis, we propose to establish their long-term performance under SST conditions, as well as their reliability and economic performance.

The major challenge arises from the total airframe configuration. The aerodynamicist has to produce a satisfactory compromise between two inherently conflicting requirements: the need for minimum drag in supersonic flight and the need for controllability and ease of handling in subsonic flight. To increase the lift-todrag ratio throughout the speed regime of the next generation HST, a proper expansion of the engine jet on the leeward side of the vehicle has been shown to be very beneficial both for the aerodynamic and propulsive analysis. The development and application of Multi-Disciplinary Optimisation tools involving aerodynamics, propulsion, thermal, structure and flight mechanism aimed to realize an optimum embedding of the propulsion unit(s) into the airframe.

ATLLAS-II aimed at addressing these various aspects concurrently to ensure that the different research disciplines served and converged to the needs of a HST conceptual design. The 13 partners are listed at the end of the article and represented industries, SME, research institutes and academia representing 7 European countries. The project started in May 2011 and finished in October 2015. The project, co-founded by the European Commission under the FP7 Framework, was a follow-up of ATLLAS-I [6][7][8] and run concurrently with LAPCAT-I/II projects on high-speed propulsion and others [9][10][11][12].

The different achievements realized within the ATLLAS-II project are reported here in different chapters, i.e. the conceptual design of a Mach 5 aircraft, the use of high-temperature lightweight materials and structures for airframe and combustor and the definition, modelling and simulation of the aero-thermal-mechanical loads. 


\section{Detailed Design of a Mach 5 Vehicle}

\section{II.1 Conceptual Vehicle and Engine Design}

The starting point in the vehicle concept development was based upon a fundamental analysis of the aircraft wake conceived as a two-dimensional flow-field to maximize cruise efficiency and to create a vehicle configuration realising this flow-field. During the initial design, surface inclination methods were used to predict aerodynamic forces whereas a method-of-characteristics code was used to develop the intake geometry coupled to a one-dimensional model for the turbofan and ramjet.

As a part of this study, the performance of a hypersonic intake was also investigated for several flight conditions by using 3D CFD simulations. Based on the aerodynamic and propulsion design different vehicle configurations were developed by GDL. The analysis was extended to consider also the effect of venting an under-expanded exhaust into the base of the fuselage. The predicted cruise efficiency of this configuration is slightly lower than for a lee-side expansion analysed in ATLLAS-I [1][13] but has the advantage of separating the aerodynamics of the wing from the propulsive jet, thereby offering an alternative way of integrating the aerodynamic and propulsive flow fields. Based on these findings, three separate vehicles were defined and analysed. The baseline configuration was chosen through a down-selection process (Figure 1). The baseline configuration features a wide body fuselage sheltered behind a nose-mounted variable geometry intake for the main engine together with nacelle-mounted engines on each wing behind smaller intakes.

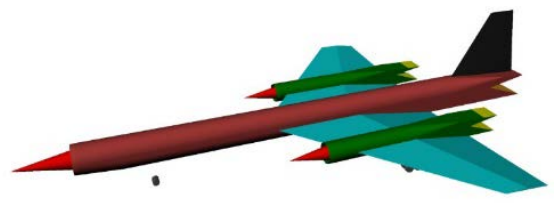

Under-expanded exhaust

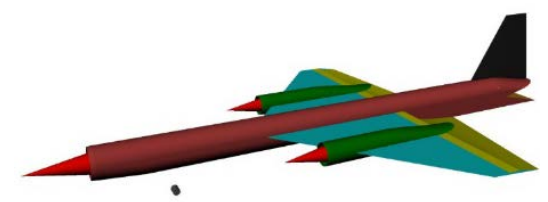

Over-expanded exhaust venting into lee of the wing

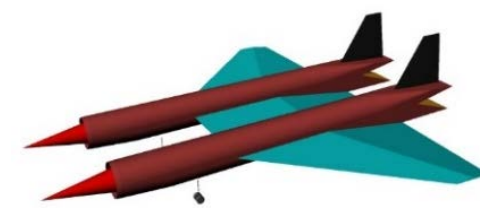

Twin fuselage with underexpanded exhaust

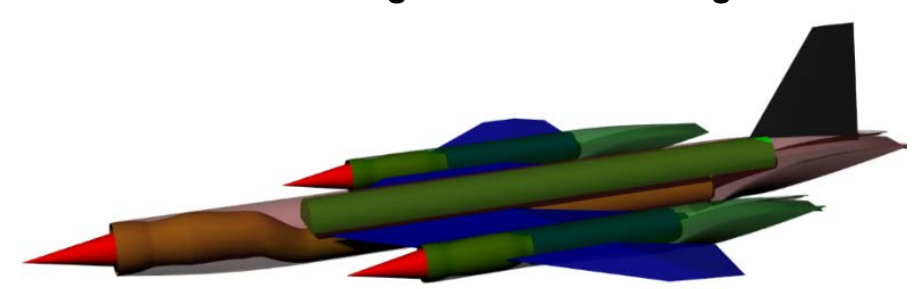

Baseline configuration

Figure 1: The ATLLAS // candidate vehicles (upper) and selected baseline configuration

The resulting geometry was assessed by FOI and ESA-ESTEC with 3D CFD at two trajectory points:

- Take-off at Mach 0.3, including angle of attack (crucial for trajectory feasibility)

- Cruise performance at Mach 5.0 (important also for thermal aspects)

At take-off, Mach 0.3, the generated lift at $10^{\circ}$ AoA is more than sufficient to assure lift-off. At cruise Mach number of 5 , a very good agreement is found with the optimization results in terms of lift and engine performance. The average surface temperature is around $1200-1300 \mathrm{~K}$, with raises up to about $1800 \mathrm{~K}$ on part of the leading edge close to the engine nacelles (Figure 2).

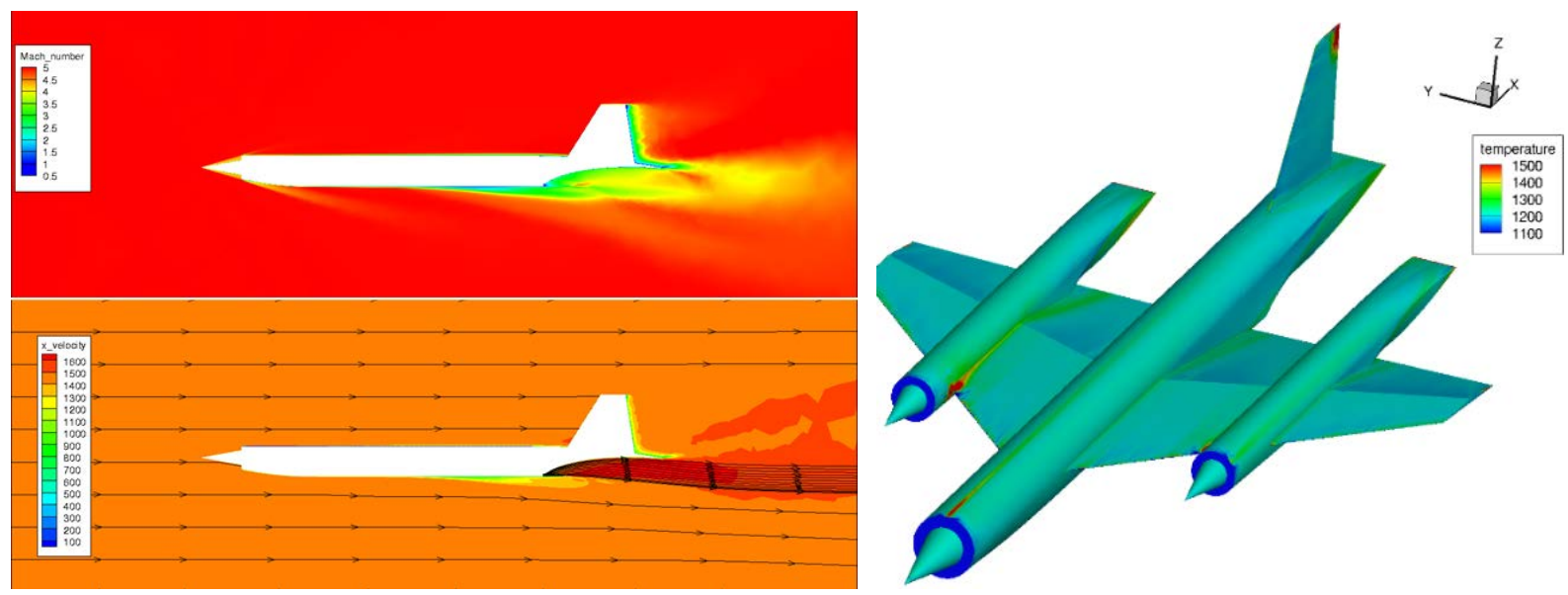

Figure 2: General flow field for Mach 5.0, AoA $0^{\circ}$ (left) and surface temperature (right). 


\section{II.2 Conceptual structural and thermal design}

The structural and thermal design were performed in order to support the configuration design process and to allow for the identification of tendencies. It was decided to perform structural analyses already in this early stage of the design process, since the application of statistical/empirical methods is handicapped due to the limited availability of corresponding data for high-speed vehicle concepts. The results of these investigations supported the configuration design process and were exploited in order to define the final configuration. Initially, a mass and centre of gravity (cog) estimation was performed for all three reference configurations using statistical/empirical methods.

Different structural designs, passenger cabin integration concepts and materials were evaluated in order to identify promising solutions. The computed aerodynamic loads for the most relevant load cases were fed into the structural analysis process, while the estimated surface temperatures allowed for material selection and thermal protection system (TPS) sizing.

As a part of the down-selection process DLR developed and used a parameterized finite element (FE) structural sizing tool to determine the structural weight needed to carry the expected flight load. The most important part of the structural investigations was formed by different finite element (FE) based trade studies. The parametric structural analysis tool HySAP (Hypersonic vehicle Structural Analysis Program) was modified in order to allow for investigation of the ATLLAS configurations [14]. Different design parameters were investigated on a comparative basis. The most relevant part was an aspect ratio study, where the impact of wing aspect ratio on the structural mass of the vehicle was evaluated (Figure 3). Furthermore, different wing rib/spar spacings, alternative wing profiles and wing/nozzle integration concepts were assessed. The FEbased investigations were complemented by first order analytical studies that investigated selected design features such as wing flow transfer duct or wing/fuselage carry-through design options.

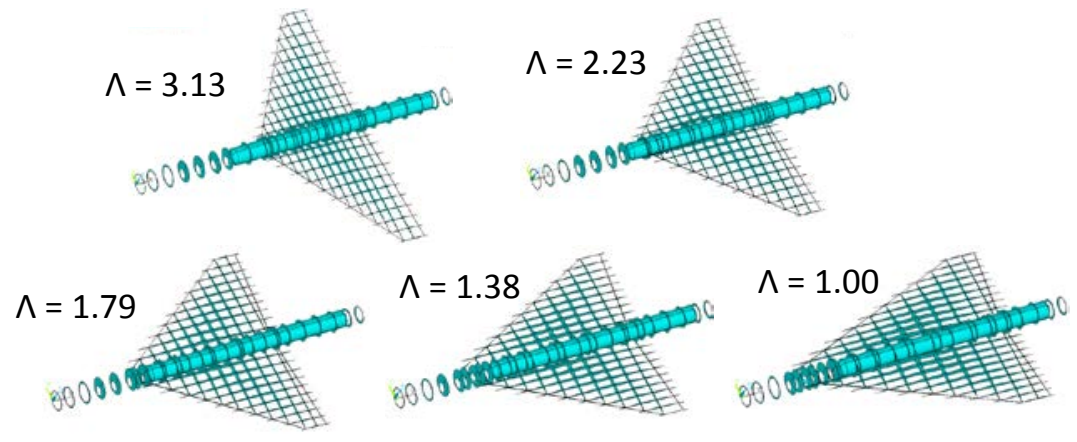

Figure 3: Internal structural architecture models for aspect ratio study

Based on the initial results of the structural analyses, a modified configuration was created integrating structural and aerodynamic considerations. For this preferred concept, a new series of structural trade-off analyses comparing different structural architectures was performed. From these concepts, a structural architecture was eventually selected. For this architecture, a structural material and structural design trade-off was done using Aluminium (Al), Titanium (Ti), and Aluminium-Lithium (Al-Li) alloys as preferred materials. On the structural concept side, uniaxial stringer stiffening and honeycomb sandwich were compared. Finally, a 1D TPS sizing study was conducted for the complete vehicle surface, comparing three different TPS architectures ( Figure 4).
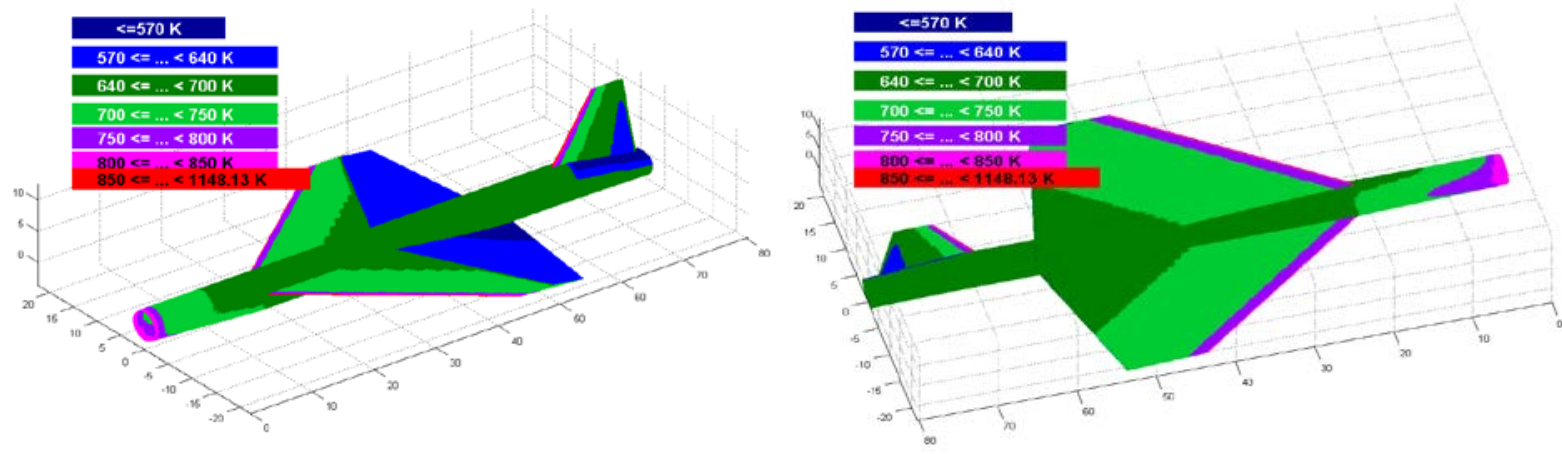

Figure 4: TPS material/concept surface partitioning for 1D TPS sizing study 
The trade-off studies revealed low weight solutions for an aspect ratio range of $\Lambda=1.5-2$. Also, a strong interaction of wing and fuselage mass was found, which might be a result of the comparatively deep wing root. The results were exploited for the redefinition of the baseline concept. Furthermore, a medium structural member spacing was found to be preferable, and an all-sandwich structural design concepts allow for lower weights for this configuration compared to stringer-stiffening. The utilization of Aluminium-Lithium as structural material showed large weight saving potentials in the order of $20 \%$ compared to Aluminium and Titanium structures. However, the better high-temperature resistance of titanium may allow for significantly higher structural temperatures. A TPS sizing study revealed that a TPS designed for a structural temperature of 300 $\mathrm{K}$ is around $58-74 \%$ heavier compared to an approach where wing and the non-passenger carrying parts of the fuselage are insulated for $480 \mathrm{~K}$. Hence, titanium was proposed for the vehicle structure.

Transient thermal simulation for a very sharp nose (with $2 \mathrm{~mm}$ radius) indicates a rather high temperature at the tip of the leading edge. The temperature at the base of the leading edge will be however significantly lower. At the tip of the leading edge, UHTC will become necessary while high temperature CMC plates will be used as a bracket to connect the leading edge to the main structure. Since the joint between the CMC plates and the main structure will be subjected to lower temperature, low cost mechanical joints of super-alloys may be considered for the ease of assembly, maintenance, and reparations.

At first sight, a high-speed cruise vehicle requires the use of high temperature materials to withstand the high thermal fluxes during flight. The long duration of a flight dictates a proper thermal protection system to cope with the integrated heat load accumulated during flight while a part of this heat might need to be evacuated after touchdown. Structural analysis shows that the thermo-mechanical fatigue is the sizing parameter for the hypersonic vehicle structural design. However, if cryogenic fuels are used instead, the cold storage opens new avenues for thermal control. For a given distance to be crossed at a given dynamic pressure for a cryogenically fuelled vehicle, it was observed that paradoxically the faster one flies, the lower the heat loads are as well as the accumulated thermo-mechanical cyclic loads [15].
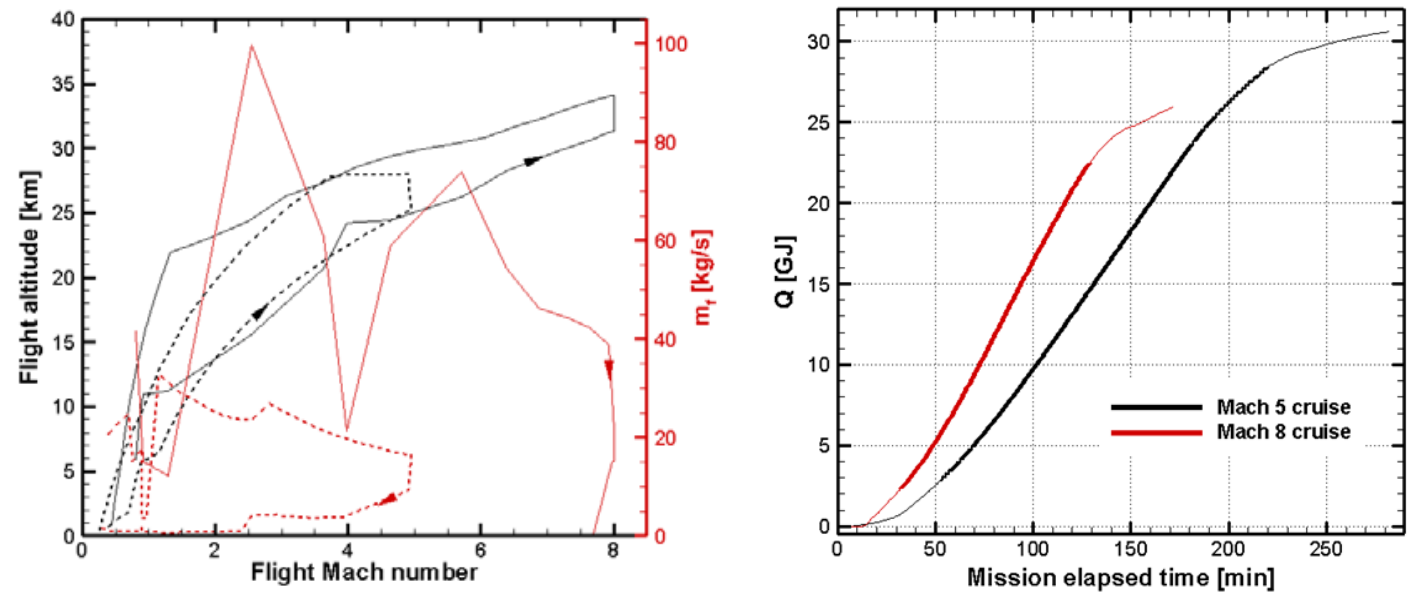

Figure 5: Comparison of missions (left picture) for M5 (dashed) and M8 (full): trajectory (black) and fuel consumption (red) and Integrated heat load Q during the Mach 5 and the Mach 8 missions (right picture).

This would result into a lighter TPS while having a longer lifetime in terms of flights. The basic analysis is discussed based on representative test cases. In order to properly assess the service life of a hypersonic cruiser, the operating temperature, the mechanical loads as well as the exposure time need to be taken into account. The heat fluxes on the aeroshell during short duration trans-atmospheric missions, e.g. launch and re-entry, increase with the cubic power of the free-stream velocity. Already a simplified zero-dimensional analysis can highlight that this approximation is not appropriate for hypersonic cruisers travelling a predefined range using a cryogenic fuel as propellant e.g. hydrogen. Actually, the thermal flux during Mach 8 flight is shown to be only 25 to $35 \%$ higher than at Mach 5. On top of this, the reduced flight times at Mach 8 yields a 20 to $25 \%$ reduction of the overall integrated heat load to the fuselage with respect to the Mach 5 cruise. This means that the integrated heat load decreases with increasing flight Mach number. The study was then extended towards a one-dimensional analysis to confirm these trends along a full trajectory [15]. This outcome is fully dependent on having cryogenic fuels on-board which is however not the starting basis for the studied kerosene based HST-concept. Hence, the airframe thermal control heavily depends here on high-temperature insulation. A similar paradox was observed from the thermo-mechanical fatigue analysis where the reduced flight time at higher Mach numbers actually increased the number of flights before the material needs to be 
replaced [16]. The scarce data available on thermo-mechanical fatigue of carbon matrix composites shows performance degradation at relative high temperatures (reported up to 1300K) [17].

A massive weight penalty is incurred if insulation alone is used to manage the cabin thermal environment. Active cooling is therefore required. This involved re-circulating exhaust cabin air through a cooling duct wrapped around the internal cabin skin. A model based on the Law-of-the-Wall was developed to estimate the heat leakage rates from the duct-cooling channel. Once the cabin thermal protection system had been developed, the last step in the analysis was to design an air-conditioning system that could not only provide conditioned air to the cabin at $10^{\circ} \mathrm{C}$, but could also provide sufficient auxiliary power to drive the hydraulic, pneumatic, and electrical systems. A novel and efficient air-conditioning and auxiliary power cycle scheme was designed requiring though small volumes of cryogenic fuel on-board in casu liquid methane. Air taken from the intake at 6 bar and $1250 \mathrm{~K}$, is cooled and expanded to cabin conditions and then used to cool the cabin-wall before finally it is used to cool the air from the intake. The cycle is expected to generate approximately $730 \mathrm{~kW}$. The methane is assumed to be burnt in the engines after it has performed its cooling duty, and for a $288 \mathrm{~K}$ temperature rise the required flow-rate of methane is $0.82 \mathrm{~kg} / \mathrm{s}$, equivalent to a fuel burn of 4.5 tons during a 90 minute cruise.

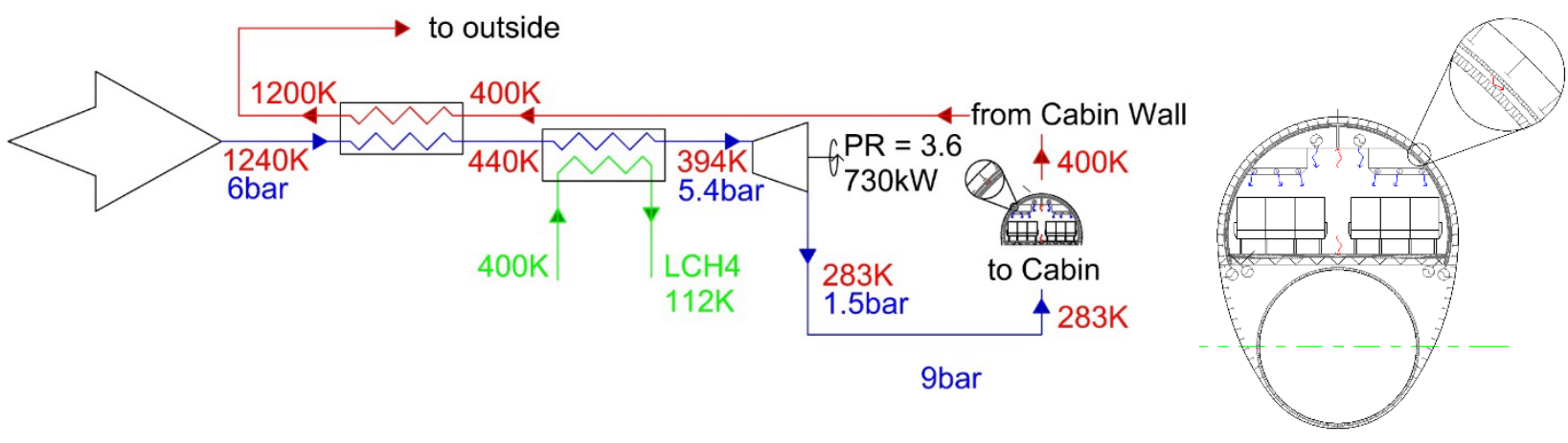

Figure 6: Cabin air-conditioning and auxiliary power cycle scheme

In order to prepare for the multi-disciplinary optimisation (MDO) a FE model was used by FOI as a starting point for a trade-off study and structural sizing analysis based on setting a constraint on the first eigenfrequency. The issue investigated here is the implication of an eigenfrequency constraint used as a substitute for the aeroelastic (flutter/divergence/control-authority) and flight handling qualities constraints. Starting for the Aircraft Handling Qualities [18] including the MIL spec [19], "the thumbprint" says something about the short period requirement form a pilot perception perspective. High natural frequency increase response with the risk of pilot induced oscillations; i.e. you would like the frequency to be above $0.5 \mathrm{~Hz}$ for good response and also relatively low damping [20][21][22][23]. Low frequency and high damping is a bad combination with bad flying qualities as result. A flight control system may of course enhance stability and handling qualities by increasing system damping, with the sacrifice of response. Based on the MIL specification, the ATLLAS // vehicle is of Class III Category and Level 1, the short period frequency suggesting upper limit of omega around $3 \mathrm{rad} / \mathrm{sec}$, in order to have good handling qualities. The final question is however, the separation between the short-period body modes and the first elastic mode. An eigenfrequency constraint on the first eigenvalue of $2 \mathrm{~Hz}$ was used in the MDO.

\section{II.3 Environmental Impact - Sonic boom and high altitude emissions}

To accurately predict the shock and expansion patterns sufficiently far from the vehicle, as input to acoustic propagation methods, an automatic mesh adaptive unstructured CFD-solver for the nearfield acoustics was developed at ONERA (Figure 7) [24]. Once coupled to nonlinear raytracing for atmospheric propagation, this model can be used to quantify the sonic boom at the ground level during the aircraft cruise in a stratified atmosphere. For ICAO standard atmosphere with no turbulence, the sonic boom from ATLLAS I/ hypersonic configuration was calculated and the ground undertrack boom was estimated to $91 \mathrm{dBA}$ (ASEL), in the same order as the Concorde ( $89 \mathrm{dBA})$ but with a peak at lower frequency. The width of the ground geometrical footprint is larger than Concorde (136 km) because of higher Mach and higher altitude (Figure 7). Localization of caustic resulting from transonic acceleration was also achieved. However, it is also well known that wind [25] atmospheric turbulence within the planetary boundary layer $(\mathrm{PBL})$ near the ground significantly alters the shape of the sonic boom waveforms. A state-of-the-art code [26] was developed by UPMC for statistical prediction of sonic boom through turbulent atmosphere. Numerous validation tests have been successfully carried out to simulate the propagation of the sonic boom in a turbulent atmosphere [27][28] including flow 
motion, sound speed and density heterogeneities, atmospheric absorption (thermo-viscosity and $\mathrm{N}_{2} / \mathrm{O}_{2}$ molecular relaxation) and rigid ground reflection (Figure 8) [24][28].
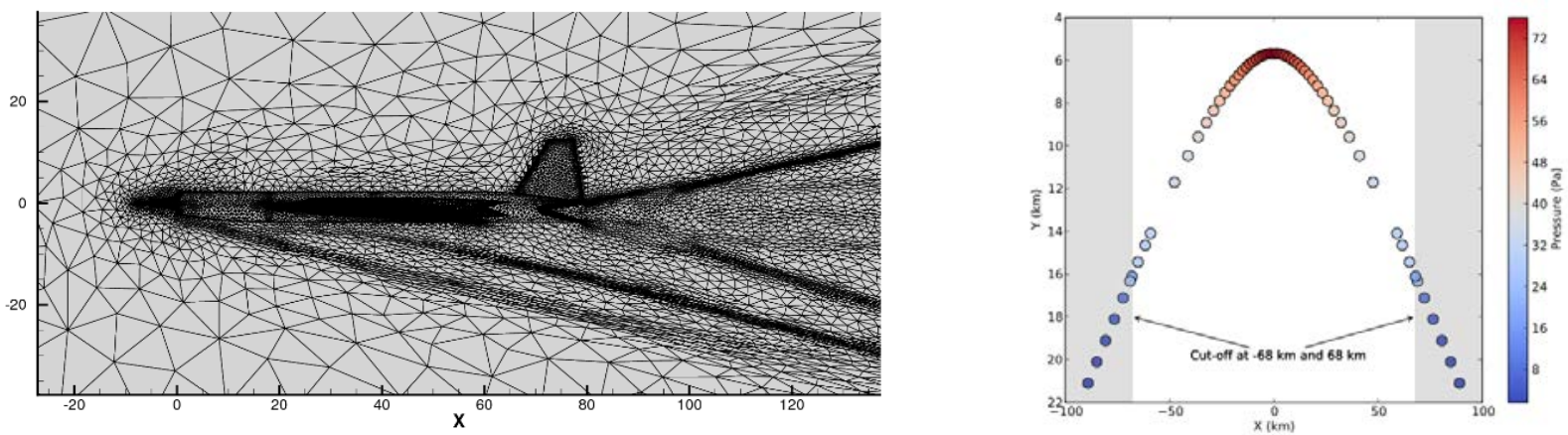

Figure 7: Left: example of automatic mesh adapted to shock capturing - Right: ground footprint of sonic boom from ATLLAS // configuration at cruise Mach number 5 (colours indicate peak overpressure in $\mathrm{Pa}$ ) [24].

\section{Low Turbulence}
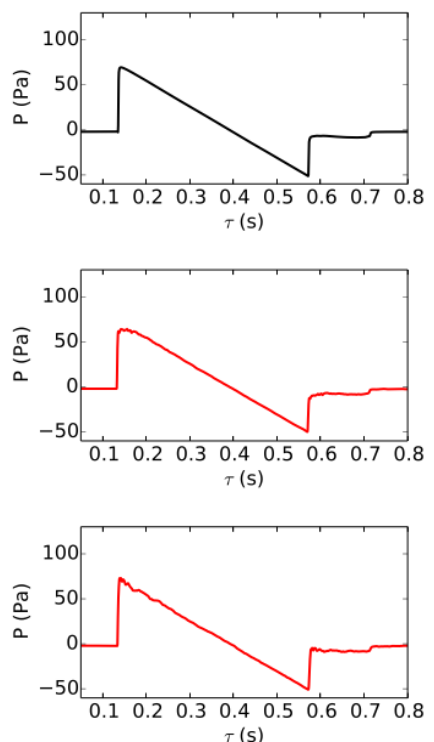

$\tau(\mathrm{s})$

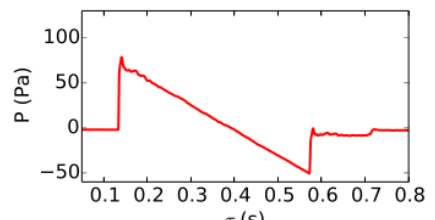

$\tau(\mathrm{s})$
High Turbulence
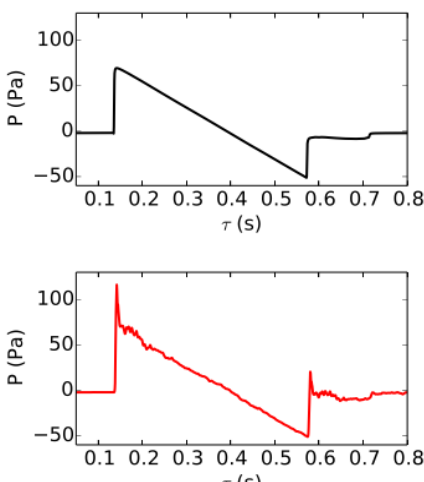

$\tau(\mathrm{s})$

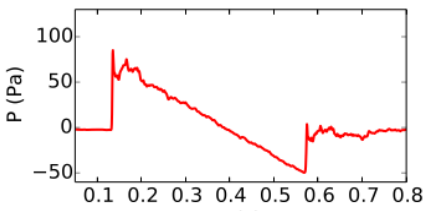

$\tau(\mathrm{s})$

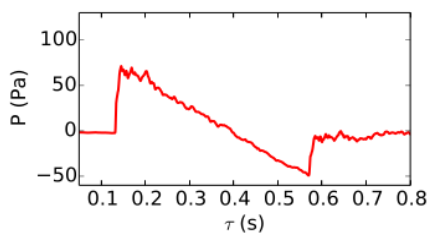

Low Turbulence
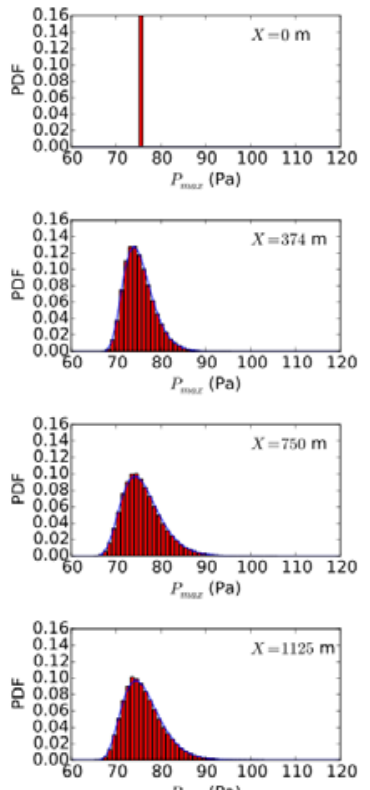

max $(\mathrm{Pa})$

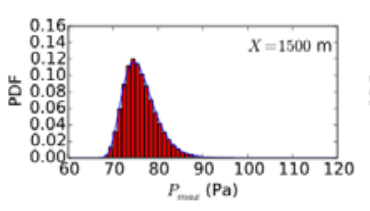

High Turbulence
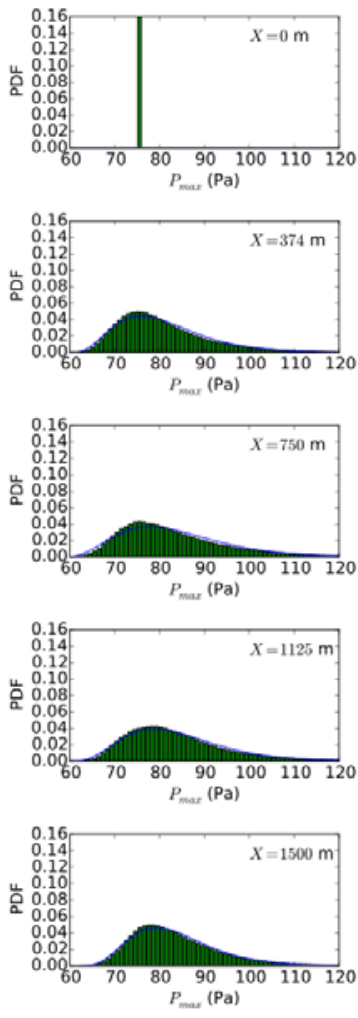

Figure 8: Left figure: examples of simulated boom pressure signatures in the PBL. Left column: small turbulence/Right column: strong turbulence. Top line (black signal): ground track boom in case of no turbulence. Right figure: histograms of peak pressure amplitude (in $\mathrm{Pa}$ ). $\mathrm{X}$ is the boom propagation distance in the PBL with $\mathrm{X}=0$ on top of $\mathrm{PBL}$ and $\mathrm{X}=1500 \mathrm{~m}$ at ground level. Left column: small turbulence/Right column: strong turbulence.

PBL is modelled by means of synthetic turbulence with a von Kármán energy spectrum. Statistical boom variability was quantified for two cases: (i) ground track sonic boom in cruise conditions (ii) sonic boom penetration into the lateral shadow zone. The first case provides information on the global annoyance caused by sonic boom, while the second specifies the geographical extent of the boom. For ground track boom, standard deviation is relatively high and positively skewed, indicating that there is a significant probability of high intensity peak pressure. For lateral boom in the shadow zone, peak overpressure is enhanced due to sound scattering by turbulence [28]. 
GDL targeted the general problem about low sonic boom vehicle shaping. An analytic impulse function $F$ generated for an ideal wave-rider design, to produce a minimum boom, was used to validate a fit for purpose Cart3D CFD code (Figure 9). Analysis of wind tunnel results reveals that the lift contribution to boom can be similar to the L.B. Jones minimum, but the disturbance generated by even a relatively fine nose can increase the $F$ integral by a factor of 3 resulting in a $\sqrt{3}$ increase in $N$ wave shock pressure.

FOI and GDL did joint work focusing on the possible atmospheric impact of a future ATLLAS // fleet. This includes potential global warming effects as well as stratospheric ozone impact from emissions of $\mathrm{H}_{2} \mathrm{O}, \mathrm{CO}_{2}$ and $\mathrm{NO}_{\mathrm{x}}$. For a traffic corresponding to 100 ATLLAS // baseline flights the results indicate a risk for ozone layer depletion of the order of 0.15 to $0.4 \%$ as a mean over the Northern hemisphere. This effect is due to a combined $\mathrm{NO}_{x}$ and $\mathrm{H}_{2} \mathrm{O}$ impact.
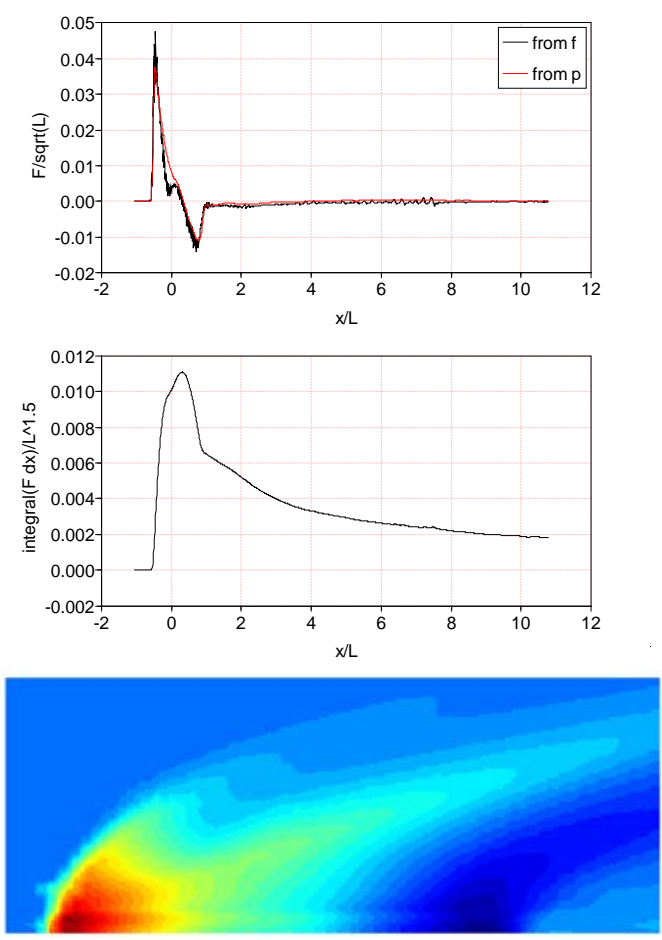
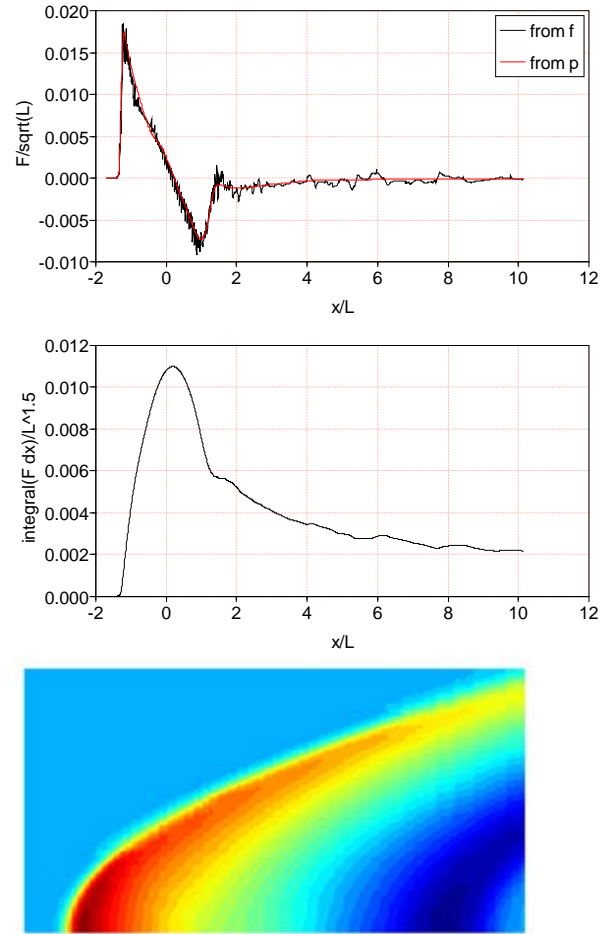

Figure 9: Verification of the Cart3D code and $F$ function derivation from downwash

\section{II.4 Overall vehicle optimization}

The integration of the different subsystems, each optimized individually with pre-set restrictions, into a single vehicle system design does not necessarily ensure a globally optimized vehicle. Due to the complexity of interdisciplinary interaction, numerically steered improvement and optimization tools are applied here to ascertain a global optimum. Modular MDO tools for the preliminary design of high-speed vehicles were developed to pre-optimise the ATLLAS /I Mach 5 vehicle. In addition, the applicability of stochastic methods was investigated such as Monte Carlo Simulation (MCS) and Stochastic Design Improvement (SDI). MCS was used to analyse a design over its entire design space by randomly varying the input parameters and recording the resulting responses. The SDI method was selected because in general the method itself is robust and fast by performing a small MCS around a start design, selecting the best design and then using that design as the new start design. The process resembles a cloud of samples being moved through the design space until no further improvement is achieved

The goal of the improvement process was to maximise range and increase the first eigenfrequency to $2 \mathrm{~Hz}$. The work consisted of setting up an interdisciplinary model for an optimisation process, ensuring the robustness of the model and finally improving the starting design by applying the Stochastic Design Improvement (SDI) method.

The designs that resulted from the SDIs were suitable for hypersonic cruise flight but looked unusual compared to traditional wing designs. Some of the designs with very low aspect ratios could not take off at a speed comparable to the Concorde. Therefore, a design with slanted spars was selected.

The result from this work shows how to use MCS for ensuring model robustness and how to set up SDI to quickly improve a design. However, it would have been beneficial to include take-off and landing performance in the SDI process. A method for inclusion of aeroelastic constraints within the structural analysis part of a 
more general multi-disciplinary optimization scheme was demonstrated on a complete vehicle including the wing. It was demonstrated how aeroelastic phenomena such as flutter damping can be analysed.

The optimizer was used for sizing taking minimum weight as cost-function and a defined value of the VonMises stress in each element as constraints. One advantage is that the same structural model can be used here for stress-, eigenfrequency and aeroelastic analysis. The main result found was that the long and heavy nacelles makes it necessary to increase the torsional and bending stiffness of the inner wing to satisfy flutter and eigenfrequency constraints (Figure 10). Making the nacelles shorter and lighter would save structural weight, and so would a thicker wing profile in the inner wing with more internal volume. The total weight resulting from the optimization increased the initial weight from 188 tons to 215 tons in order to satisfy the constraints.

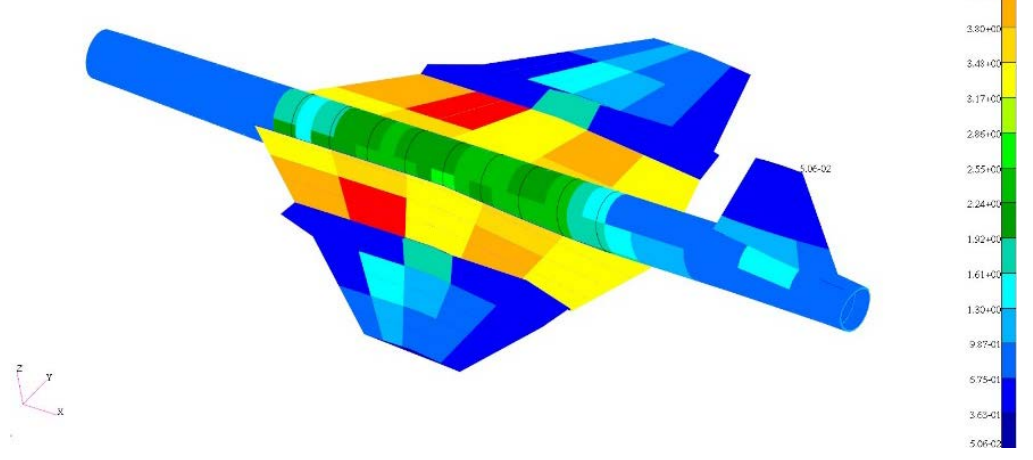

Figure 10: Design variables at the end of the optimization (allowed: $0.5<\mathrm{dv}<50$ )

Finally, various methodologies for design improvement and multidisciplinary optimization (MDO) were setup for ATLLAS // vehicle assessing the implication on weight or range on the chosen set of design parameters and constraints. DLR-SART performed a range optimization study on the reference configuration using the method of stochastic design improvement (SDI) whereas DLR-RFZ used the simplex method. The SDI study was limited to the cruise part of trajectory and clearly shows the importance on added relevant constraints into the optimization in order to avoid sub-optimization. The DLR-RFZ work on the other hand used an adapted detailed FE model and used a CFD code for the Nose-to-Tail evaluation. Necessary trajectory and engine modules were also integrated. The weight minimization procedure was executed with eigenfrequency and aeroelastic constraints included as a part of the multidisciplinary optimization (Figure 11). The objective function module collects for each iteration lift, drag, moment coefficient and mass-data, and combines it into a punished Breguet range function. The result shows that the improved vehicle has a better range, L/D and less weight, compared to the starting original design (Table 1). Figure 12 shows the new shape and the effect on the design variables respectively.

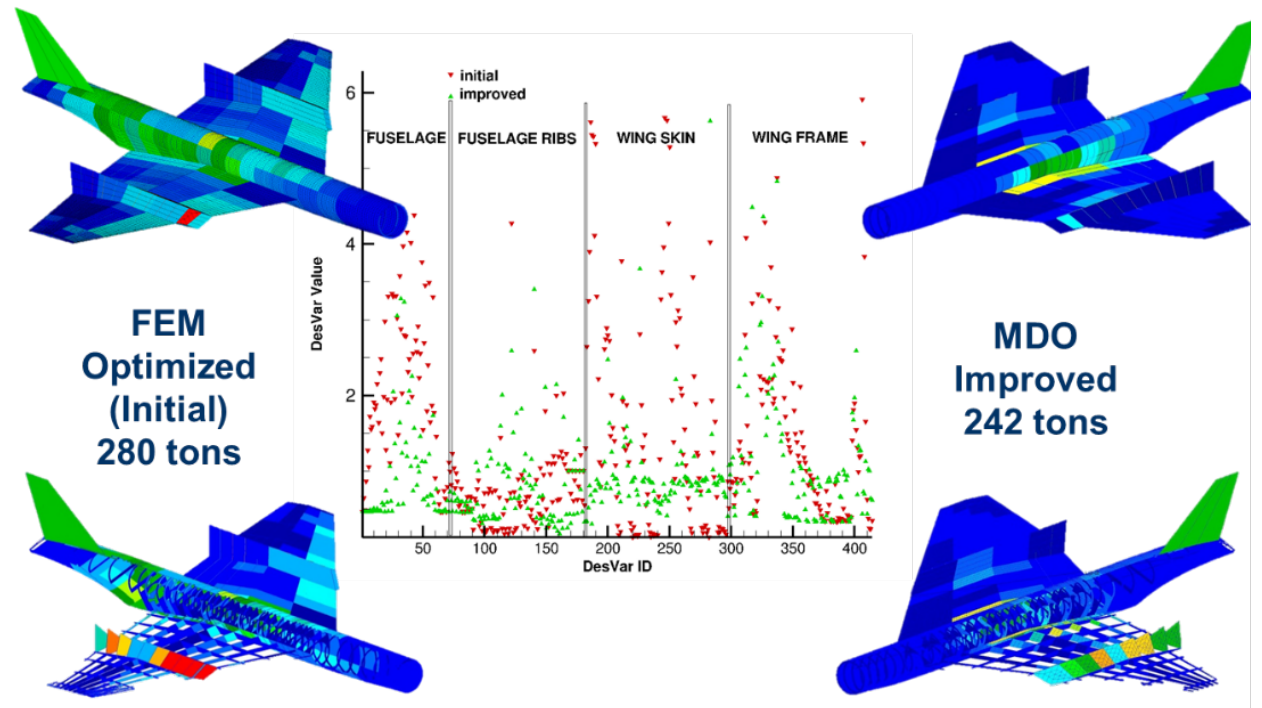

Figure 11: Result from structural optimization and change in design variables 


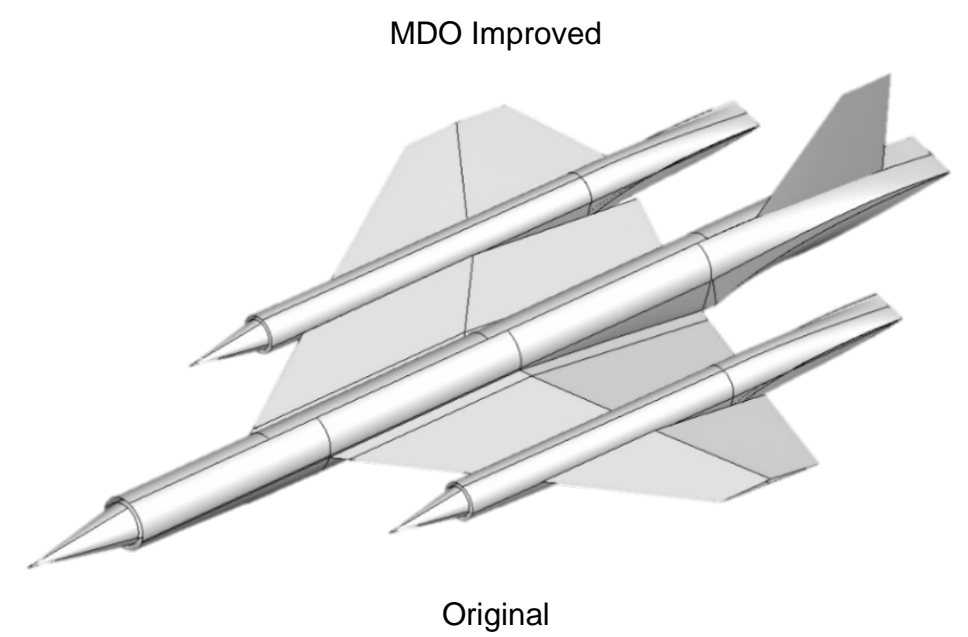

Figure 12: Result from MDO original (lower) and improved (upper part)

\begin{tabular}{|l|c|c|}
\hline Range & $\begin{array}{c}\text { Original } \\
\sim 6800 \mathrm{~km}\end{array}$ & $\begin{array}{c}\text { Improved } \\
\sim 9800 \mathrm{~km}\end{array}$ \\
\hline Fuel & 187 tons & 223 tons \\
\hline Dry mass & 280 tons & 242 tons \\
\hline Wing area & $807 \mathrm{~m}^{2}$ & $835 \mathrm{~m}^{2}$ \\
\hline L/D & 8.5 & 9.4 \\
\hline
\end{tabular}

Table 1: Summary DLR MDO result

The evolution of vehicle weight as a function of time is plotted in Figure 13. From this picture, it is clear that the original estimation of vehicle weight is significantly lower than the final weight. A more detailed analysis shows that the eigenfrequency constraint is a strong design driver that should have caused more action. This constraint was originally created as a substitution for the aeroelastic (flutter/divergence/control-authority) and flight handling qualities constraints. For the future, one should include also flight-handling constraints, so that the eigenfrequency constraint could be removed. Possibly a safety factor between the structural eigenfrequencies and flight dynamics rigid body modes, for a few points in the envelope, as suggested in the literature would have been sufficient.

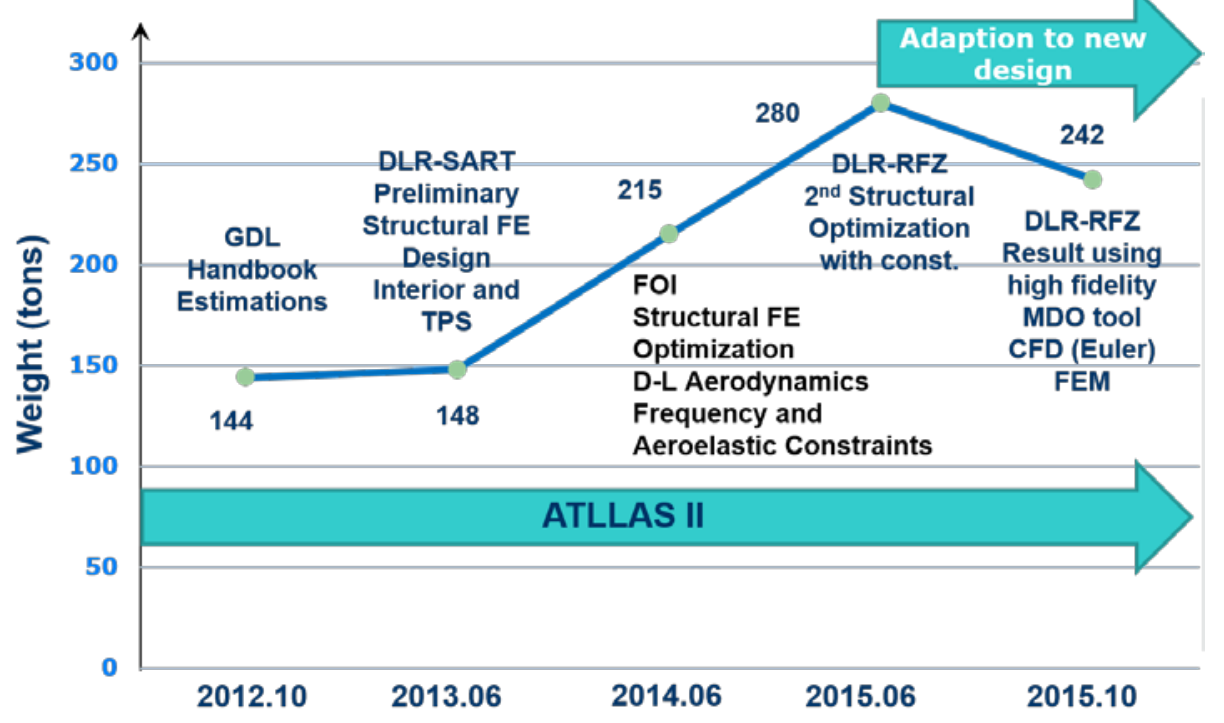

Figure 13: ATLLAS // Mach 5-6 vehicle dry weight evolution

As an ultimate verification, the vehicle design was tested experimentally and numerically for subsonic, transonic and supersonic speed to see how the design, mainly driven by cruise conditions, is able to cope with take-off and transonic acceleration. Also, variable settings of control surfaces to investigate trimming and 
stability were part of the test campaign. The wind tunnel model scale is $1 / 70$, having a wing span dimension of $646 \mathrm{~mm}$ and length of $1356 \mathrm{~mm}$ (Figure 14).

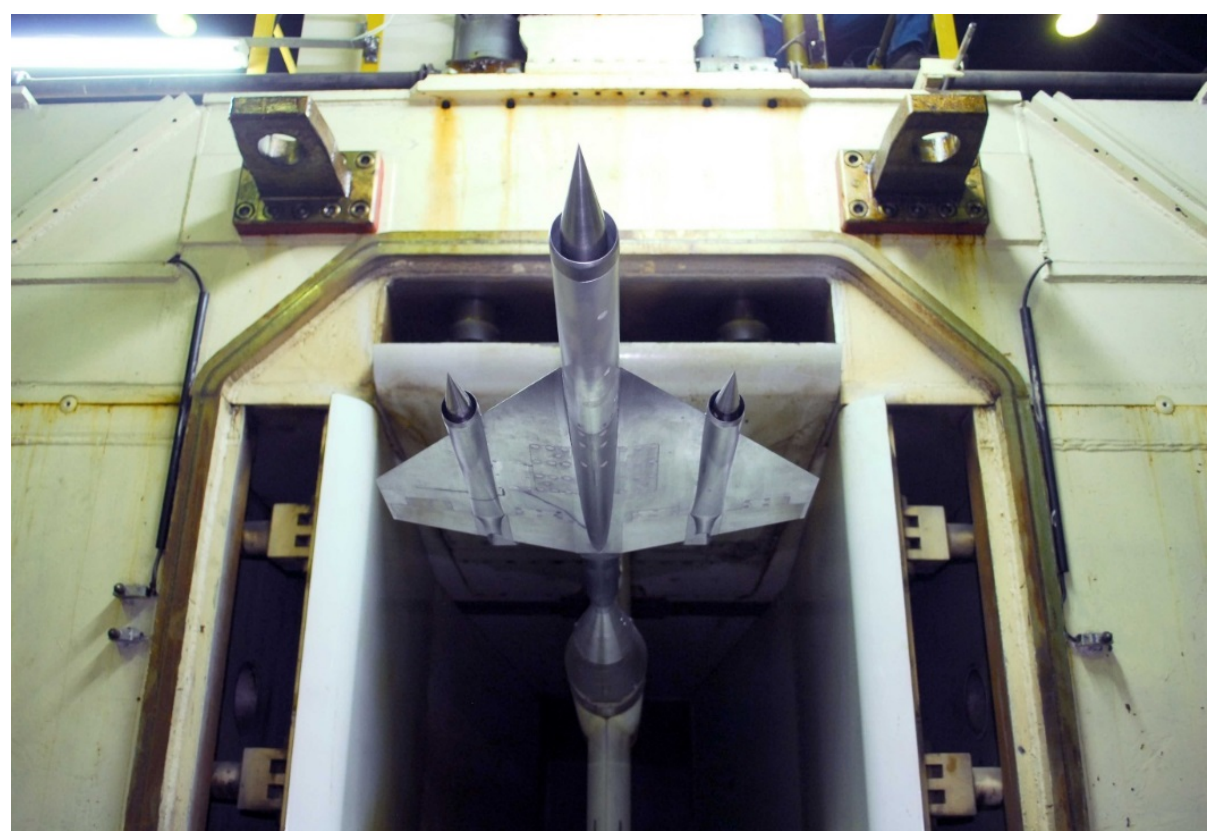

Figure 14: The transonic wind-tunnel-model with interior flow-path for the baseline

Pressure measurements were performed along with sonic boom detection and schlieren visualization. In total, a number of 110 WT runs were performed. Stage I measurements included measurements of forces, moments, pressure on the model and pressure measurement at the model exits up to Mach 2.5. Bottom wall pressure measurements for sonic boom characterization were performed during Stage II.

Nose-to-Tail validations were carried out by ESA-ESTEC (TAU-code), FOI (Edge-code [29]) and MBDA (CEDRE-code). Varying grid dimensions and refinement, Mach number, angle of attack (AOA) and cone position (to change the intake area for higher Mach) were assessed.

The experimental L/D curves are compared with CFD and acceptable alignment is observed between wind tunnel data and simulation result. Mach number 1.2 is considered to be relatively difficult to predict as it is slightly above the transonic range where the shocks starts to form and the result is sensitive to the shock position. The experimental L/D curves for Mach numbers 1.2, 1.6 and 2.5 are compared with CFD simulation, including also the internal engine surfaces in the force calculation, in Figure 15 and Figure 16. One may notice here that run 7883 (blue curve) for Mach 1.2 is close to the CFD simulation. This may suggest that the $4 \%$ porous wall setting is more in line with the free-stream conditions used in all CFD simulations. This result is very good taken into account that the accuracy of the modelling of the flow though the engines will have a direct influence on this property.

Pressure transducers were installed on the wind tunnel model to provide point pressure data to compare with CFD (intakes, wing, aft part of the model, see Figure 17). For the Mach 0.5 case, a reasonable agreement is found on the wing, while a bigger difference is found for the ones in the intakes. At higher Mach numbers, a good match is often found at low angle of attack.
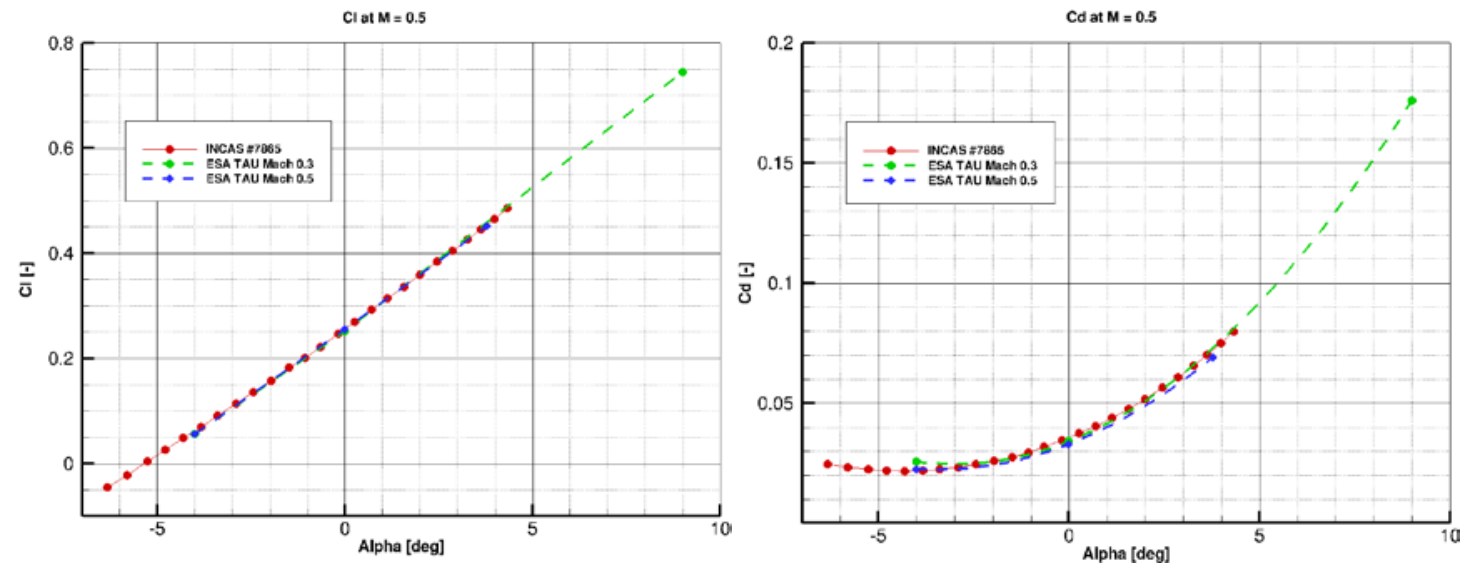
Figure 15: Lift coefficient (left) and drag coefficient (right) for Mach 0.5 (includes results of Mach 0.3 simulations)
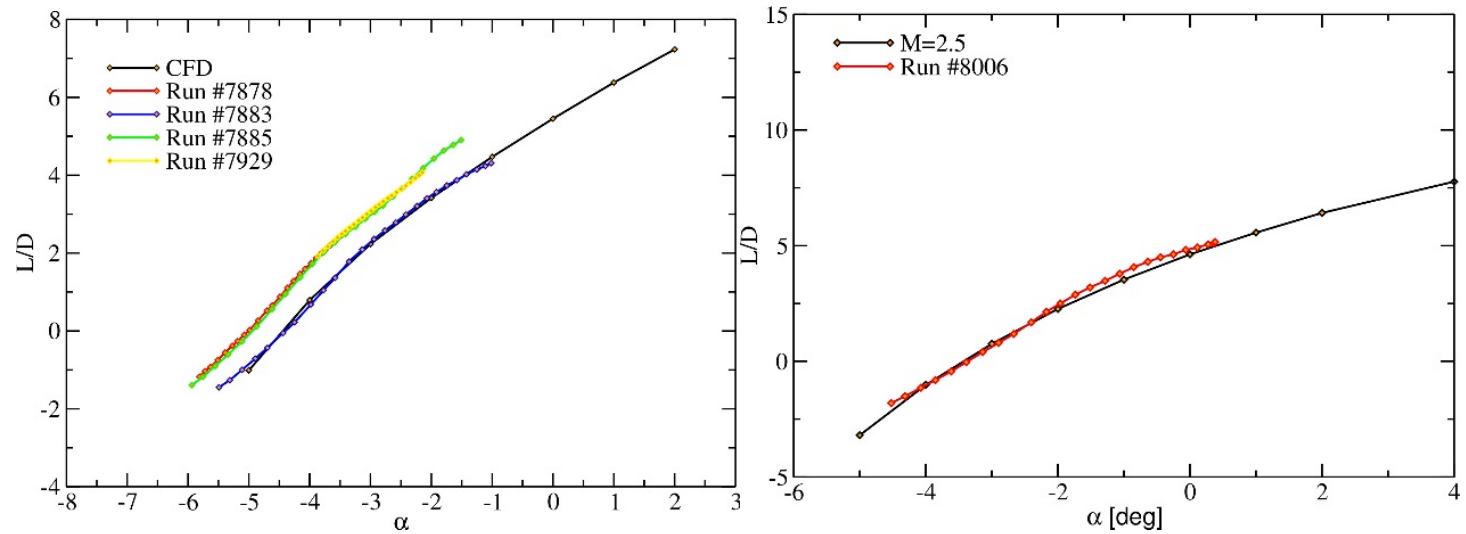

Figure 16: Comparison CFD simulated and WT data at Mach 1.2 and 2.5 (internal surface included)
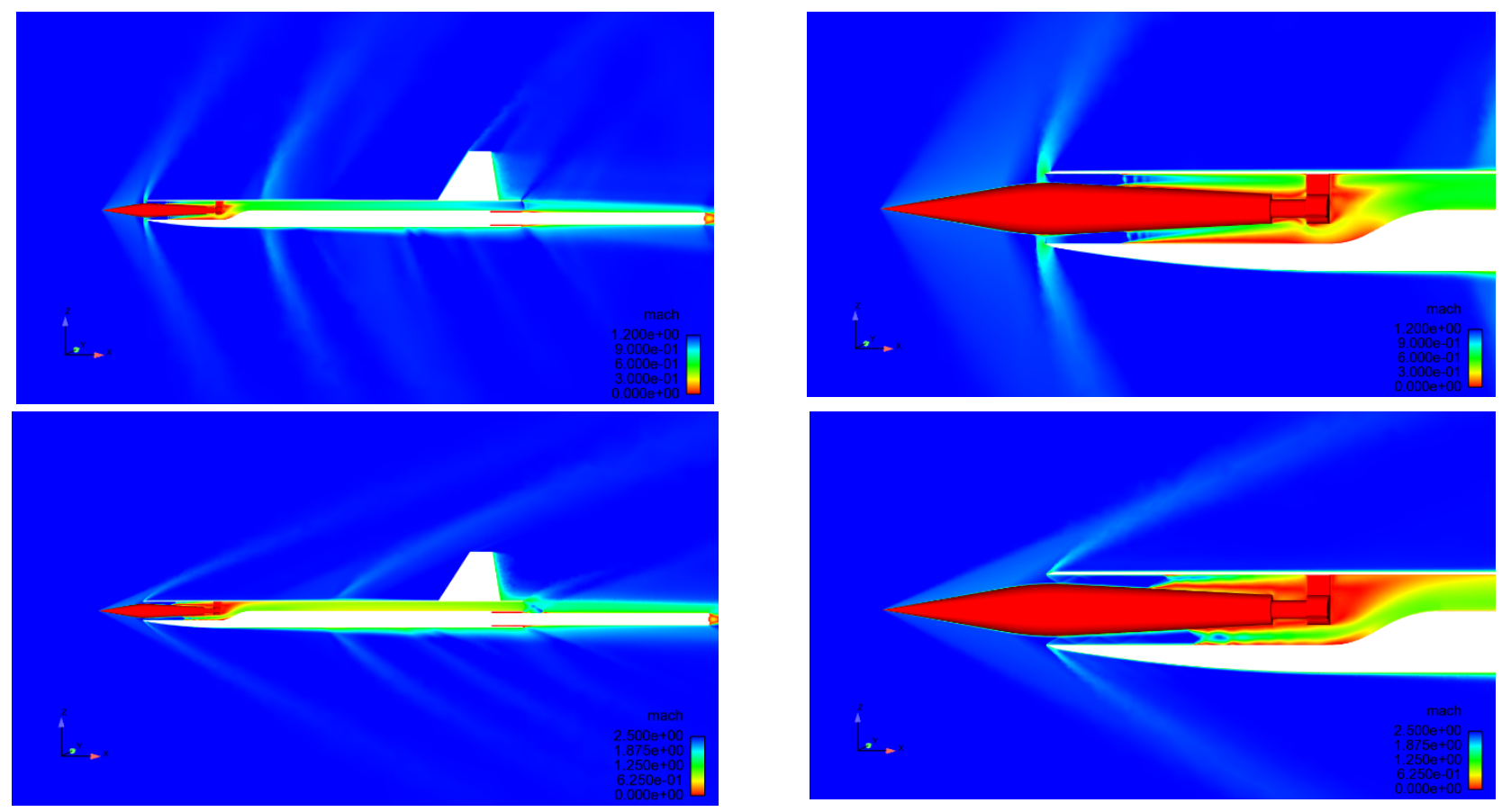

Figure 17: Flow visualisation of CFD simulation result at Mach 1.2, 1.6 and 2.5, $\alpha=3^{\circ}$

\section{II.5 Discussion}

A fully integrated Mach 5-6 vehicle design taking into account several disciplines in the trade-off and optimization were carried out and allowed setting the requirements for the material manufacturing, processing and testing, discussed in the next sections. The general findings of these design and optimization loops are summarised below:

\section{Aerodynamics and propulsion:}

- The conceptual design analysis was extended to consider the effect of venting an under-expanded exhaust into the base of the fuselage. The predicted cruise efficiency of this configuration is slightly lower than for a lee-side expansion analysed in ATLLAS I, but has the advantage of separating the wing aerodynamics from the propulsive jet, offering an alternative way of integrating the aerodynamic and propulsive flow fields

- For a given range: the faster one flies, the lower the integrated heat load: the heat flux has less time to penetrate into the structure; the faster one flies: the higher the external wall temperature but levels off due to the highly non-linear heat radiation

- The convective heat transfer doesn't increase with the power of 3, but flattens out at higher flight speeds

- Good agreement was achieved between CFD simulations and wind tunnel experiments increasing the 
accuracy of predicted cruise efficiency

\section{Structure, materials and thermal protection:}

- The temperature at the base of the leading edge will be lower and metallic solution might be still doable for Mach < 4, but will have a negative impact on the mass and might require active cooling of panels (increasing the mass even more)

- $\mathrm{CMC}$ is a preferred solution for Mach > 4. CMC promises good specific strength for extreme temperature applications but oxidation, creeping, and fatigue issues remains to be a big challenge

- High emissivity is preferred

- Fatigue behaviour at high temperature may be rather different from the fatigue behaviour at room temperature for $\mathrm{CMC}$ materials considered. While the creeping property may limit CMC for the skin application, it is the structural random dynamic load that will dominate fatigue life of the TPS at high temperature

- The long duration of a flight dictates a proper thermal protection system to cope with the integrated heat load accumulated during flight while a part of this heat might need to be evacuated after touchdown. However, a part of this load can already be exploited on-board for power generation during flight.

- A cabin air-conditioning and auxiliary power cycle scheme was designed

\section{Environmental issues:}

- For ICAO standard atmosphere with no turbulence, the sonic boom from ATLLAS II hypersonic configuration was calculated and the ground undertrack boom was estimated to $91 \mathrm{dBA}$ (ASEL), in the same order as the Concorde ( $89 \mathrm{dBA})$ but with a peak at lower frequency. Width of ground geometrical footprint is larger than Concorde (136 km) because of higher Mach and higher altitude

- For ground track boom with turbulence, standard deviation is relatively high and positively skewed, indicating that there is a significant probability of high intensity peak pressure. For lateral boom in the shadow zone, peak overpressure is enhanced due to sound scattering by turbulence.

- For a traffic corresponding to 100 ATLLAS // baseline flights the results indicate a risk for ozone layer depletion

\section{Multi-disciplinary optimisation:}

- Use of relevant constraints are extremely important in the MDO-process: from the evolution of vehicle weight as a function of time. it is clear that the original estimation of vehicle weight is significantly lower than the final weight; the eigenfrequency constraint was identified as a strong design driver

- For future work, one should include also flight-handling constraints, so that the eigenfrequency constraint could be removed.

A research plan from 2016 to 2025, including additional R\&T and demonstrations, was formulated. The development roadmap includes envisaged developments and demonstrations of different key technologies and systems with special emphasis on demonstrating long-time exposure for hot structures to operational conditions and lifetime endurance investigations for advanced materials. Mainly ground testing and dedicated flight experiments are proposed before use on large-scale $A / C$ demonstration. In flight demonstration would focus to small scale, critical technologies along with high-speed powered flight, take-off and landing and transonic flight. 


\section{Aero-Frame \& Materials Integration}

Based on experiences made in ATLLAS I, lightweight airframe materials were supposed to be developed further with respect to long-term applicability. As materials are exposed to high thermal and structural loads (especially regions like nose structures, wing leading edges and air intakes), they need to be specifically tailored to this application. Hence, certain components demand for high specific strength, high ductility and toughness, increased oxidation resistance as well as high creep and fatigue resistance at elevated temperatures.

The focus within the current project was directed towards material design, investigation of oxidation resistant coatings and investigation of long-duration characteristics such as creep and fatigue properties, as recommended at ATLLAS I reviews. Following materials were under investigation along with their mechanical integration issues and their specific application.

- Titanium matrix composites (TMCs)

- Hollow sphere structures / tube stacking structures (HSSs/TSSs)

- Ultra-high temperature ceramics (UHTCs)

- Ceramic matrix composites (CMCs)

In addition, feasibility and integration aspects of structures and materials were considered.

\section{III.1 Titanium Matrix Composites}

For titanium matrix composites (TMCs) [30][31], a survey on published alloy data was performed where the need of creep data was detected. For this reason, tubular and flat TMC samples were manufactured consisting of different titanium alloys (Ti-6242, Ti-834) as well as fibre-reinforced and monolithic samples. Thereby, the creep rupture was considered for tests from 1 to 1000 hours. Extensive investigations were performed for the different samples. As estimated, fibre reinforced TMCs showed significantly higher creep strength at tested temperature levels of $600^{\circ} \mathrm{C}$ using Ti-834 alloys. Furthermore, the enhanced performance of Ti-6242 vs. Ti834 alloys was confirmed (Figure 18).

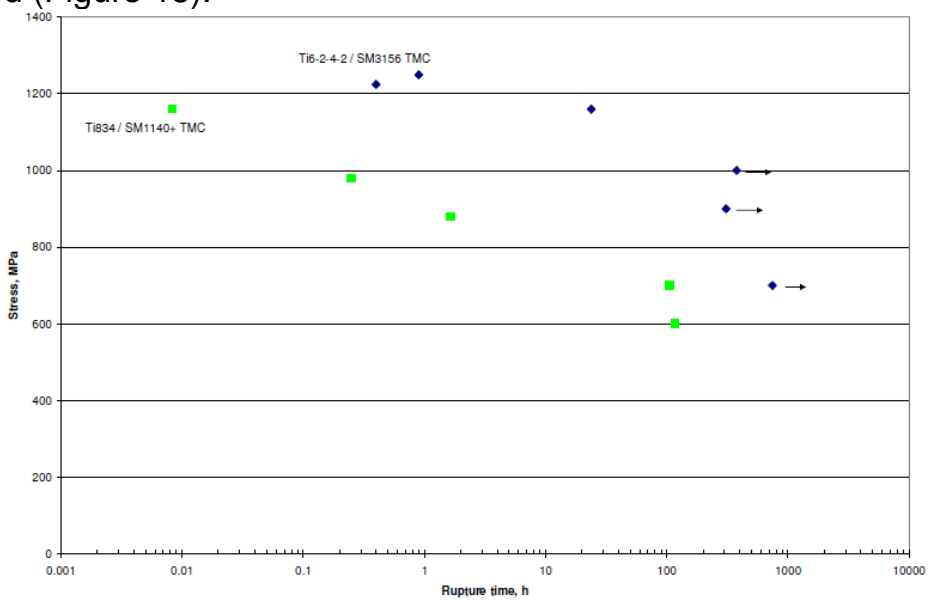

Figure 18: TMC creep behavior at $600^{\circ} \mathrm{C}$ (Ti-6242 vs. Ti-834)

The envisaged TMC material is intended for use as canard structural components e.g. panels, shaft.... Due to the impinging hypersonic airflow, the component could heat up to $1000^{\circ} \mathrm{C}$ and above. Aerodynamic forces induce bending loads, which result in tension and compression stresses within the material. It is therefore necessary to investigate the effect of combined thermo-mechanical loading. For this reason, thermo-gradient mechanical fatigue tests were conducted at DLR. As depicted in Figure 19, the thermal gradient is obtained by outer surface heating with an induction coil and simultaneously internal cooling with pressurised air. A steady-state thermal gradient is typically achieved after 20 to 40 seconds. The high-energy input allows heating rates comparable to those e.g. in real turbine blades of a jet engine. Realistic cooling rates are achieved by forced air-cooling from the inner bore of the specimens. The test cycle can be very short due to the high heating and cooling rates. Thus, the fatigue load of an entire flight mission can be imposed on the specimen within 3 to 5 minutes. 


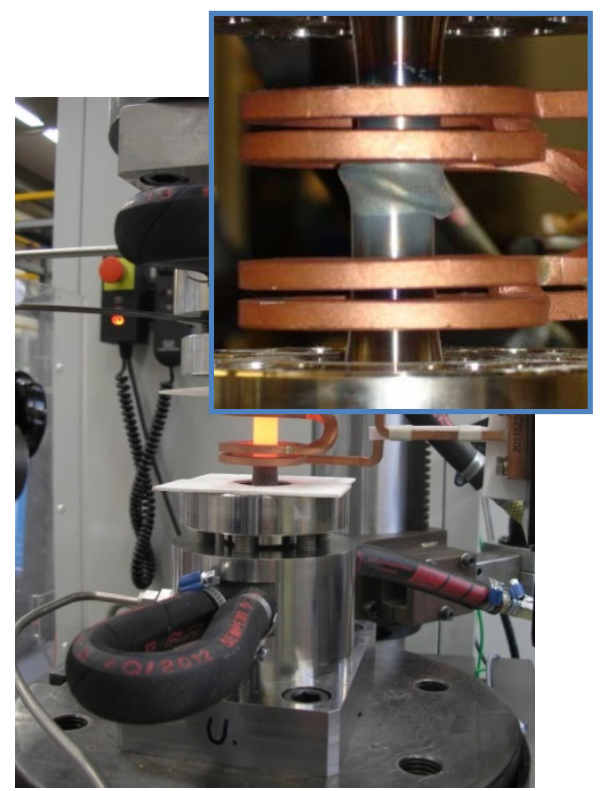

a) TGMF test setup

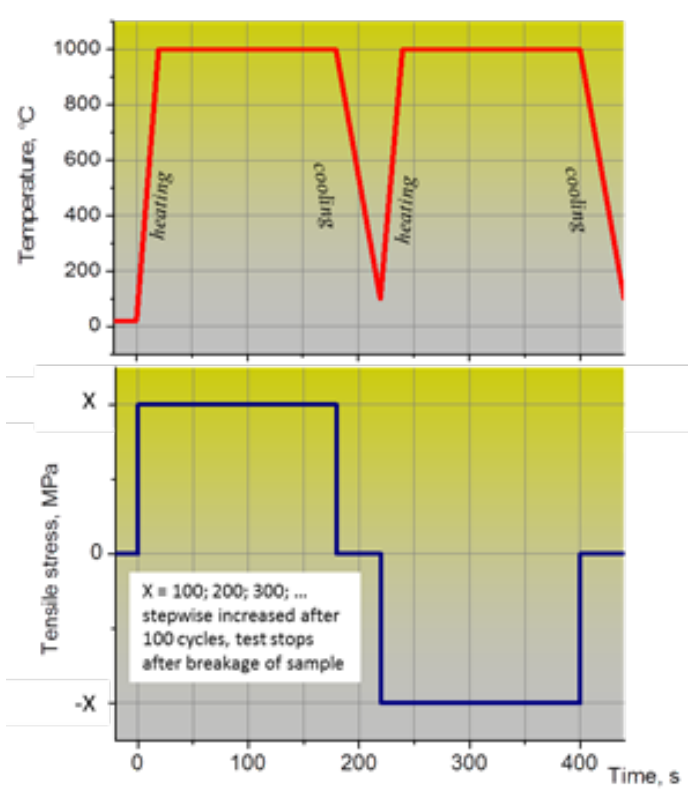

b) exemplary TGMF testing scheme

Figure 19: TMC TGMF-testing

The loading sequence consisted of inductive heating to high temperature (500 and $\left.1100^{\circ} \mathrm{C}\right)$, holding at high temperature, and cooling to low temperature. The thermal cycling is thereby synchronized with an applied cyclic axial force; see Figure $19 \mathrm{~b}$.

By means of this testing procedure, the maximum allowed stress levels at different temperatures were obtained. In total, 11 of 15 fibre reinforced and 2 monolithic samples were tested, where temperatures up to $1000^{\circ} \mathrm{C}$ were reached. After each 10 cycles, the temperatures were increased by $100^{\circ} \mathrm{C}$. The procedure was repeated until a failure was detected, which mainly occurred under compression, as indicated in Figure 19 a. Figure 20 exemplarily shows some results for different stress ( \pm 50 and $\pm 100 \mathrm{MPa})$ and temperature levels and various sample types: monolithic titanium (black), axially reinforced TMC (green) and $20^{\circ}$ off-axis reinforced TMC (red). The influence of fibre reinforcement on the sample's strength is clearly visible. A fully axial reinforcement resulted in approximately $200 \mathrm{MPa}$ higher strengths; off-axis reinforcement exhibits slightly lower fatigue strength as it would have been expected. Furthermore, the fatigue strength strongly depends on the applied alternating stresses as well; if they are decreased from \pm 100 to $\pm 50 \mathrm{MPa}$ the same fatigue strength is achieved at approximately $100 \mathrm{~K}$ higher temperature levels.

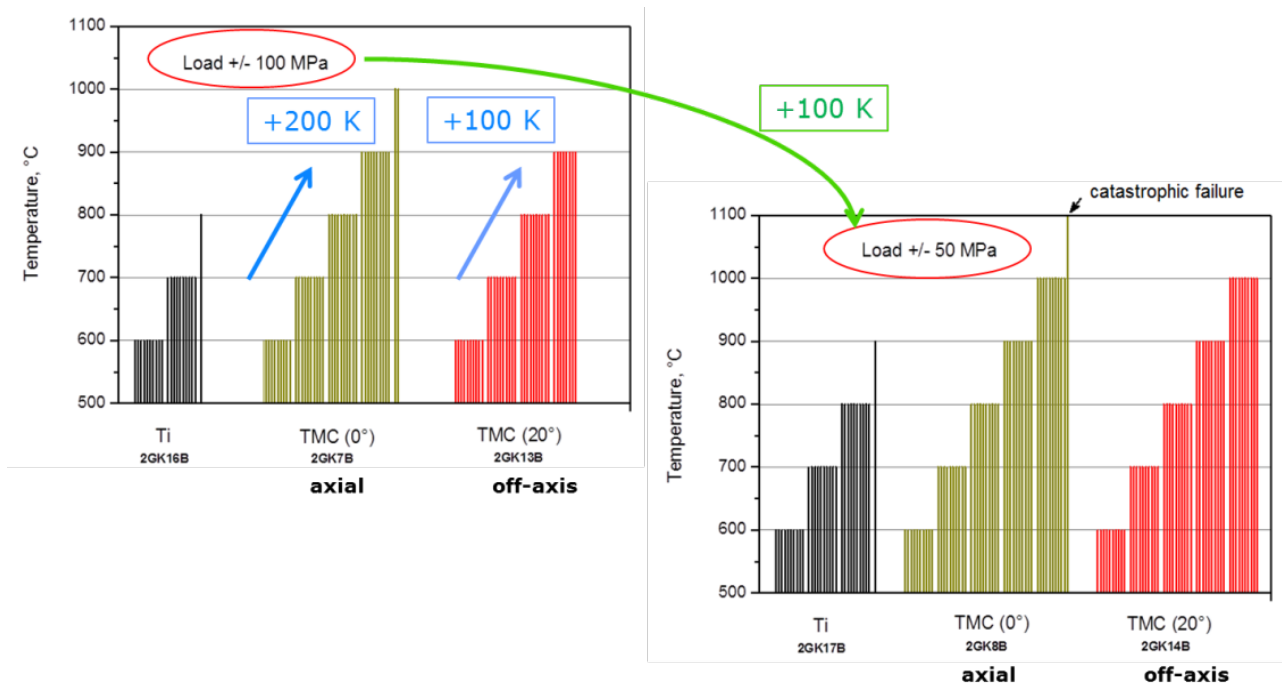

Figure 20: TMC TGMF test results (black: monolithic Ti, green: axially reinforced TMC, red: $20^{\circ}$ off-axis reinforced TMC) 
Subsequently, TMC canard prototypes were considered for thermal testing at operational relevant conditions, i.e. arc jet testing. An internal impingement cooling was elaborated to control the surface temperatures. Figure 21 shows a typical slit geometry along with its resulting surface temperature trace. Based on these numerical results, TMC canard wing parts were designed and manufactured by TISICS. Four canard assemblies were provided for thermal tests in DLR's arc jet facility L3K (Figure 22). Two of them were made with a blunt leading edge radius of $\mathrm{R} 0.8$, whereas the others were manufactured rather sharp-edged.

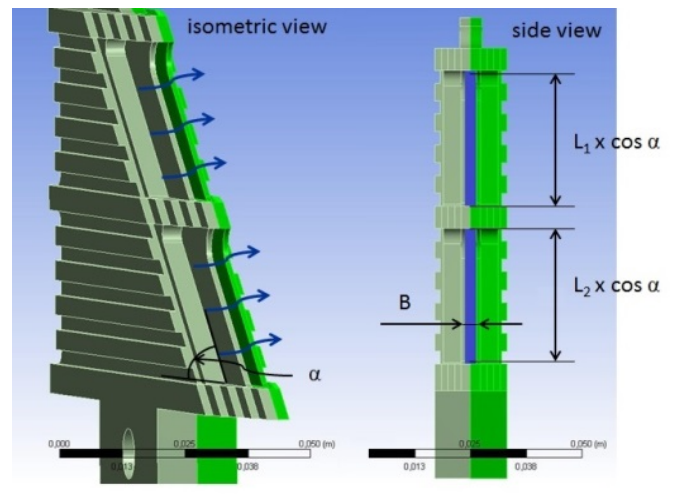

Slot jet (blue area) with the following geometric parameters: $B=5 \mathrm{~mm}$ - width of slots; $L_{1}=L_{2}=50 \mathrm{~mm}$ - length of slots

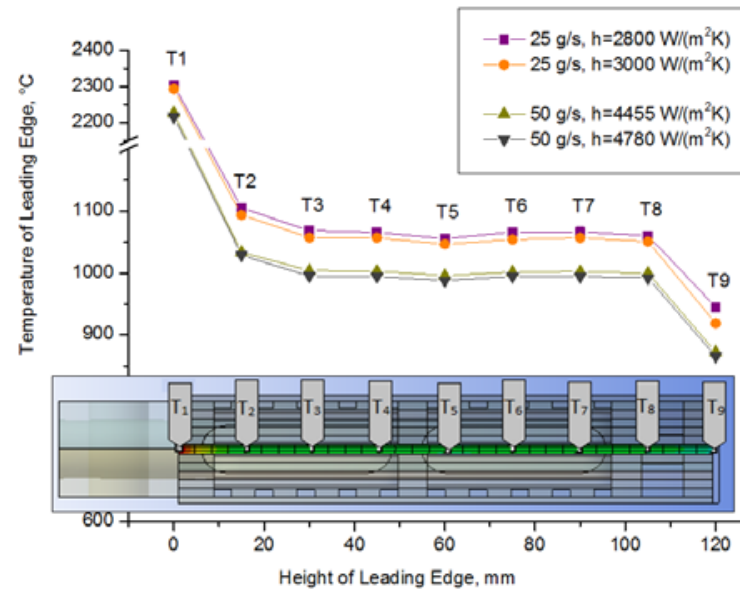

Height of Leading Edge, mm

Figure 21: TMC canard finite element analysis

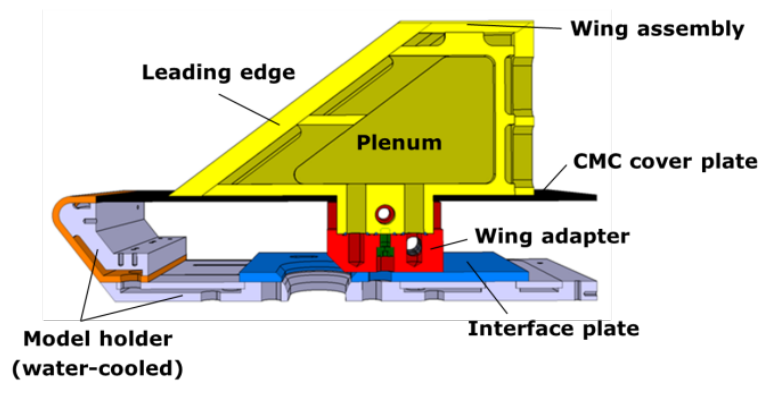

(a) TMC canard wings

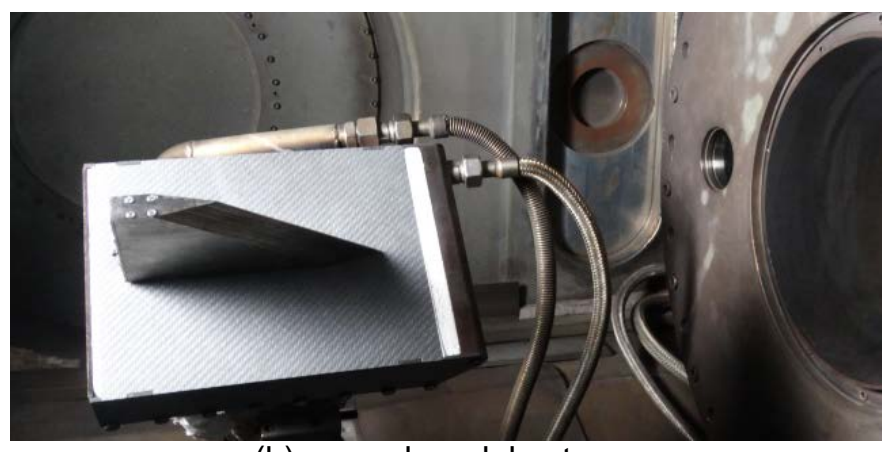

(b) canard model setup

Figure 22: TMC canard model

The coolant system proofed stable operation during all tests of the campaign. Unfortunately, the needed cooling rates of $50 \mathrm{~g} / \mathrm{s}$ were not obtained necessary to reach steady state conditions within the TMC's operational temperature range of $1000^{\circ} \mathrm{C}$. During the tests, leading edge surface colours changed which came along with oxidation and slight erosion effects at the upper end of the leading edge (Figure 23), where infrared system indicated temperatures up to $800^{\circ} \mathrm{C}$.

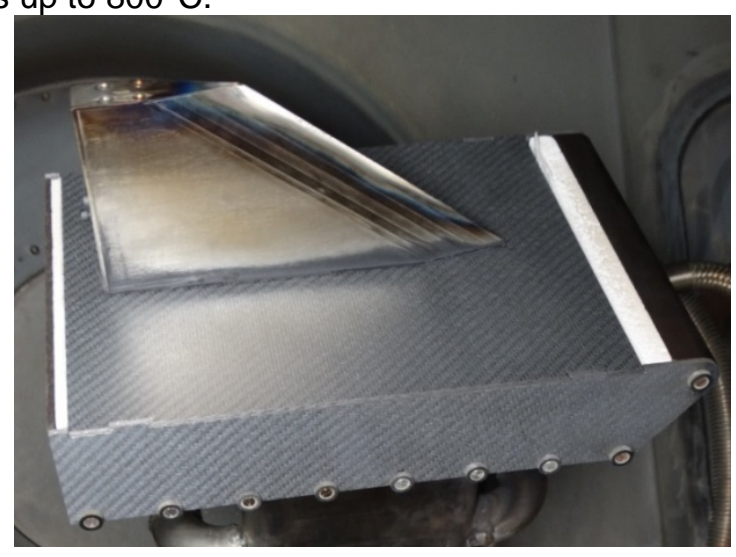

Figure 23: TMC canard wing (final appearance) 


\section{III.2 Hollow Sphere Structures and Tube Stacking Structures}

Within the current project, HSS (hollow sphere structure) [32] and TSS (tube stacking structure) materials were further developed by ONERA. The differentiation between HSS and TSS materials is mainly related to their intended use: HSS are rather randomly oriented and hence less predictable [33], but such materials are very favourable for parts of honeycomb like structures with acoustic damping abilities. On the other side, TSS are oriented, regular structures and therefore preferred from an industrial point of view. HSS materials exhibit a dedicated material behaviour in a well-defined direction, which is reflected by high oriented stiffness and energy absorption. Furthermore, due their regular nature, the simulation and characterisation of TSS based components is simplified as they can be considered as 2D.

With respect to material modelling, compression tests before and after oxidation treatments on TSS were performed [34]. TSS were brazed with various brazing materials and thermal treatment variants which resulted in a choice of optimised brazing process for materials of both high mechanical strength (at room and high temperature) and increased oxidation resistance [35]. The elementary cells consisted of Inconel $₫ 600$ tubes. Tensile tests on single tubes have been performed at elevated temperatures. At room temperature and $600^{\circ} \mathrm{C}$, the material's behaviour is mainly driven by plasticity effects. However at $800^{\circ} \mathrm{C}$, the behaviour is governed by viscosity effects at the lowest strain rates; at higher strain rates the material tends to saturate and is then mainly driven by plasticity.

Furthermore, compression tests were performed for TSS at high temperature conditions within a vacuum furnace to avoid oxidation effects (Figure 24). An inverse traction-compression setup was installed to improve the guidance of the compressive plate displacement. Optical access existed from outside so that the compressive plates displacement could be measured and digital images could be correlated to simulations. In addition, creep tests on TSS were performed at high temperature in air enabling oxidation effects.

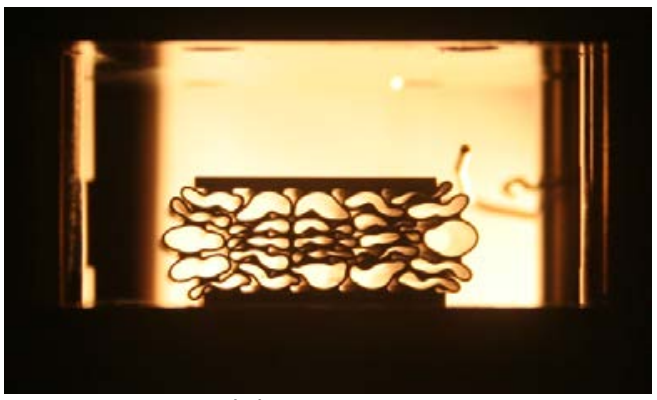

(a) test setup

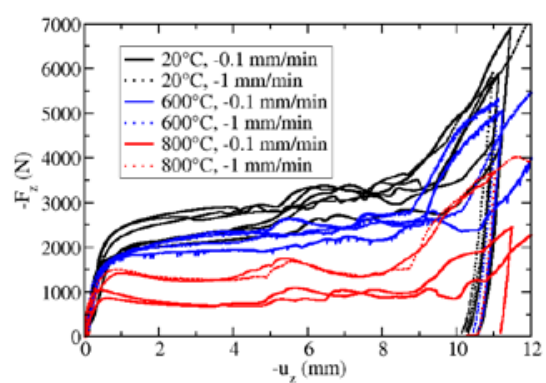

(b) test results

Figure 24: TSS compression tests at RT and HT

Additional work on HSP materials was dedicated to the design and manufacture of transpiration cooled panel structures for tests at combustion relevant conditions at the METHYLE facility (Figure 25 a) [33][36]. In terms of an assembly of cellular material and ceramic materials (Error! Reference source not found. $b$ ), two brazing solutions have been tested: dense or porous $\mathrm{Al}_{2} \mathrm{O}_{3}$ with $\mathrm{Cu}$, and $\mathrm{SiC}$ with $\mathrm{Ag}$. For both solutions, the addition of a TiAl sub-layer through PCT deposition process is necessary to ensure good wetting. Finally, a transpiration cooled HSS sandwich plate was manufactured, characterised and provided as a demonstrator [37].

Furthermore, investigations on the replacement of the extensive brazing process were initiated. For this reason, TSS made of stainless steel 316L were 3D-printed via the SLM (selective laser melting) technique and compared to conventionally Cu-brazed $316 \mathrm{~L}$ tubes.

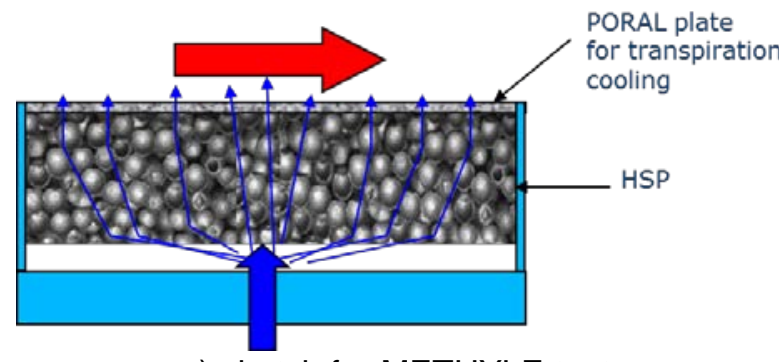

a) sketch for METHYLE tests

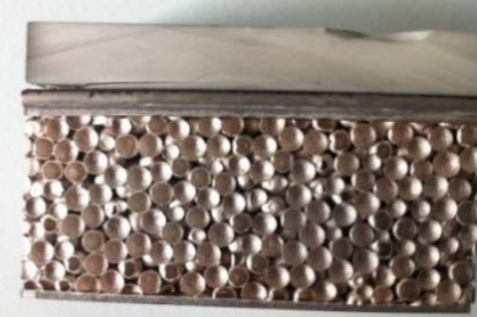

b) hollow spheres, tubes and $\mathrm{Al}_{2} \mathrm{O}_{3}$ skin

Figure 25: HSP sandwich structure

Parallel to all before mentioned characterisation efforts, numerical simulations were performed to get an insight of the material behaviour at various operating conditions. As depicted in Figure 26, small sandwich structures with a squared stacking of $5 \times 5$ tubes were considered. Thereby, the tubes had an outer diameter of $4 \mathrm{~mm}$, skin thickness of $1 \mathrm{~mm}$ and mean braze joint width of $1.43 \mathrm{~mm}$. 


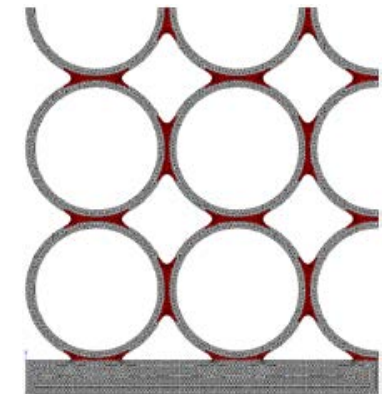

a) finite element mesh

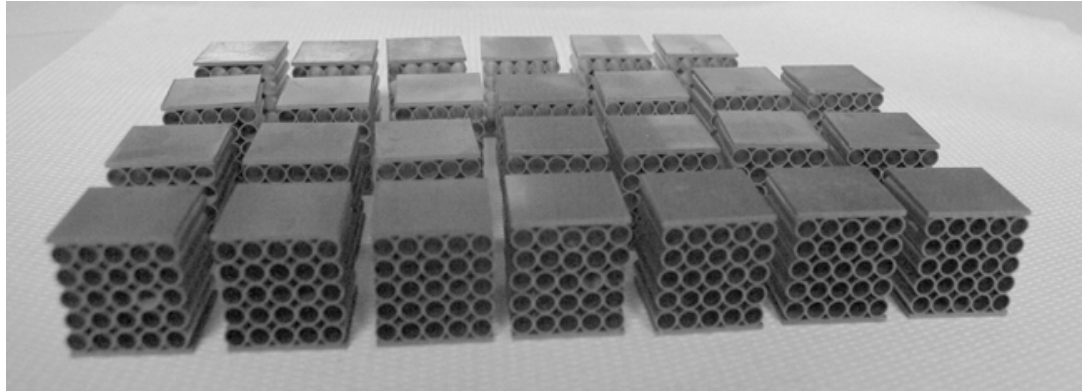

b) compression sandwich samples

Figure 26: TSS numerical modelling vs. experiments

The comparison of quasi-static compression tests (Figure 27) showed a good agreement between numerical modelling and experiment being independent of the applied temperature levels. It can be stated that strain rate effects were only detected at $800^{\circ} \mathrm{C}$ (experiments) but not at room temperature and $600^{\circ} \mathrm{C}$.
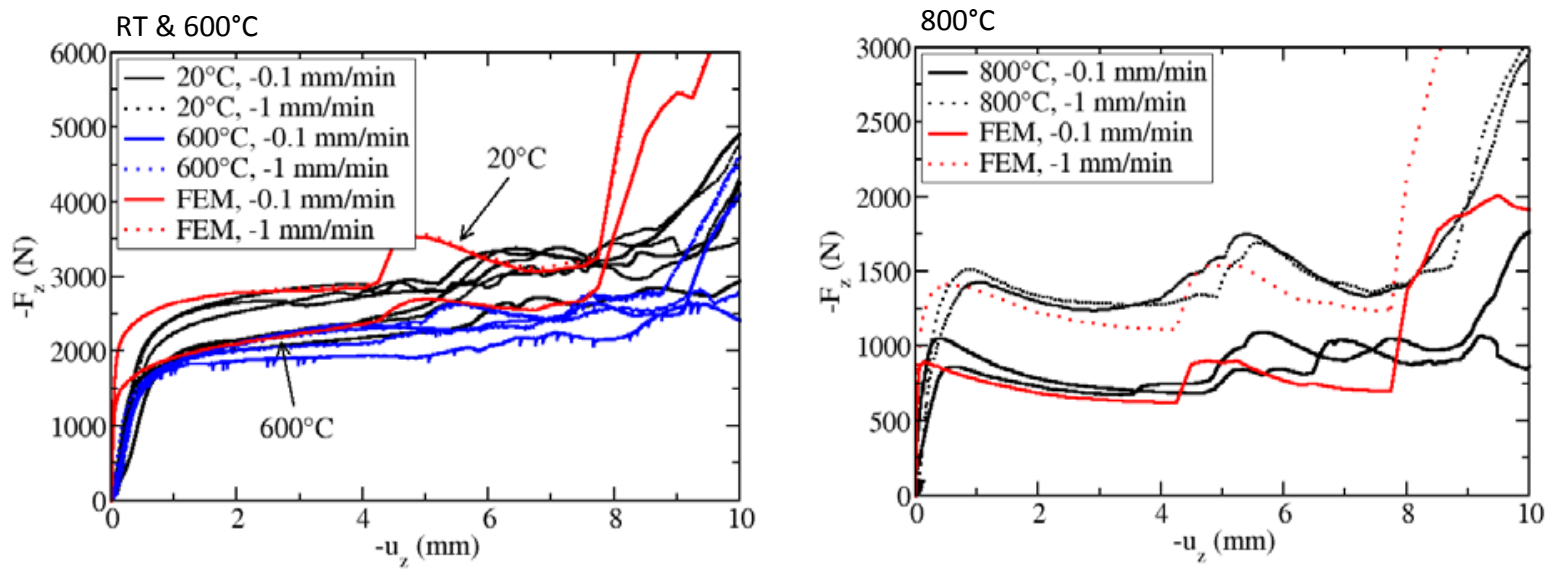

Figure 27: TSS quasi-static compression tests (simulation vs. experiments)

Nevertheless, the comparison of creep compression tests (Figure 28) showed some differences between numerical modelling and experiment results. As previously mentioned, creep tests were conducted following a three-stress-level approach. At $600^{\circ} \mathrm{C}$, the simulation is not able to capture the viscous effect highlighted and the considerable increase of the displacement from the beginning of the third stage. This important gap observed between experiment and modelling induces that some characteristic times of the creep phenomena were not captured from the monotonic tensile tests on single tubes, even if various strain rates were applied.
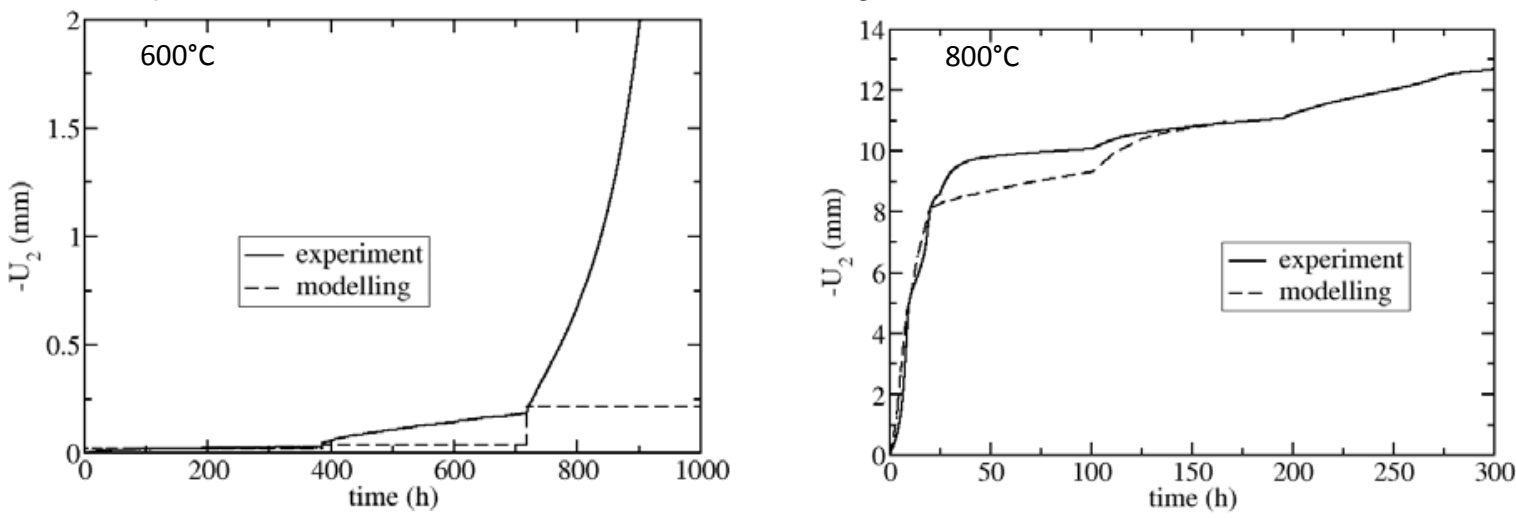

Figure 28: HTS creep compression tests (simulation vs. experiments)

Some coupling between plasticity and viscosity may exist at this longer time scale that cannot be neglected anymore as an important part of the total viscous contribution at this particular temperature. At $800^{\circ} \mathrm{C}$, the numerical computation delivers good results compared to the experiments but unfortunately the simulation diverged before the third stress level.

III.3 Ceramic Matrix Composites

Within the scope of this project, two different types of ceramic matrix composites (CMCs) were investigated by DLR: SiC/SiCN (non-oxide) and WHIPOX (oxide) with respect to those evaluated in ATLLAS I [38]. 
$\mathrm{SiC/SiCN}$ was manufactured via a PIP (polymer infiltration pyrolysis) process: SiC-fibre fabrics were infiltrated with a preceramic polysilazene precursor via a resin transfer moulding (RTM) process. After curing, plates were pyrolysed leading to a ceramisation (formation of $\mathrm{SiCN}$ ) of the matrix.

WHIPOX material is manufactured using computer-controlled winding techniques, whereas the winding pattern can be varied in a broad range. A Nextel ${ }^{\mathrm{TM}} 610$ fibre bundle is infiltrated with water-based slurry. The infiltrated fibre bundle is pre-dried and wound-up on the winding mandrel. After the winding-process, the wound bodies are dried or cut-up and removed from the mandrel. The sintering process is generally conducted at temperatures up to $1300^{\circ} \mathrm{C}$ in air. For the envisaged materials, samples have been prepared for

- oxidation resistance tests (arc-heated facility L2K and HVOF facility ERBURIG ${ }^{k}$ )

- basic characterisation, only SiC/SiCN (tensile at room temperature, coefficient of thermal expansion, heat capacity, heat conductivity)

- extensive characterisation (4-point bending creep, tensile creep, fatigue, DNS, ILSS, tensile at high temperature, notch sensitivity)

Basic thermo-mechanical properties of $\mathrm{SiC}_{\mathrm{pyc}} / \mathrm{SiCN}$ were determined before and after exposure to air $\left(1100^{\circ} \mathrm{C}\right.$, $20 \mathrm{~h}$ ). Before exposure to air, $\mathrm{SiC}_{\text {pyc }} / \mathrm{SiCN}$ material exhibits high specific strength (tensile strength $\sim 230 \mathrm{MPa}$ ) and high fracture toughness (strain to failure $\sim 0.36 \%$ ), no abrupt failure after maximal stress in bending test. After air exposure however, strength and strain to failure decreased to appr. 30\% compared to the unexposed case. The exposed material showed much more brittle fracture behaviour, which can be identified by less fracture toughness (less strain to failure) as well as less fibre-pullout as depicted in

Figure 29. Furthermore, SEM-micrographs indicated active (PyC-coating at temperatures $>450^{\circ} \mathrm{C}$ in air) and passive (silica $\mathrm{SiO}_{2}$ formation from SiC-fibres and $\mathrm{SiCN}$-matrix at temperatures $>800 \ldots 1000^{\circ} \mathrm{C}$ ) oxidation effects supporting $\mathrm{SiC}_{\mathrm{pyc}} / \mathrm{SiCN}$ embrittlement and strength degradation.

Before exposure

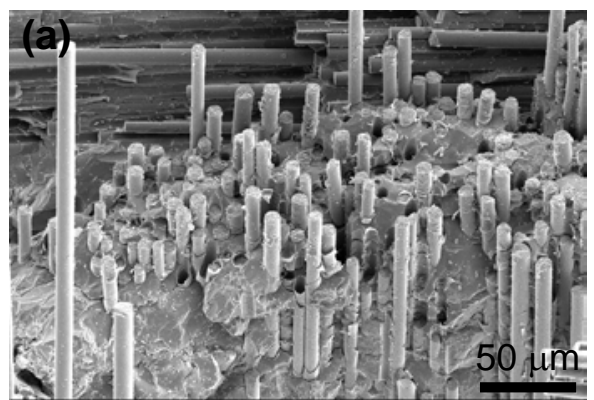

After exposure

$\left(1.100^{\circ} \mathrm{C}, 20 \mathrm{~h}\right.$, Luft $)$

Figure 29: CMC analysis: SiCpyc/SiCN fracture surfaces from bending tests

To receive damage tolerant composites with high fracture toughness, the $\mathrm{SiC} / \mathrm{SiCN}$ material (Figure $30 \mathrm{a} / \mathrm{b}$ ) was equipped with a pyrolytic carbon $(\mathrm{PyC})$ or monazite $\left(\mathrm{LaPO}_{4}\right)$ fibre coating, respectively. In order to improve the oxidation resistance of the WHIPOX material (Figure $30 \mathrm{c} / \mathrm{d}$ ), the samples were externally coated with silicon carbide $(\mathrm{SiC})$ and a spinel based top coat $\left(\mathrm{CoFe}_{2} \mathrm{O}_{4}\right)$ yielding in higher emissivity behaviour and oxidation resistance. To assess the oxidation resistance of the CMC materials, samples were prepared for tests at DLR's arc heated facility L2K. Following, two test campaigns have been conducted at temperatures up to 1650 and $1250^{\circ} \mathrm{C}$ for $\mathrm{SiC} / \mathrm{SiCN}$ and WHIPOX samples, respectively.

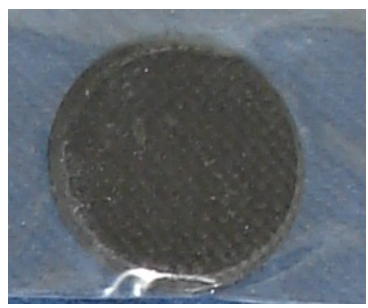

a) $\mathrm{SiC}_{\mathrm{LaPO}} / \mathrm{SiCN}$

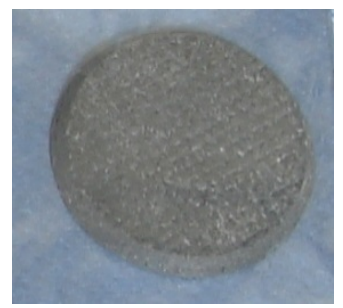

b) $\mathrm{SiC}_{\mathrm{PyC}} / \mathrm{SiCN}$

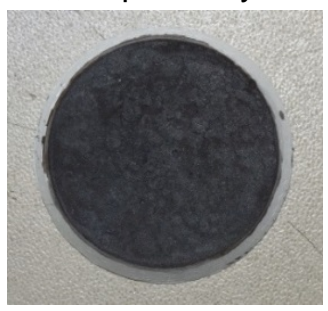

c) WHIPOX $\mathrm{CoFe}_{2} \mathrm{O}_{4}$

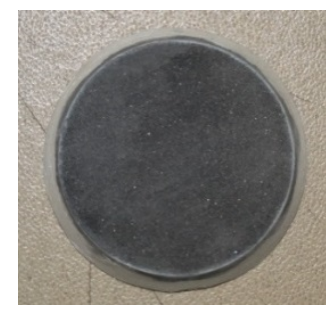

d) WHIPOX SiC

Figure 30: CMC samples for oxidation tests in L3K

Figure 31 exemplarily shows a test with a $\mathrm{SiC} / \mathrm{SiCN}$ sample at a stagnation point temperature of about $1650^{\circ} \mathrm{C}$. During these tests, the $\mathrm{SiC} / \mathrm{SiCN}$ materials showed no major differences between each fibre coating and none to only minor cycling effects during the start-up phase of the tests. These tests indicated the high performance of SiC/SiCN materials but the detected mass losses demand to have an external EBC (environmental barrier 
coating) to withstand harsh oxidative environments. WHIPOX material exhibited nearly zero mass losses, however it was not comparable as it was tested at significantly lower heat flux conditions.

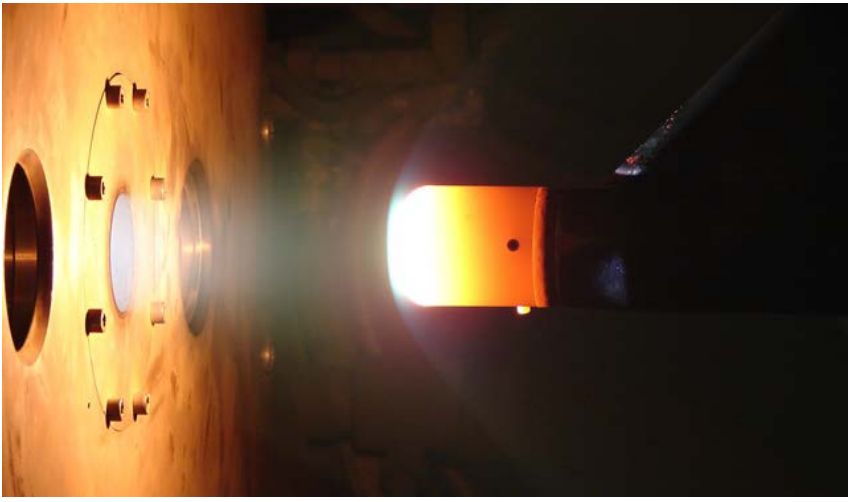

Figure 31: CMC oxidation resistance test at arc heated facility $\mathrm{L} 2 \mathrm{~K}\left(\mathrm{SiC} / \mathrm{SiCN}\right.$ at $\left.1650^{\circ} \mathrm{C}\right)$

CMC materials are designed to be damage tolerant. A way to characterise this is to conduct tests with stress intensifying elements. For this reason, samples with artificial slot and holes geometries (Figure 32) were prepared and tested for SiC/SiCN and WHIPOX. The tests indicated that both materials are insensitive or only poorly sensitive against such weakened regions.

Fatigue tests of WHIPOX at high temperature showed degradation effects of its stiffness and a development of hysteresis in the loading-unloading cycle. Based on current findings, a forthcoming failure cannot be predicted. Tensile tests on SiC/SiCN materials (Figure 33) indicated a high strength of $244 \mathrm{MPa}$ at room temperature. However, at elevated temperatures the samples tended to oxidise which resulted in a significantly decreased tensile strength; this is also due to a missing EBC coating.
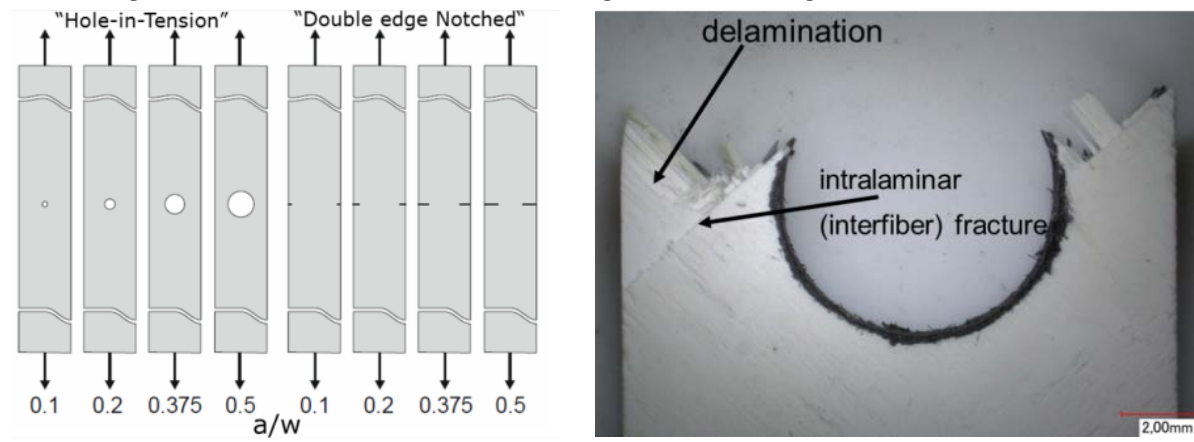

Figure 32: CMC test on stress intensifying elements (right: WHIPOX)

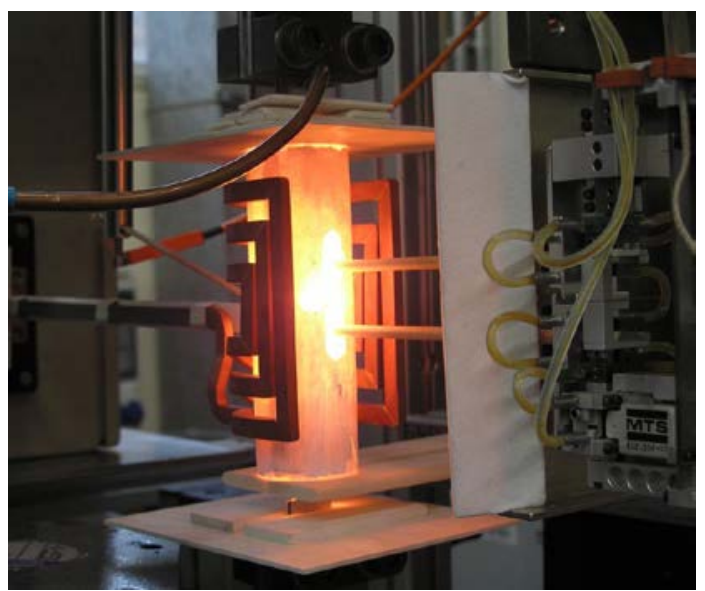

(a) experimental setup

\begin{tabular}{ccccc}
$\begin{array}{c}\text { sample } \\
\#\end{array}$ & $\begin{array}{c}\text { strength } \\
{[\mathrm{MPa}]}\end{array}$ & $\begin{array}{c}\varepsilon \max \\
{[\%]}\end{array}$ & $\begin{array}{c}\text { Temp. } \\
{\left[{ }^{\circ} \mathrm{C}\right]}\end{array}$ & \\
\hline $487-1 / 4 \mathrm{SH} 129 \mathrm{C}$ & 244 & 0.44 & $23(\mathrm{RT})$ & \\
\hline $488-1 / 4 \mathrm{SH} 134 \mathrm{C}$ & & & & \\
& & & & $\begin{array}{c}\text { Sample/platelets } \\
\text { slipped }\end{array}$ \\
\hline $489-1 / 4 \mathrm{SH} 139 \mathrm{C}$ & 87 & 0.18 & 1200 & \\
\hline $504-1 / 4 \mathrm{SH} 149 \mathrm{C}$ & 71 & 0.28 & 1000 & \\
$504-2 / 4 \mathrm{SH} 150 \mathrm{C}$ & 76 & 0.27 & 1000 & \\
\hline $504-4 / 4 \mathrm{SH} 152 \mathrm{C}$ & 58 & 0.12 & 1200 & \\
\hline $504-5 / 4 \mathrm{SH} 153 \mathrm{C}$ & 53 & 0.12 & 1200 & \\
\hline
\end{tabular}

(b) experimental results

Figure 33: CMC RT/HT tensile tests ( $\left.\mathrm{SiC}_{\mathrm{pyc}} / \mathrm{SiCN}\right)$

Like for tensile tests on SiC/SiCN materials, fatigue tests delivered similar results (Figure 34). The room temperature fatigue strength is with about $200 \mathrm{MPa}$ at a load cycle number of $10^{5}$ very favourable. However, as for tensile tests at elevated temperatures, the fatigue strength tends to decrease to about $80 \mathrm{MPa}$ at a load cycle number of $10^{5}$ as the samples are being oxidised during the tests and no EBC was existent. 
Fatigue testing of WHIPOX showed a distinct scatter in experimental results. Because of this, no reliable predictions can be made for load peaks beyond the linear-elastic regime.

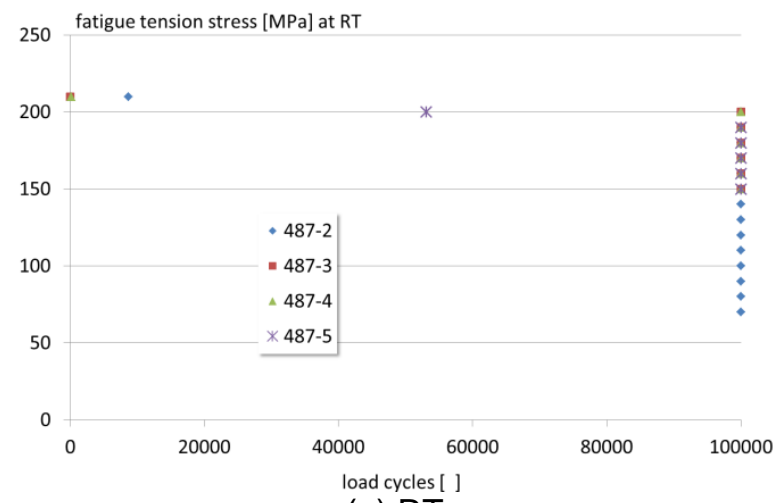

(a) RT

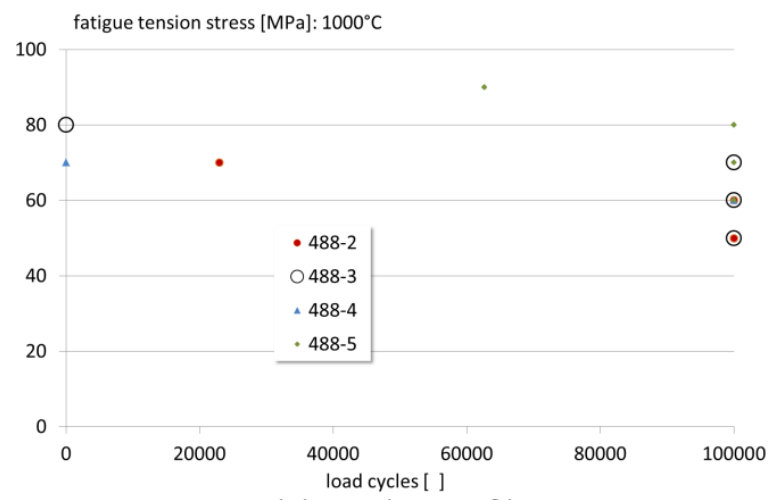

(b) $\mathrm{HT}\left(1000^{\circ} \mathrm{C}\right)$

Figure 34: $\mathrm{CMC}$ fatigue tests $\left(\mathrm{SiC}_{\mathrm{pyc}} / \mathrm{SiCN}\right)$

Finally, long-running creep tests were performed on SiC/SiCN material (Figure 35). Based on the three characteristics, all Norton creep parameters were determined for $\mathrm{SiC}_{\mathrm{pyc}} / \mathrm{SiCN}$ material which makes future creep predictions possible.

In general, this material offers a very high potential for high-temperature and long-duration applications. However in future, an EBC becomes crucial for this type of materials in order to protect the material against hot gas infiltration.

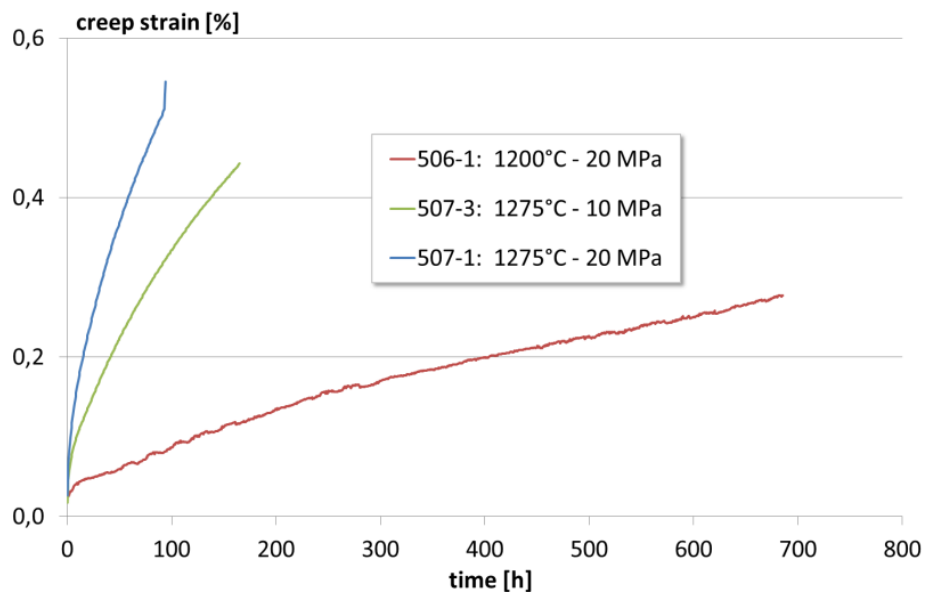

Figure 35: CMC creep tests (SiC/SiCN)

\section{III.4 Ultra-High Temperature Composites}

The Ultra high temperature ceramics (UHTC) manufacturing continued from ATLLAS I [39][40] and efforts concentrated on the spark plasma sintering (SPS) method. ONERA manufactured monoliths for three different compositions:

1. $\mathrm{ZrB}_{2} / 7.5 \%$ vol. SiC

2. $\mathrm{HfB}_{2} / 20 \%$ vol. SiC

3. $\mathrm{HfB}_{2} / 20 \%$ vol. $\mathrm{SiC} / 3 \%$ vol. $\mathrm{Y}_{2} \mathrm{O}_{3}$

The achieved densities were quite promising as $96 \%$ of the theoretical density was detected. However, it was decided to skip the composition " $\mathrm{ZrB}_{2} / 7.5 \%$ vol. SiC" due to a lack of process reproducibility and structural integration issues. Besides samples for extensive characterisation, bigger discs of $60 \mathrm{~mm}$ diameter and 12 $\mathrm{mm}$ thickness could be successfully manufactured. Such geometries enable to extract bigger parts as foreseen in other workpackages; Figure 36 shows the sintered hafnium-based materials. 

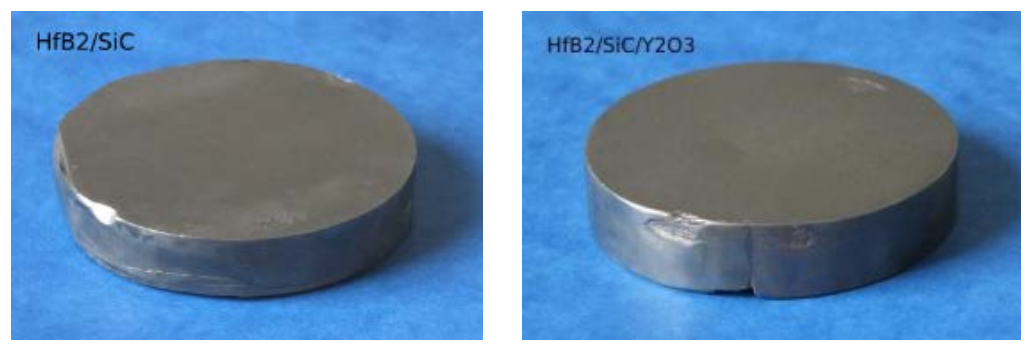

Figure 36: UHTC Hf-based sintered discs

Machining trials were performed via classical diamond machining but also via WEDM (wire electro-discharge machining) in order to check the feasibility of machining this type of material. With these methods, smalldiameter holes and round-shaped (leading edge) geometries were successfully applied. Subsequently, samples were machined for characterisation reasons (Figure 37).
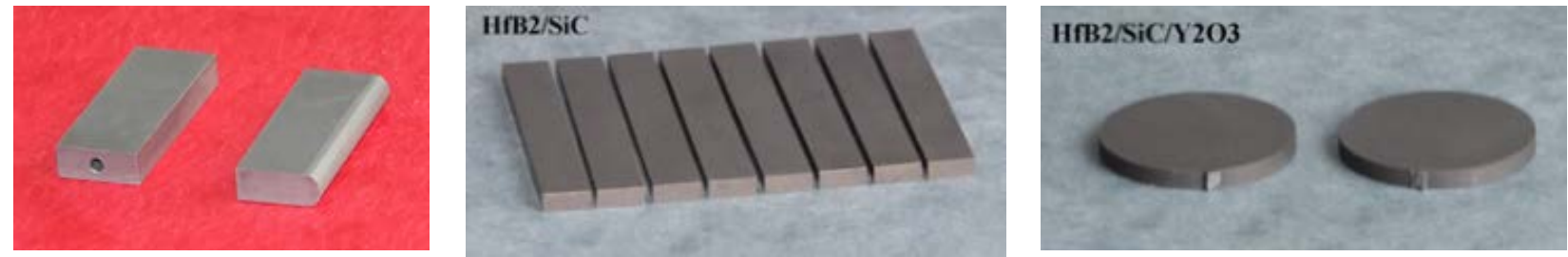

Figure 37: UHTC EDM machined samples

The characterisation of UHTC material was conducted at various levels: physical properties (densification state by water impregnation), microstructure (SEM observations, X-Ray diffraction), mechanical properties (Young's modulus by impulse excitation technique, flexural stress and modulus of elasticity at room temperature, Vickers Hardness, fracture toughness), thermal properties (coefficient of thermal expansion, thermal diffusivity by laser flash technique), oxidation resistance (thermogravimetric analyses at lab under air, BLOX4 facility at ONERA, METHYLE DMR test bench at MBDA).

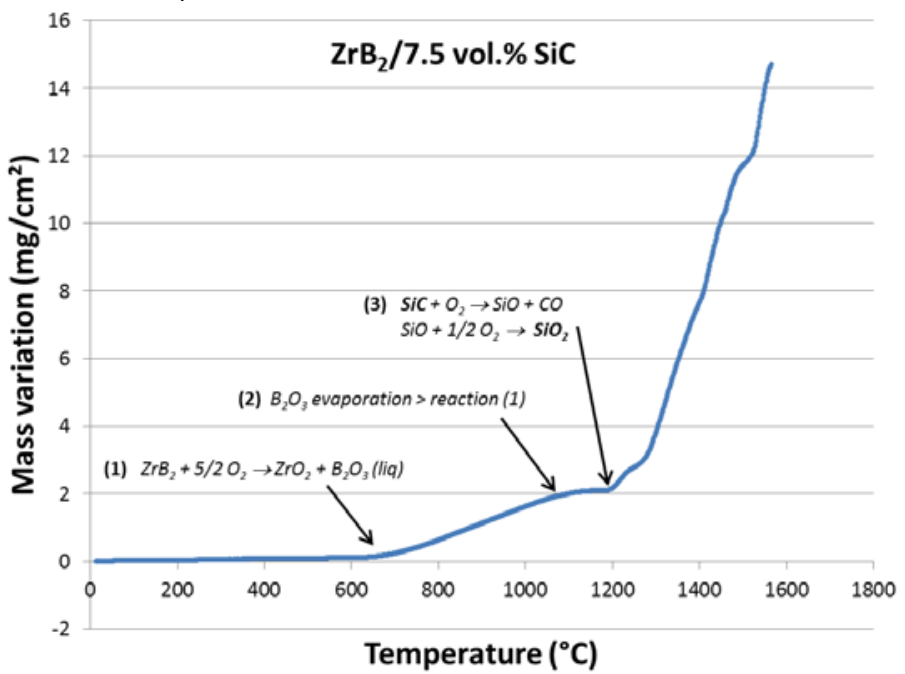

Figure 38: UHTC, TGA investigation for $\mathrm{ZrB}_{2} / \mathrm{SiC}$

For instance, thermogravimetric analyses up to $1550^{\circ} \mathrm{C}$ indicated multiple simultaneous mechanisms when $\mathrm{ZrB}_{2} / \mathrm{SiC}$ material is exposed to oxidation in air atmosphere (Figure 38): While the formation of $\mathrm{ZrO}_{2}, \mathrm{~B}_{2} \mathrm{O}_{3}$ and $\mathrm{SiO}_{2}$ results in a weight gains, the vaporisation of $\mathrm{B}_{2} \mathrm{O}_{3}$ and the formation of $\mathrm{SiO}$ and $\mathrm{CO}$ results in weight losses.

At the end, the oxidation resistance of selected UHTC compositions was investigated in the BLOX4 facility at ONERA at average laser fluxes of 7.0 to $10.3 \mathrm{MW} / \mathrm{m}^{2}$ resulting in surface temperatures of 1800 to $2000^{\circ} \mathrm{C}$. This is fully representative for operational heat fluxes of hypersonic airbreathing propulsion systems. Figure 39 shows the appearance of some samples after different testing conditions and durations. Extensive microstructural analyses were connected to these oxidation tests. On the outer surfaces, the formation of oxide layers $\left(\mathrm{SiO}_{2}, \mathrm{HfO}_{2}\right.$ and $\left.\mathrm{ZrO}_{2}\right)$ was notably observed whereas the core structure depends heavily on heat flux levels, test duration and testing atmosphere. 


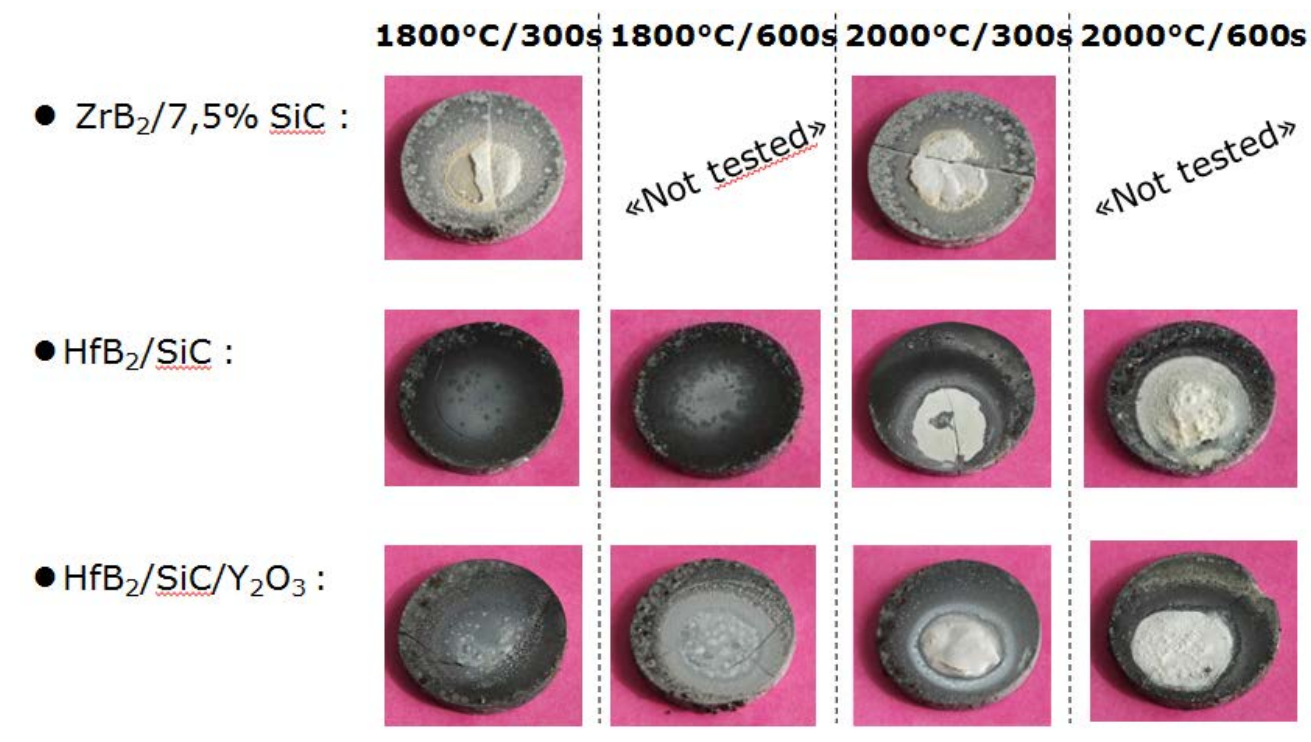

Figure 39: UTHC BLOX4 sample appearance after tests

Besides CMC materials, UHTC materials were foreseen for strut injector components of ram- or scramjets. Due to the SPS manufacturing process, UHTC materials cannot be manufactured in bigger sizes like other ceramics. Hence, it was considered to provide the pure strut injector part only. However, manufacturing trials were not satisfactory, as can be seen in Figure 60. Also, the dovetail connection along with its sealing concept shown in Figure 61 was of high risk. Hence, the injectors were redesigned so that only the injector's leading edge section (being the most exposed region) was made from UHTC. For this reason, CMC base parts were additionally provided by DLR, as shown in Figure 61 (left).

\section{III.5 Structures and Materials}

With regard to sustained flight, a transferability study was performed by DLR on its SHEFEX II approach of thermal protection system (TPS) panels. It turned out that for the occurring aero-thermal and mechanical loads, this design approach is suited in general, but needs to be adapted to other boundary conditions. Environmental impacts were considered critical as there is only minor knowledge available: waterproof barrier coatings become necessary and different types of impact (bird, hail, lightning strikes) need to be considered for future applications. Additionally, dynamic fatigue tests need to be performed to identify weak spots as the current TPS approach which was designed for short-term (re-entry) applications only.

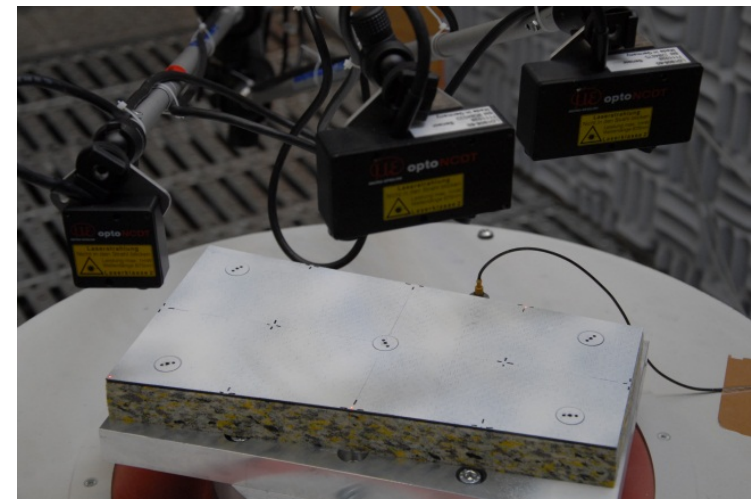

a) test article with laser displacement sensors

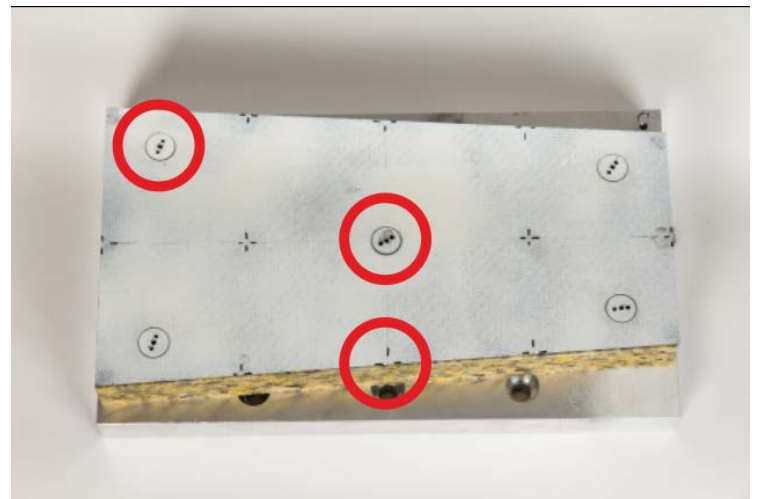

b) measurement locations

Figure 40: Structures and materials - SHEFEX II TPS panel shaker tests

For this reason, a shaker setup was prepared for the SHEFEX II TPS panel [41]. Figure 40 shows DLR's electrodynamic shaker facility with the installed panel setup installed for tests at room temperature. A PSD spectra "Load 1" (Figure 41 a) was derived which corresponds to a Mach 6 flight at $32 \mathrm{~km}$ altitude. Using this load spectrum, the setup was tested for an accumulated $100 \mathrm{~h}$ test time, which corresponds to $\sim 25$ flights of 4 $\mathrm{h}$ duration each. It could be stated that after this test period, no change in structural response was measured 
(Figure $40 \mathrm{~b}$; Figure $41 \mathrm{~b}$ ) and hence no damage was existent. In a second test series, the load spectrum was doubled to "Load 2". After another $4 \mathrm{~h}$ test, a deviation of mechanical responses was detected and further testing was stopped as one connection got loose. Nevertheless, this did not result in any failure of the structural parts.

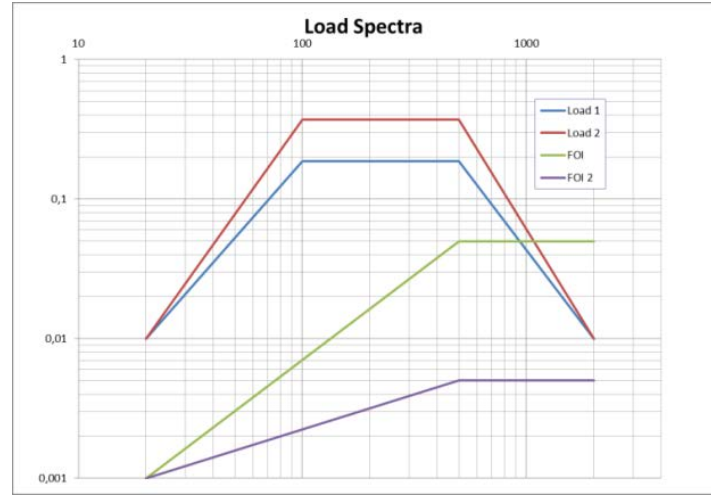

a) load spectra

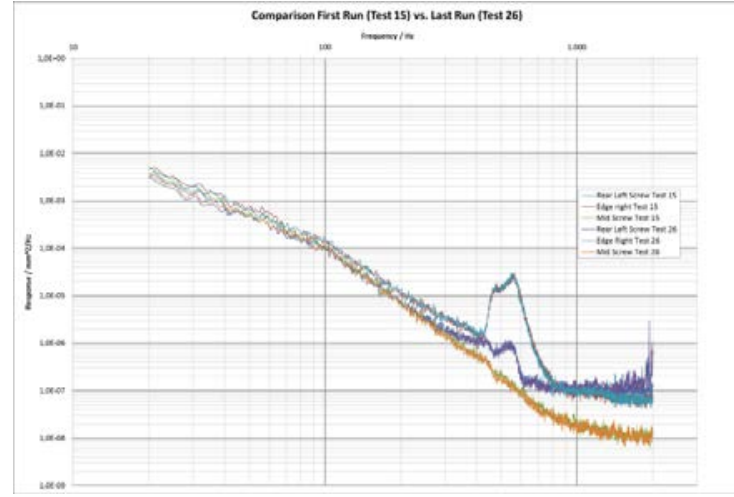

b) measured response at start (15) and after $100 \mathrm{~h}$ (26)

Figure 41: Structures and materials - load spectra and results after $100 \mathrm{~h}$

\section{III.6 Discussion}

Based on experiences made in ATLLAS I, lightweight airframe materials were supposed to be developed further with respect to long-term applicability. As materials are exposed to high thermal and structural loads (especially regions like nose structures, wing leading edges and air intakes), they need to be tailored for this application. Hence, certain components demand for high specific strength, high ductility and toughness, increased oxidation resistance as well as high creep and fatigue resistance at elevated temperatures.

The focus was directed towards material design, investigation of oxidation resistant coatings and consideration of long-duration characteristics like creep and fatigue, as recommended at ATLLAS I reviews. Following materials were under investigation along with their mechanical integration issues and their specific application.

- Titanium Matrix Composites (TMCs)

- Hollow Sphere Structures / Tube Stacking Structures (HSSs / TSSs)

- Ultra-High Temperature Ceramics (UHTCs)

- Ceramic Matrix Composites (CMCs)

TMCs were manufactured and tested at realistic, operational relevant conditions. Here, the focus was to push the limits for high thermal and mechanical loading environment. TMC materials were characterised at such testing conditions in a TGMF (thermo-gradient-mechanical fatigue) facility. These tests were accompanied by corresponding finite element analyses. Furthermore, a generic leading edge canard wing was designed including internal impingement cooling and a TMC-based design. TMC canard manufacturing routes were assessed and four canard wings were and provided for arc jet tests. Finally, tests were conducted in the archeated facility L3K to assess the feasibility of TMC-based components at increased heat loads. However, it turned out that the applied impingement cooling was not sufficient to achieve steady-state conditions.

It becomes therefore important to consider different means of thermal protection such as thermal barrier coatings and more effective cooling techniques for future components. Furthermore, it should be aimed to operate TMC materials at a slightly less demanding operating environment which is closer to (if not at) that accepted for the material. TMC is an excellent lightweight structural material of high strength and stiffness that could also support other materials like CMCs capable of operating at higher temperatures.

HSS and TSS materials were manufactured and thoroughly characterised at both room and high temperature conditions, with a special focus on creep compression behaviour. New high-temperature architectures in form of TSS were considered; this resulted in sandwich like structures capable for different applications. The numerical simulation of such structures was further optimised using quantitative constitutive material data which enabled an enhanced prediction of such structures.

The switch from random to regular oriented structures enables to better predict such structures; the use of tube structures corresponds to quasi 2D-extruded structures with a favourable, distinctive material behaviour.

As CMC materials, SiC/SiCN and WHIPOX were manufactured and thoroughly characterised for basic thermomechanical and damage tolerance behaviour at both room and high temperatures. In order to estimate their 
lifetime behaviour, dynamic fatigue and creep tests were performed as well. Furthermore, the material's oxidation resistance was investigated in the arc-heated facility L2K and in the atmospheric burner rig ERBURIGk.

$\mathrm{SiC} / \mathrm{SiCN}$ materials indicate an excellent performance; for long-term applications however, the material demands for a sophisticated EBC to improve its oxidation resistance. WHIPOX proved to be applicable for long-term applications in the medium temperature range up to $1200^{\circ} \mathrm{C}$.

The selection of UHTC candidate compositions was finalised; three different compositions were thoroughly characterised. Furthermore, bigger sample geometries were manufactured and the feasibility of UHTC was proved in operational relevant conditions, such as the BLOX4 and METHYLE facilities.

In order to increase again their operational capabilities, the next step is to develop reinforced UHTC materials to obtain a better damage tolerance behaviour.

For structures and materials, a TPS panel was set-up was tested at a shaker facility at room temperature. The tests performed successfully proved the feasibility for long-term applications of up to 100 hours, corresponding to about 25 flights of 4 hours flight duration each at Mach 6 and cruise altitude of $32 \mathrm{~km}$. Within an accumulated test time of 100 hours, no failures were detected. In addition, theoretical work on the connection of hot aeroshells to cold substructures as well as on the contribution of single TPS systems to the overall global stiffness was considered.

Small TPS panels successfully proved their applicability for long-term application. For realistic hypersonic cruiser vehicle lengths however, bigger panels may become necessary which come along with increased thermal expansion effects and manufacturing issues. Reducing the TPS size would be a possible, but at the end laborious option. Hence at the end, a trade-off must be found.

\section{Combustor \& Material Integration}

Advanced hot structures needed for manufacturing future hypersonic transport aircraft were investigated in ATLLAS I. The promising identified structures can be cooled or uncooled based on metallic or ceramic materials. Promising technologies were tested and simulated in ATLLAS I with moderate durations (up to several minutes) [43][44][45][46][47][48][49] though hundreds of hours in cumulative times and a few hours of flight are required for the actual system. One objective in ATLLAS // is to test the high-temperature materials and structures under relevant chemical and aero-thermal conditions with test time from minutes to hour.

Two demonstrations were highlighted as important to be done: incremental testing of dual-mode ramjet fin injectors on the one hand and the capability assessment of a nozzle sandwich, derived from the work performed on metallic hollow spheres packing concept. These technologies can be used on a high-speed airliner fly at Mach 5 and beyond. Examples of these aircraft are given on the figure below Figure 42.

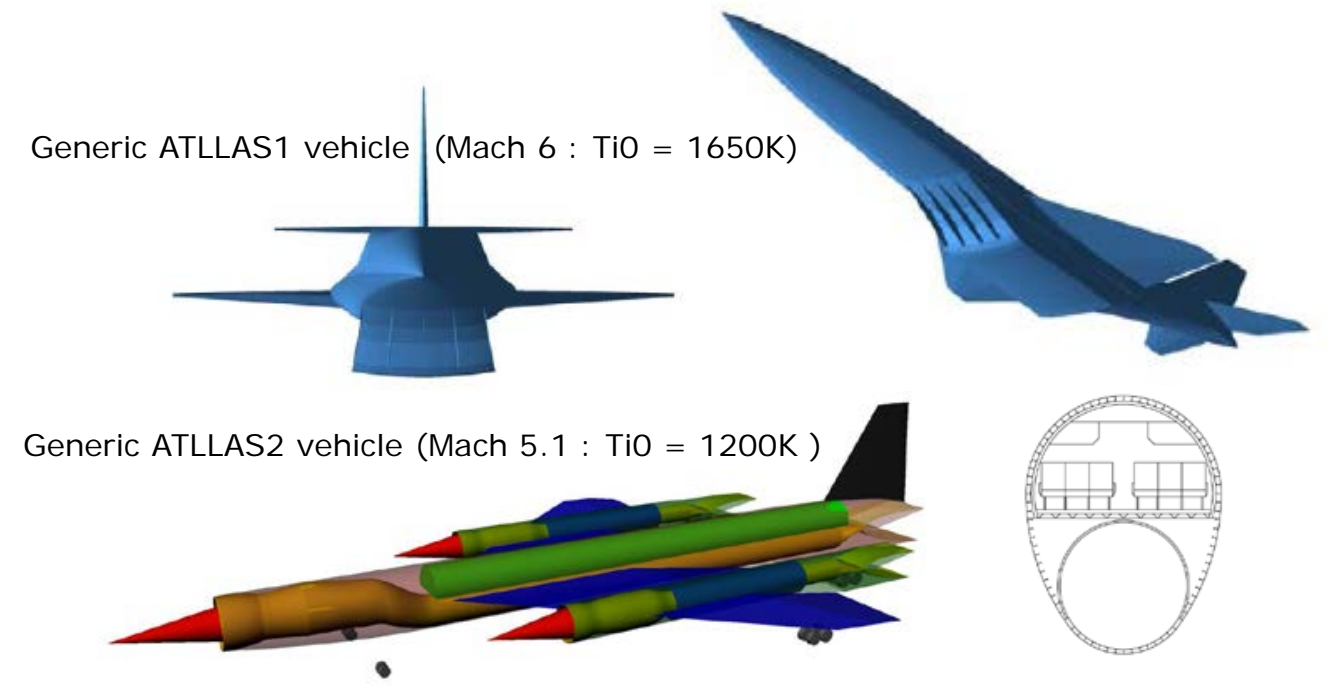

Figure 42: Generic high-speed aircraft projects used for technology guidance in ATLLAS projects

The vehicle system studies from ATLLAS I/II were used as guidelines to define the architecture and the test conditions. The enhanced materials and their characterization, described in the previous section are the starting basis for the industrial-type of experiments: long duration test in the ERBURIG ${ }^{\mathrm{K}}$ test facility in Airbus Group Innovations (Germany) and industrial METHYLE dual-mode ramjet test facility in Bourges (France). These tasks allow to experimentally and numerically investigate, in a generic but relevant way, different 
combinations of materials and cooling techniques. They will provide an interesting database for numerical simulations described in the next section. Possible applications of these structures on a future high-speed airliner are depicted in Figure 43 and details can be found in [47][50][51].

nose

Leading edges rudder

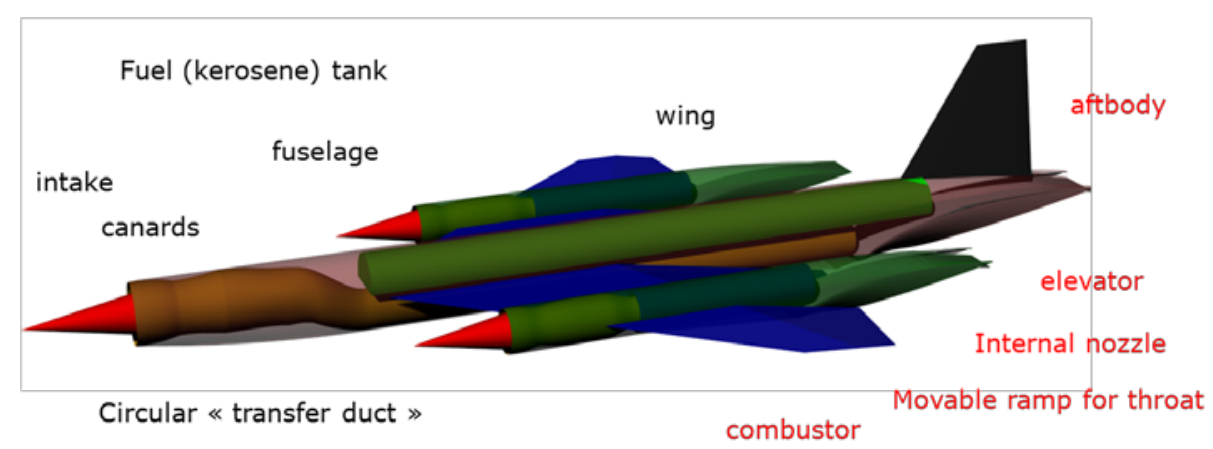

BL bleeds

-External diverter

-Porous bleed

-Internal bleed

Flame Holder

-Air Pax cabin control

Injectors

Figure 43: System studies as a guideline for structures to be used in different sub-systems

Material and structures for combustors and advanced hot structures within ATLLAS // allow investigating various advanced technologies with future applications:

- Different structures (pin fin, injectors, uncooled CMC, HSS panel...)

- Different cooling techniques (pin fin, convective, transpiration, radiative)

- Different materials (metallic foams and skins, CMC including PTAH-SOCAR, massive UHTC)

- Different test environments (from lab to industry engine, from isolated phenomena to full real complex)

- Different level of test documentation (instrumentation)

- Different levels of pre-test and post-test computations (engineering, CFD...)

- Different durations (but generally minutes to hours)

- Different applications on future high-speed airliner.

The following table and figure illustrate in a synthetic way the different systems and materials investigated. The various test series were prepared and analysed with design tools and with respect to possible use in high speed combustion environment and integration. The design structures were tested with different levels of environment representability on one hand and instrumentation on the other hand (Figure 44). The benefit between previous ATLLAS I program and current ATLLAS // results is summarized in Table 2 and detailed in the following sections.

Some of the test series were realized in industrial test facilities, previously developed thanks to European funding (FEDER, FRED, FSE...), especially the METHYLE high speed and combustion research test facility in Bourges, France. 


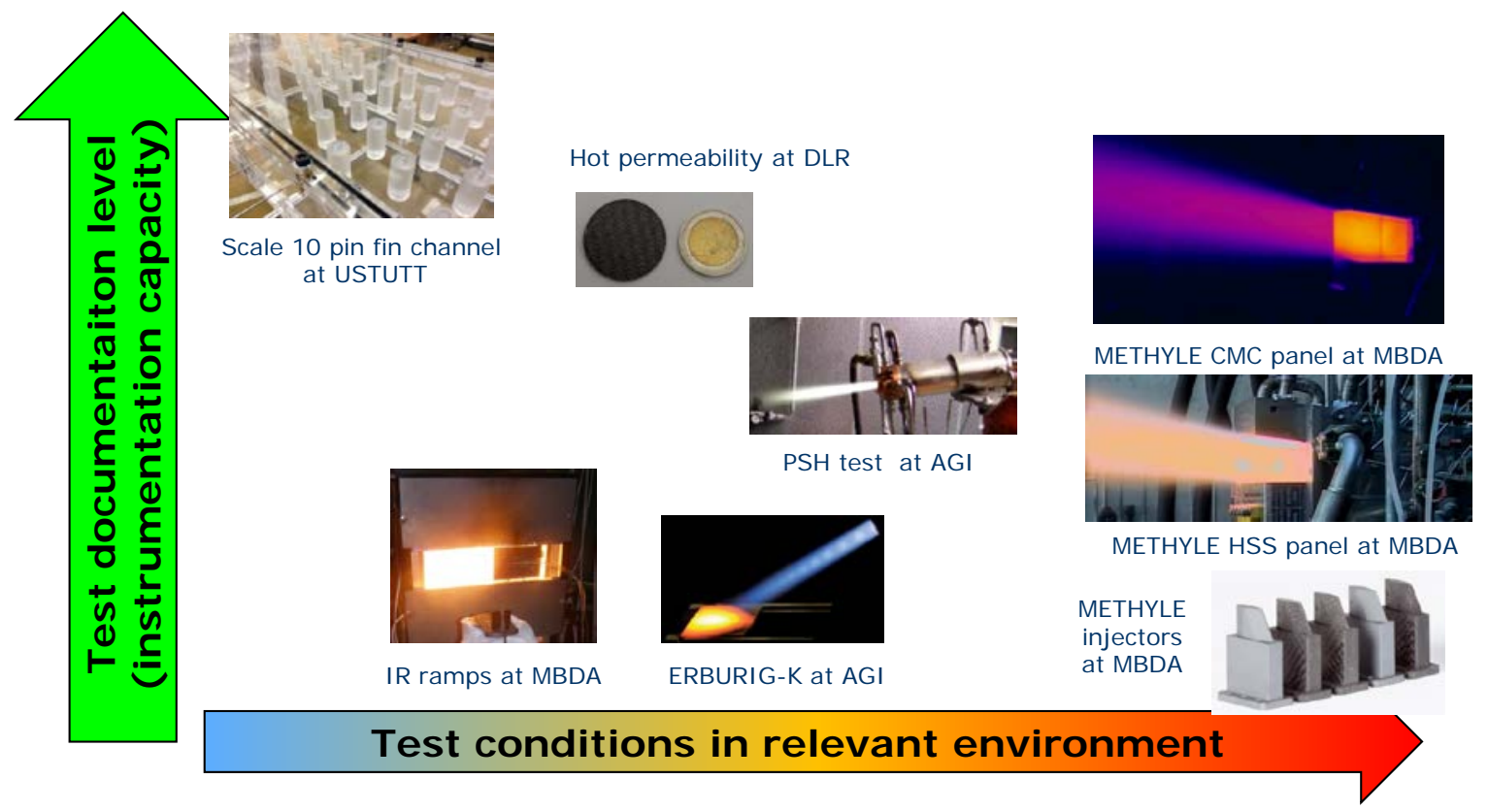

Figure 44: Testing chart for Combustor and Material Integration in ATLLAS //

\begin{tabular}{|c|c|c|c|c|c|c|}
\hline Type & Cooling & Material & Technique & In ATLLAS I & In ATLLAS II & End of ATLLAS II \\
\hline \multirow{2}{*}{$\begin{array}{l}\text { Pin fin } \\
\text { channel }\end{array}$} & \multirow{2}{*}{ Convective } & CMC & $\begin{array}{l}\text { PTAH- } \\
\text { SOCAR }\end{array}$ & PSR at TUM & $\begin{array}{l}\text { PSH at ERBURIG long } \\
\text { duration }\end{array}$ & 4 PSH ducts tested \\
\hline & & Perspex & Generic & computations & $\begin{array}{ll}\text { Detailed } & \text { basic } \\
\text { experiment } & \end{array}$ & $\begin{array}{l}\text { Tests and CFD } \\
\text { Performed }\end{array}$ \\
\hline \multirow{2}{*}{$\begin{array}{l}\text { Injection } \\
\text { struts }\end{array}$} & $\begin{array}{l}\text { Transpiration } \\
\text { Convective }\end{array}$ & CMC & I & none & $\begin{array}{l}\text { METHYLE } \\
\text { Industrial TF }\end{array}$ & $\begin{array}{l}5 \\
\text { successfully tested in } \\
\text { METHYLE with } \\
\text { CH4/H2 combustion }\end{array}$ \\
\hline & Convective & UHTC & I & Material sample & $\begin{array}{l}\text { USTUTT (academic) } \\
\text { METHYLE (industrial) }\end{array}$ & $\begin{array}{l}2 \text { injectors } \\
\text { successfully tested in } \\
\text { METHLYE with } \\
\text { CH4/H2 combustion }\end{array}$ \\
\hline $\begin{array}{l}\text { External } \\
\text { wall }\end{array}$ & $\begin{array}{l}\text { None } \\
\text { (radiative) }\end{array}$ & $\mathrm{CMC}$ & different & Material charac. & $\begin{array}{l}\text { ERBURIG flat plate test } \\
+ \text { METHYLE } \\
+ \text { IR lamps }\end{array}$ & $\begin{array}{l}\text { IR, ERBURIG and } \\
\text { METHYLE } \\
\text { performed } \\
\text { successfully }\end{array}$ \\
\hline $\begin{array}{l}\text { HSS } \\
\text { panel }\end{array}$ & $\begin{array}{l}\text { Transpiration/ } \\
\text { convective }\end{array}$ & Metallic & $\begin{array}{l}\text { Porous } \\
\text { Hollow } \\
\text { Spheres } \\
\text { sandwich }\end{array}$ & HSS manufacturing & $\begin{array}{l}\text { METHYLE industrial TF } \\
+ \text { IR lamps }\end{array}$ & $\begin{array}{l}\text { IR \& METHYLE Tests } \\
\text { performed } \\
\text { successfully with } 2 \\
\text { coolant rates }\end{array}$ \\
\hline
\end{tabular}

Table 2: List of material and structures successfully investigated

\section{IV.1 Pin fin channels}

This technique is already used by heat exchangers, turbomachinery components, PTAH-SOCAR composite monobloc technique. Its application on future high-speed airliners mainly deals with zones in contact with high heat fluxes from combustion process, and possibly in some other areas like hot boundary layer bleeds (Figure 45). The work performed in ATLLAS // in this area allows to significantly increase the scientific know how in two directions:

- Long duration testing of CMC cooled structures where pin fins in the cooling channel are generated by perpendicular stitching

- Detailed documentation of pressure drop as well as local heat transfer of staggered pin fins channels. 


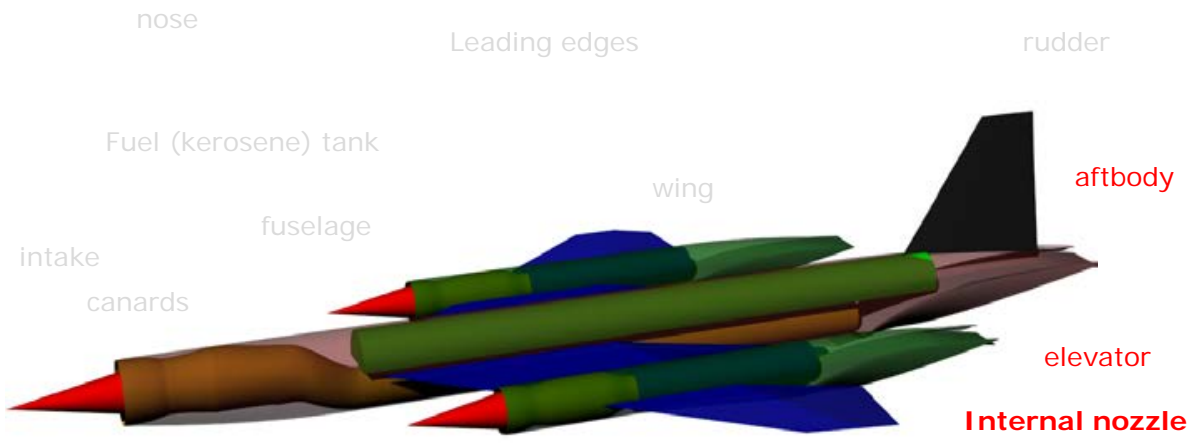

Circular « transfer duct »

Movable ramp for throat

BL bleeds

- External diverter

- Porous bleed

- Internal bleed

- Air Pax cabin control

Flame Holder

Injectors

Pin fin channels

Figure 45 : synthesis view of pin fin channels possible use of high-speed airliner

A unique experiment with warm air and perspex channel, associated with advanced measurement techniques, was elaborated at University of Stuttgart [52]. Three different channels were defined with different X/D - S/D $-\mathrm{H} / \mathrm{D}$ geometrical parameters [53]. The detailed experimental work allows to document a huge amount of data on pressure drop, wall heat transfer and pin fin local heat transfer and verify against literature [54][55].

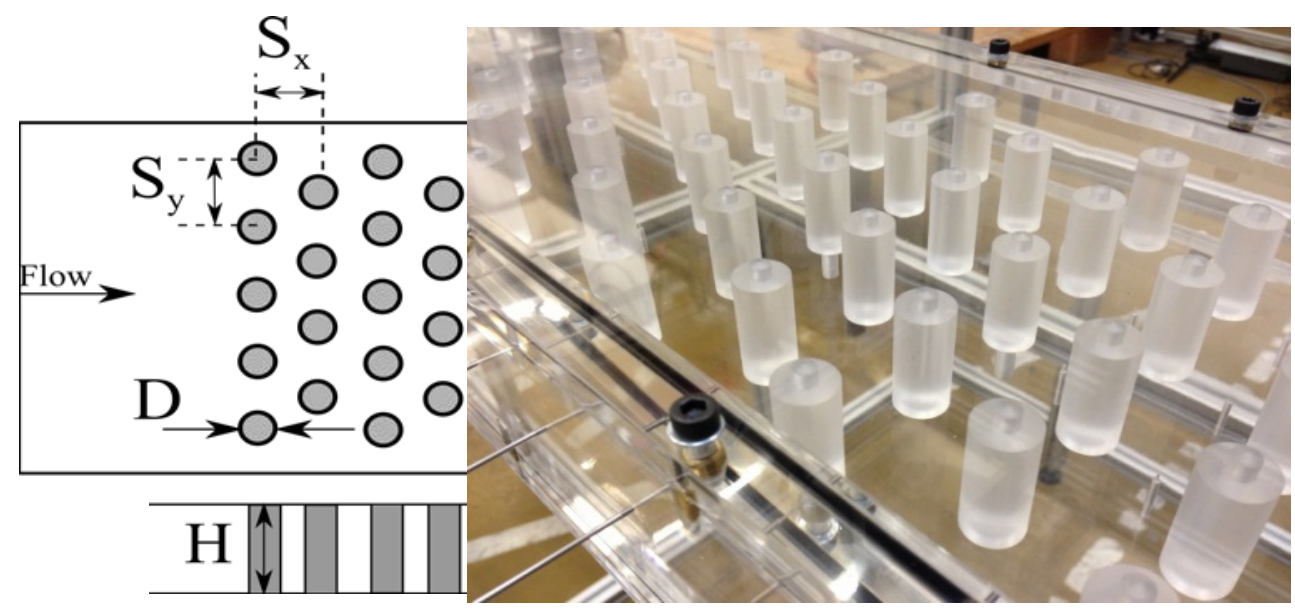

Figure 46 : pin fin channel at USTUTT and pattern definition
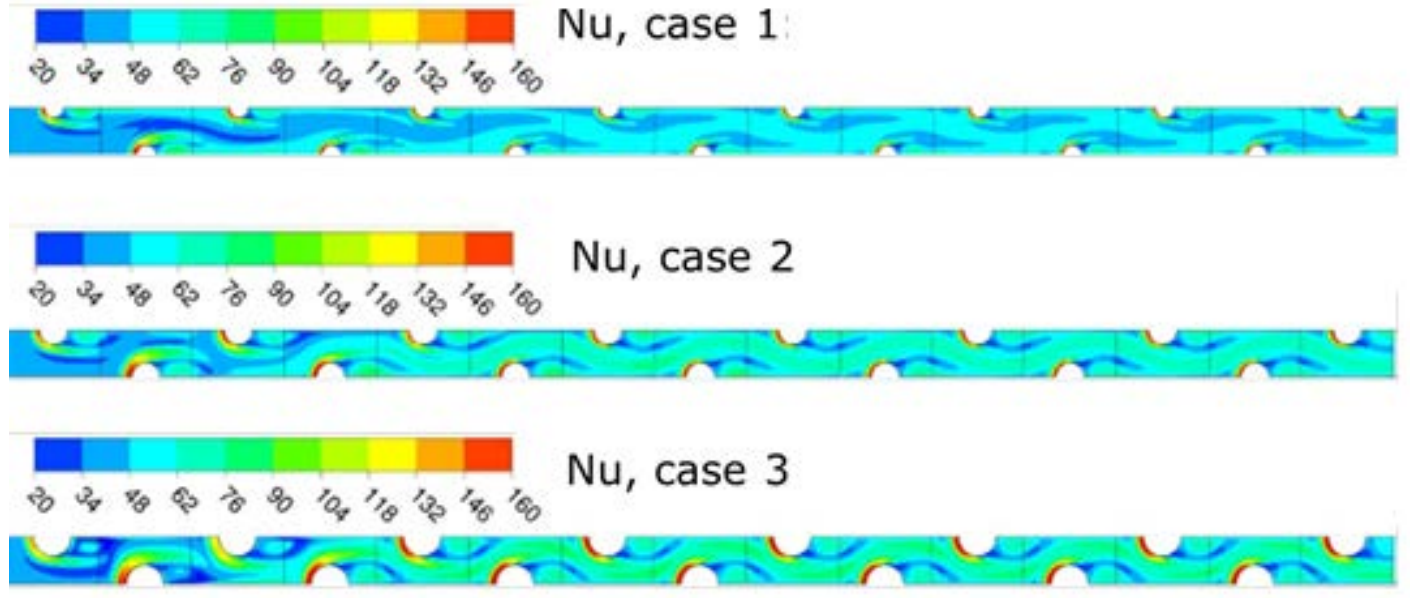

Figure 47 : Different pin fin patterns in 2D channels investigated numerically at USTUTT 


\section{heat transfer coefficient $\left[\mathrm{W} /\left(\mathrm{m}^{\wedge} 2 \mathrm{~K}\right)\right]$}

360

350

316.6

300

283.3

250

240

216.6

200

183.3

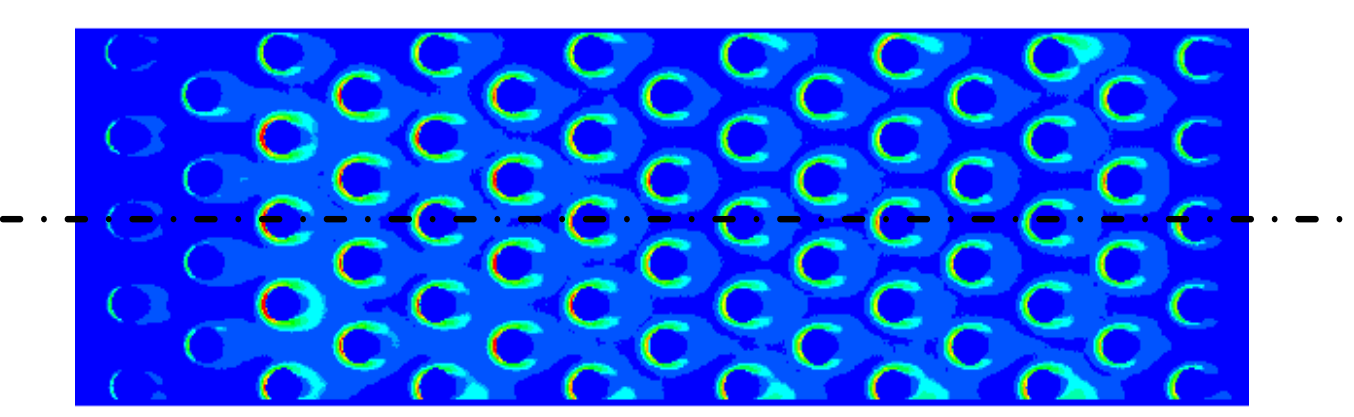

180

150

Figure 48: example of measured heat transfer coefficient map in pin fin generic channel

Further, the lumped heat capacitance method is applied to determine the heat transfer coefficient on the pin fin (Figure 49a) for the configuration $S_{x} / d=S_{y} / D=2.5$ and $H / D=2$. An array averaged pin fin Nusselt number is determined for each Reynolds number for all rows and compared with correlations from the literature (Figure 49b). The experiments agree very well with the correlations of the literature for low Reynolds numbers as well as for higher ones. The overall deviation of the Nusselt number experimental data from the correlations is due to the different considered array configurations.
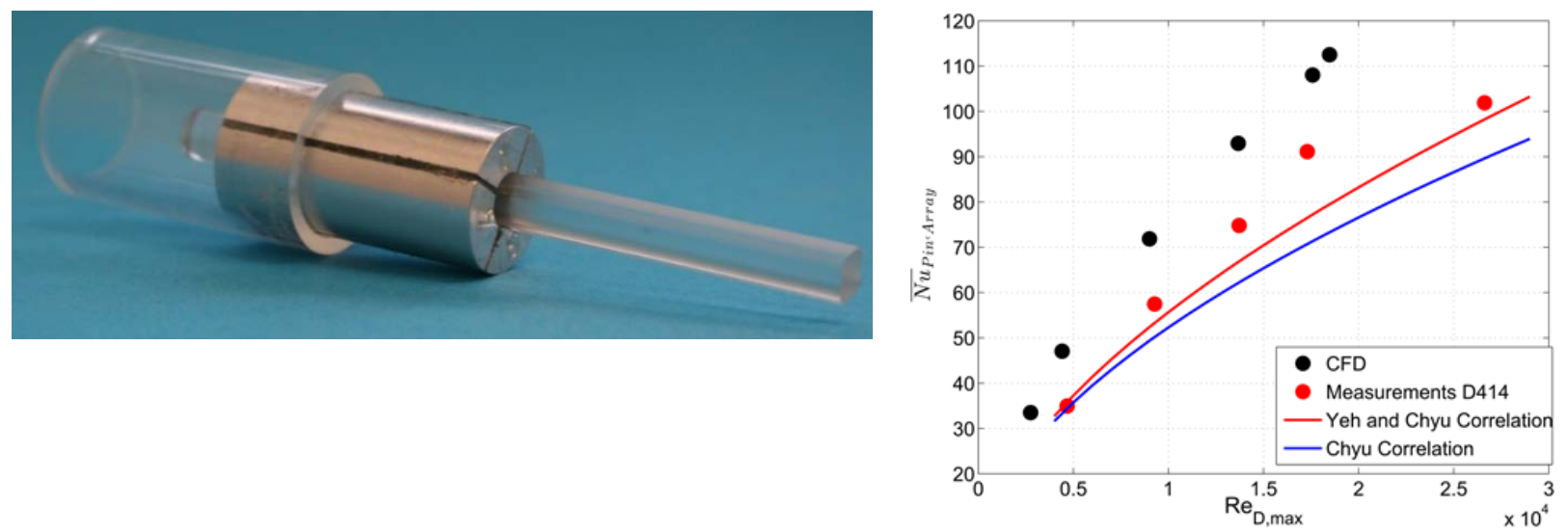

Figure 49: Left: instrumented aluminium pin fin with 4 quadrants; Right: Array averaged pin fin Nusselt number compared with correlations and CFD

With the same logic as in ATLLAS I, some round PTAH-SOCAR monobloc cooled pin fin structures were manufactured and tested in ATLLAS II. The conical PSH samples were tested during several hours, while in ATLLAS I the cylindrical PSR similar ducts were tested during several minutes.

The existing and previously checked modelling (MBDA NANCY empirical code) of such PTAH-SOCAR structures was used to compute the hot wall temperature, about $1800 \mathrm{~K}$, as only the coolant temperature can be measured in such experiments. Post-test analysis was made on the tested components, for instance the $\mathrm{SiO} 2$ layer created by oxidation on the inner hot wall was measured.

These results will be useful to define in future $R \& T$ programs solutions (refined coating, for instance) to ensure thousands of hours operating with combustion of such cooled CMC structures. From ATLLAS I to ATLLAS II we already demonstrated minutes to hours' life duration in strong oxidative environment, but this has to be continued for application on future high-speed airliners.

Besides the possible applications summarized in the Figure 45, the pin fin results of ATLLAS // can benefit to:

- Knowledge on pin fin heat exchangers (metallic ones, PTAH-SOCAR ones...)

- Passenger area cooling

- Equipment's cooling

- CFD and coupled simulations enhancement / verification (difficult test case family for local heat transfer computation).

- used for different applications in aeronautics as well as electronics (Figure 51) 

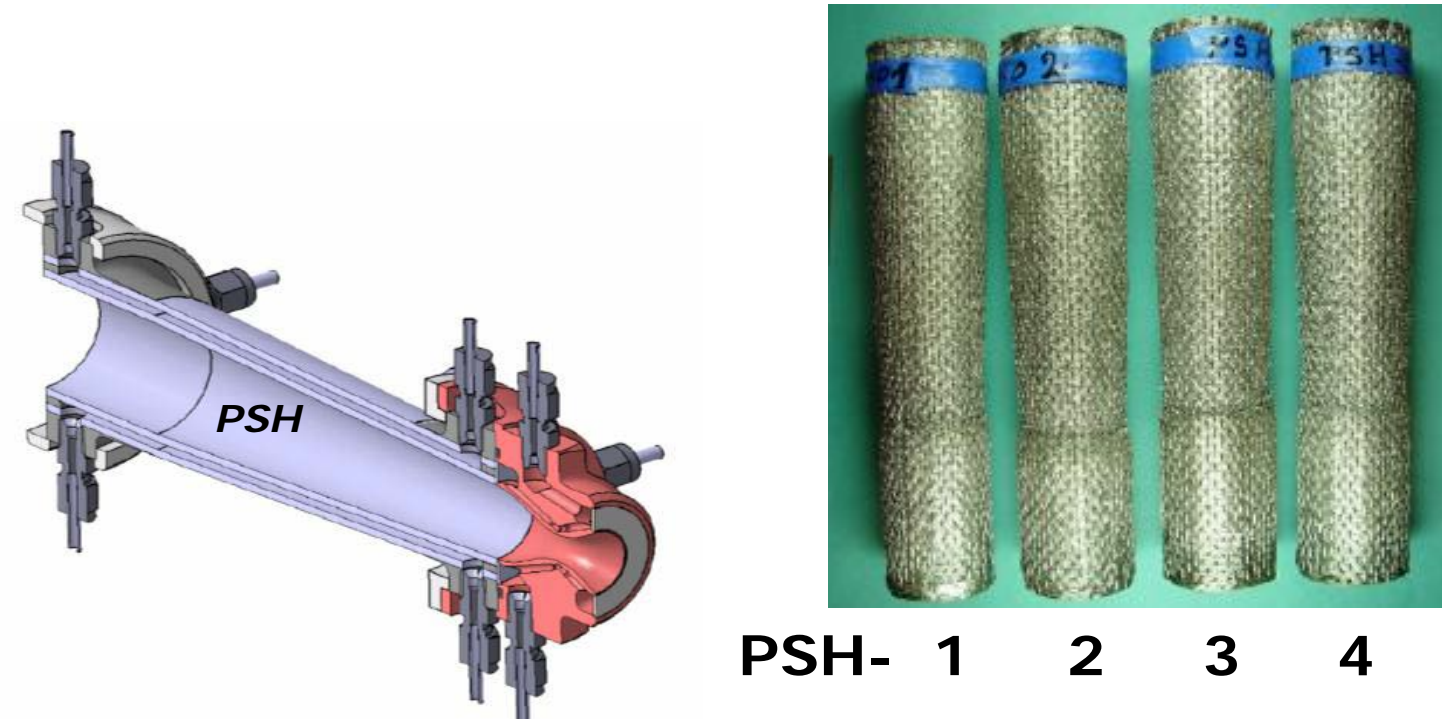

\section{PSH- $122 \quad 3 \quad 4$}

Figure 50 : pin fin cooled CMC testing in ERBURIG-K

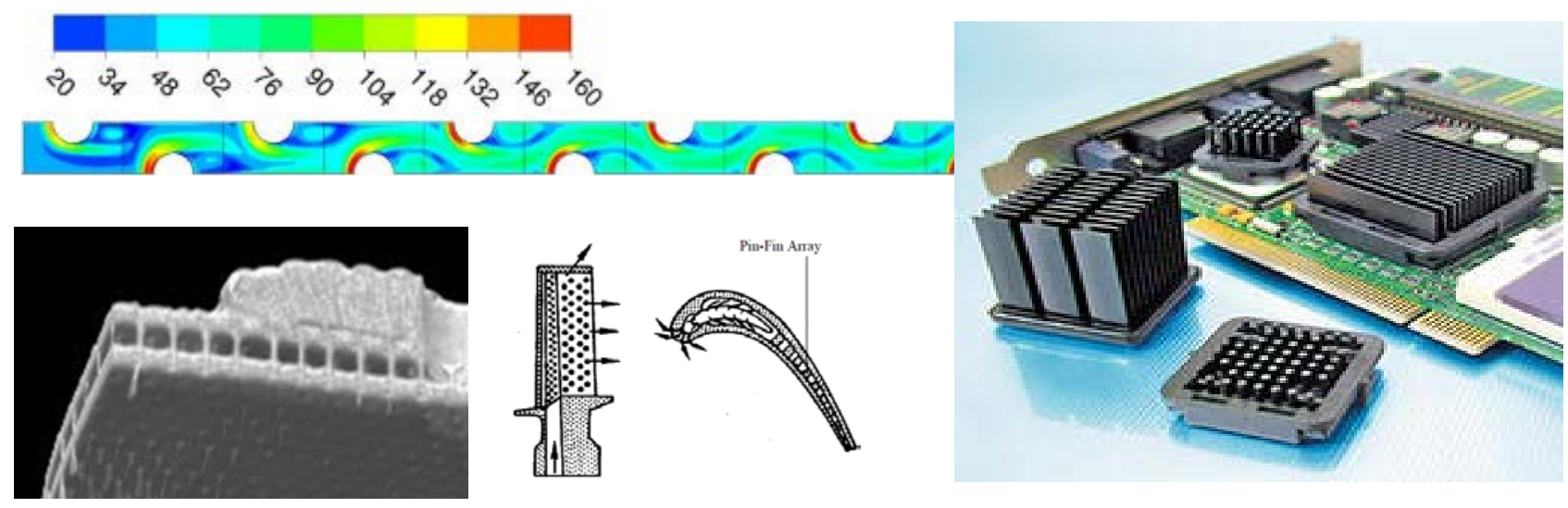

Figure 51: Examples of pin fin cooling systems

IV.2 Multifunctional porous wall

The high thermally loaded walls of propulsion units require particular material development. HSS sandwich core combined with high-temperature panels appears as attractive component for lightweight, hightemperature, actively cooled structures, identified as a key technology in ATLLAS I. In order to evaluate the thermal insulation performance of HSS, thermal characterisation of hybrid HSS structures need to be performed under realistic conditions. The present HSS technology is one of the possible solutions to organize cores of advanced structures, as it can be drawn on the following figures extracted from the Ashby metal foam "bible" [56] .

A HSS panel was designed, tested in hot conditions in METHYLE under Mach 6 flight conditions with combustion. Associated computations were performed, and the design capability is claimed to be sufficient to design any multifunctional metallic hollow sphere sandwich on various applications. This multi-functional design capability was realized through work in different subtasks, as summarized in Figure 54: the upper part illustrates the testing devoted to hot permeability on porous materials while the medium part illustrates the different works performed on defining and testing of a multifunctional sandwich which was computed as illustrated on the bottom part of the same figure.

A generic HSS multifunctional sandwich was designed and manufactured for cold and hot characterization (Figure 55). Its performance was tested under IR lamps prior to its integrating in the METHYLE facility. The methods of computing the complex structure of double layer HSS panel, i.e. 1D (cutter code from MBDA) and in 2D or 3D (CFD ACE code by ESTEC) were checked on these experimental results (Figure 56). The simulations were then extended with coolant flow in the HSS panel to simulate the METHYLE test (Figure 57). 


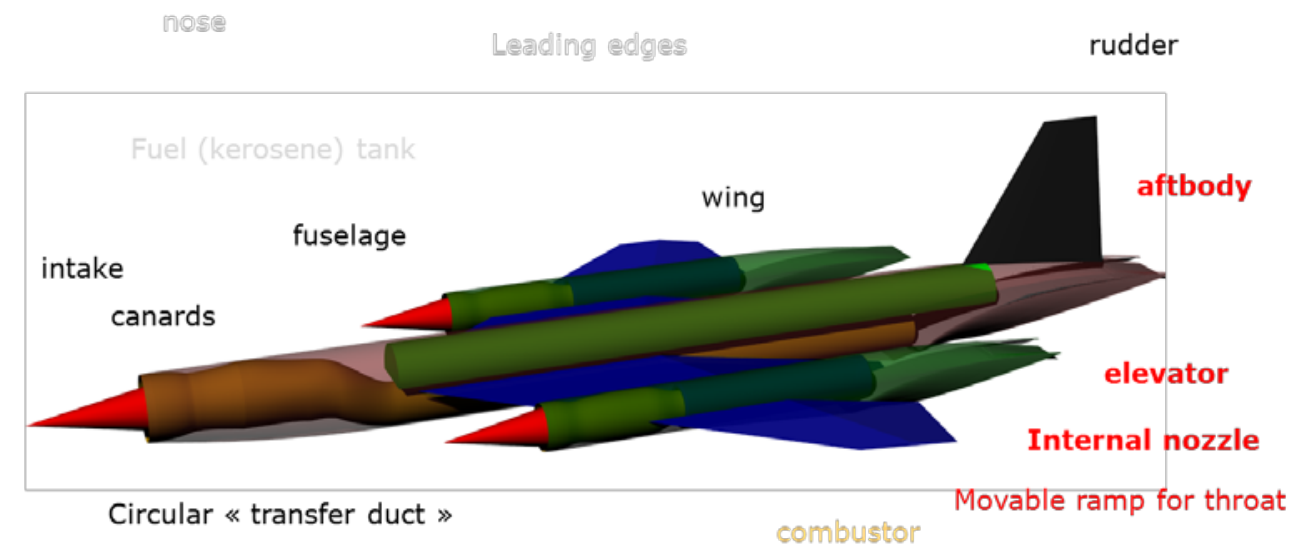

$\mathrm{BL}$ bleeds

-External diverter

-Porous bleed

-Internal bleed

- Air Pax cabin control

Multifunctional HSS

Figure 52 : synthesis view of HSS possible use of high-speed airliner

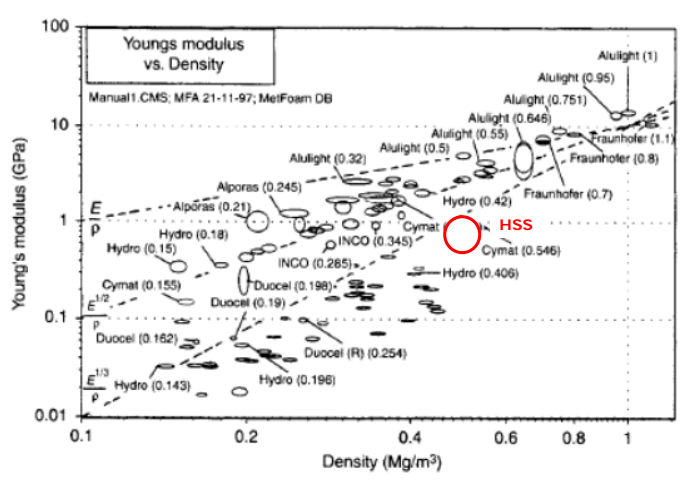

Figure 4.6 Young's modulus plotted against density for currently available metal foams. Output from CES3.1 with the MetFoam '97 database

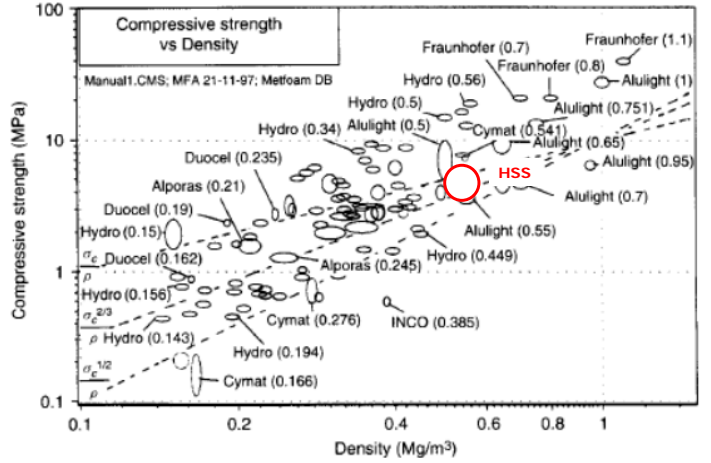

Figure 4.7 The compressive strength plotted against density for currently available metal foams. Output from CES3.1 with the MetFoam '97 database

Figure 53 : HSS possible use for metal foam sandwiches [56]

- Characterization of porous material with GN2, GH2, temperature, stress (DLR)

- Multifunctional hollow sphere materials (ONERA, MBDA)
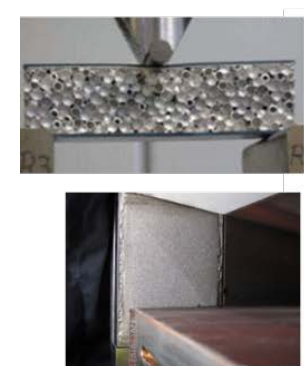

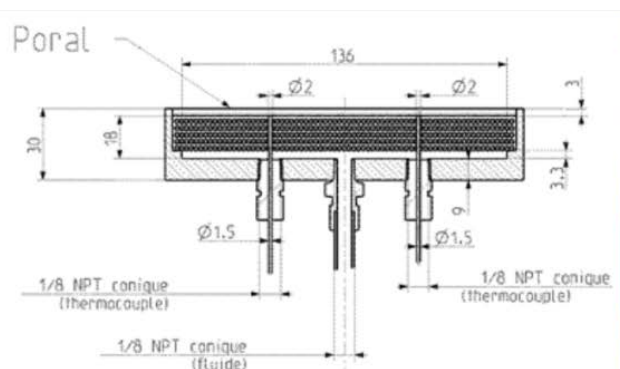

$1 / 8$ NPT conique

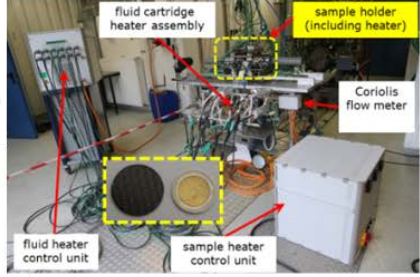

- Associated 3D coupled simulations (ESTEC)

- IR ramps checking

- Fluid calibration in the panel

- METHYLE hot test
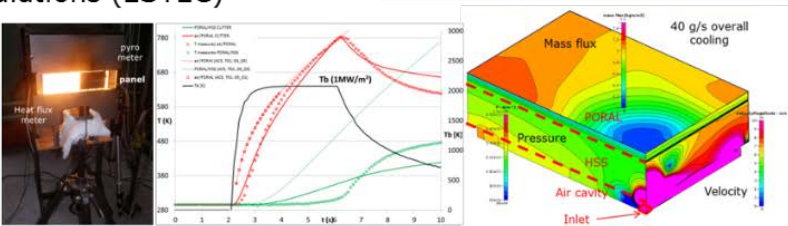

Figure 54: Permeable materials for advanced multifunctional structures 

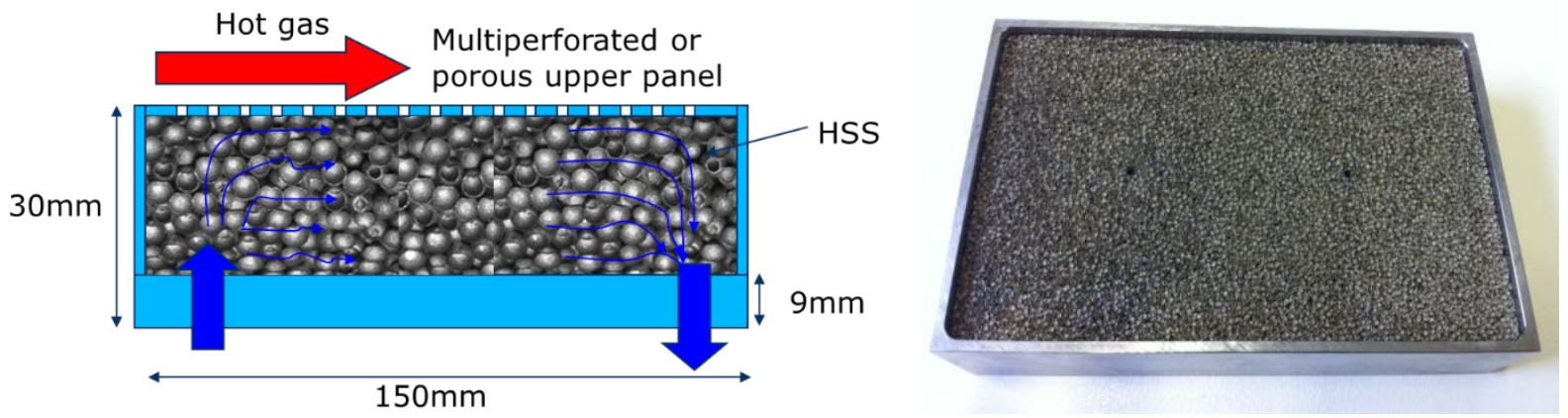

Figure 55: Principle of HSS multi-functional panel designed and tested in ATLLAS /I

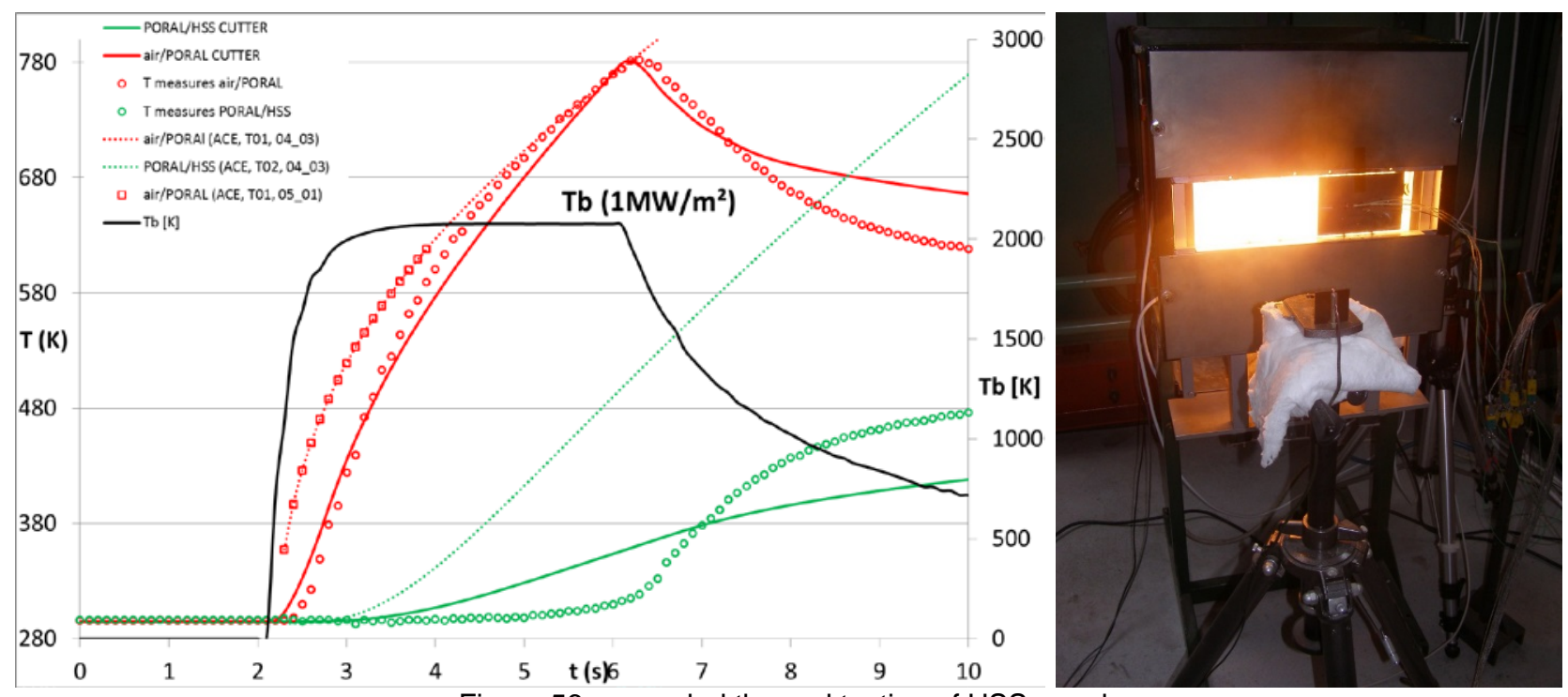

Figure 56 : uncooled thermal testing of HSS panel

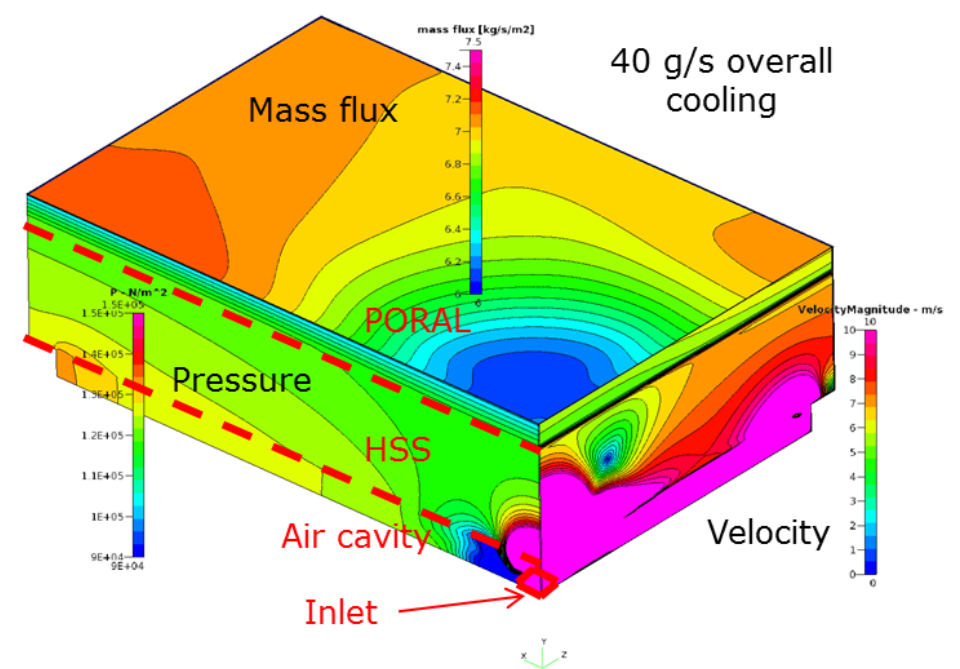

Figure 57: Example of 3D transpiration cooling computation of HSS panel

The panel was successfully tested in METHYLE with two different mass flows, at the exit of the MBDA dualmode ramjet, combustion with flight conditions of Mach 6. Post-test analysis of the apparently not damaged panel allows checking any possible oxidation of the upper layer as well as minor change of permeability. A small decrease of permeability was registered after the test, probably due to dust deposit in the inner wall through incoming GN2 coolant and to soot deposit on the hot porous layer. 
The methods to predict the mechanical, fluidic, thermal characteristics of different multifunctional HSS structures with different materials were checked during ATLLAS I and ATLLAS II. Acoustic behaviour of HSS was investigated and proven but the associated design methods are still to be developed for such industrial design. These methods can be used to prepare suitable customized multifunctional structures, e.g. after- body, wing skin, boundary layer bleed. In future studies, additive manufacturing may also participate to extend the usability of such multifunctional structures.
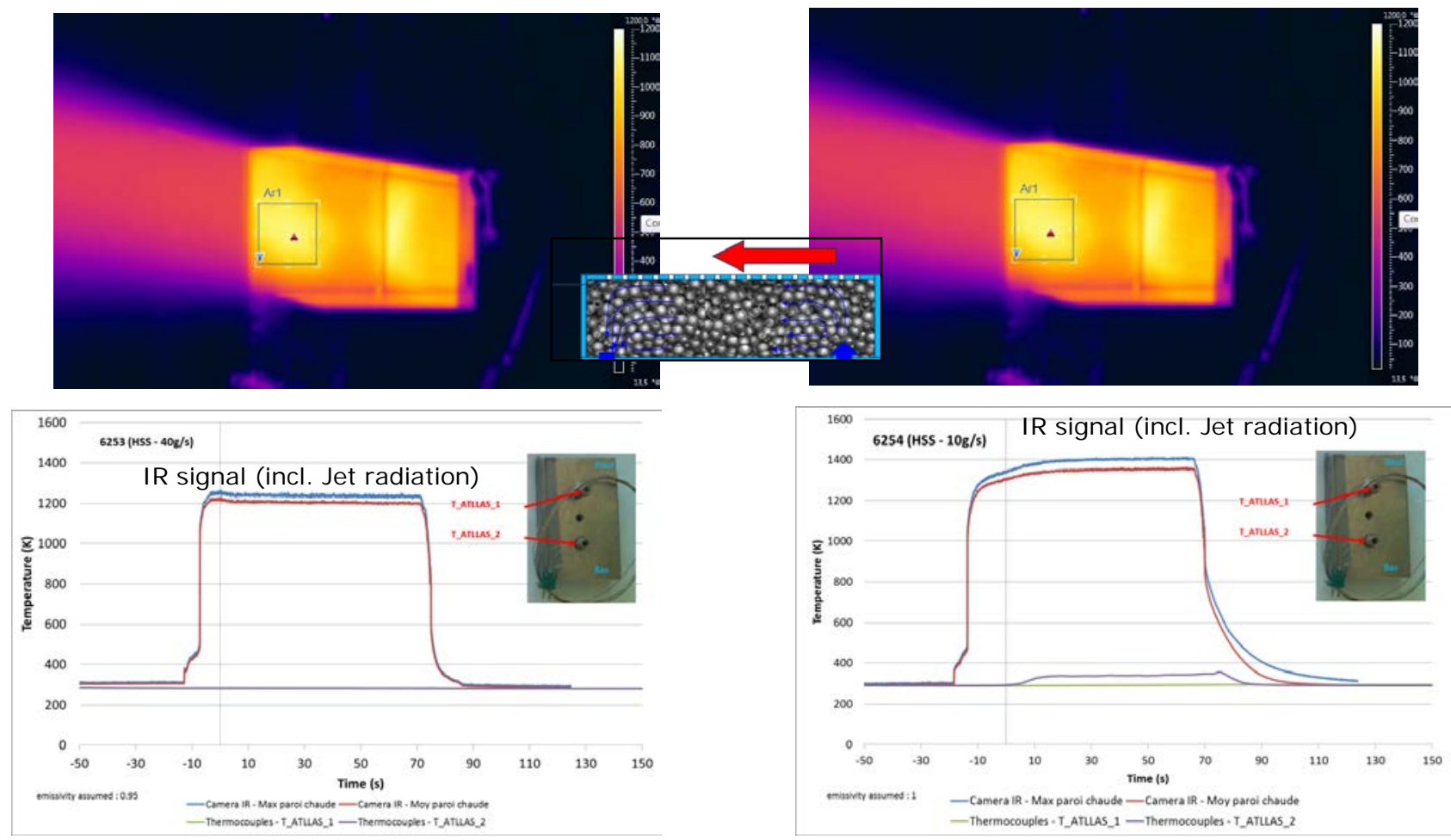

Figure 58 : hot testing of multifunctional generic HSS panel at Mach 6 with combustion

\section{IV.3 Injection struts technology}

This technological effort may be used for different applications, not only injection struts, in a future high-speed airliner (Figure 59). Based on different projects and published results, and on the test facilities capacities, a generic diamond shape injection strut was defined. Different technologies of cooling (convective, transpiration) and different materials (UHTC and CMC) were applied to manufacture these samples [57].

eading edges

rudder

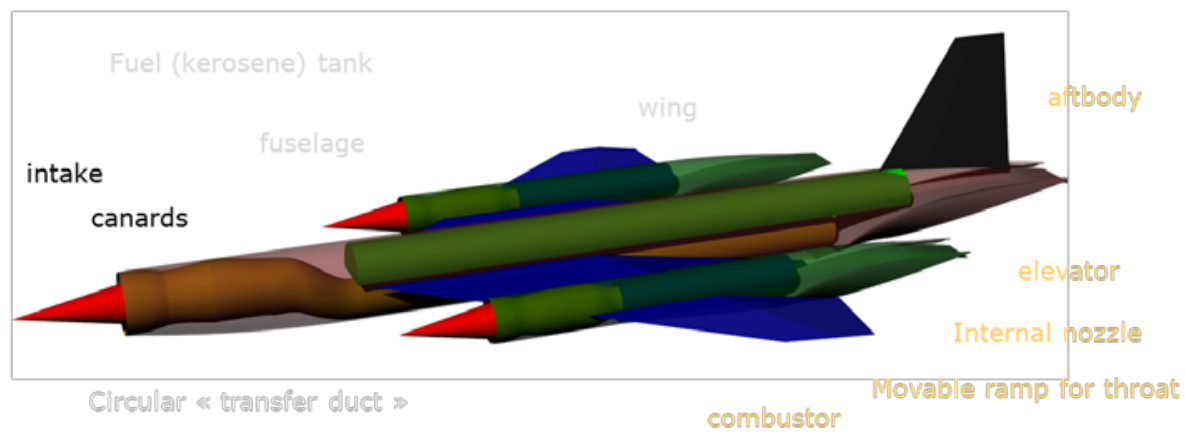

BL bleeds

- Extrernal diverter

Porous bleed

Internal bleed

Ali Pax caloin control

Flame Holder

Injectors

\section{Injection struts technology}

Figure 59: Synthesis view of CMC/UHTC fin technologies possible use of high-speed airliner 
This generic injector was defined to address the technology challenges on possible actual systems, without any combustion or injection optimization which was out of the scope of ATLLAS /I and would depend on each propulsion system. Based on this generic design, different technologies were considered which led to a modified injector shape in order to cope with actual possibilities. Two ways were investigated in ATLLAS // for such injectors: CMC (convective or transpiration cooled) and massive UHTC.

An important work was carried out on the manufacturing of the injector with UHTC. However, all attempts to manufacture a solely monolithic UHTC injector failed (Figure 60). ONERA and DLR redesigned a CMC-based injector with a blunt (R1) UHTC leading edge (Figure 61).
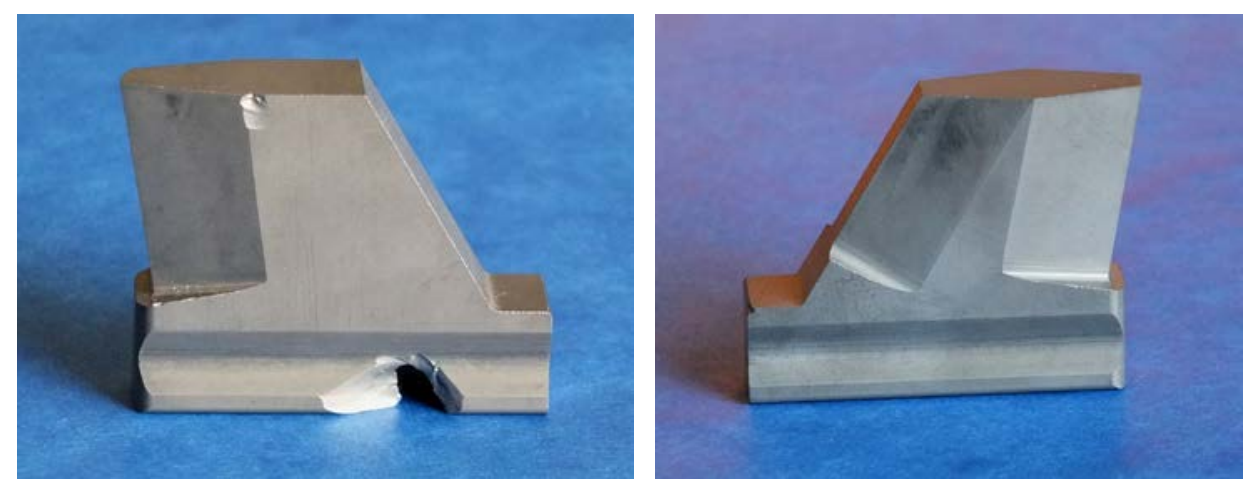

Figure 60: Examples of massive UHTC struts (at left, $\mathrm{HfB}_{2} / \mathrm{SiC} / \mathrm{Y}_{2} \mathrm{O}_{3}$ prototype broken during fuel tube drilling and at right $\mathrm{HfB}_{2} / \mathrm{SiC}$ sample stopped before the machining finalisation)
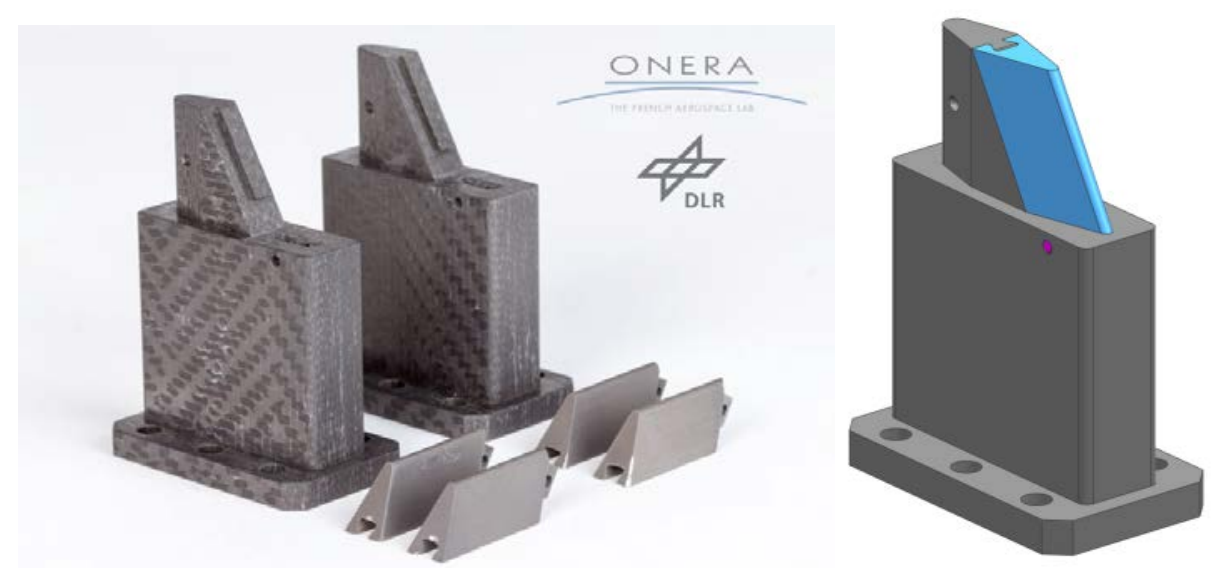

Figure 61: Final design: injectors with UHTC leading edge with $\mathrm{CMC}$ base before hot test

Subsequently, the hybrid UHTC-CMC design was transferred to pure CMC-based designs. In total, nine different types of CMC-based injectors were designed and manufactured by DLR; ONERA provided 4 UHTC leading edges for the hybrid components. The applied CMC material is C/C-SiC, manufactured in-house by DLR. The basic principle of CMC-based injectors was pre-qualified via pressurisation tests. Finally, the prototypes of nine different injector approaches were provided for testing, as depicted in Figure 62:
i. passive, blunt (R1) and sharp-edged CMC injectors (2x)
ii. passive, blunt (R1) and sharp-edged CMC injectors with increased oxidation resistance (2x)
iii. passive, blunt (R1) CMC injector with increased maturity level (1x)
iv. active transpiration-cooled, blunt (R1) CMC injectors (2x)
v. passive, blunt (R1) hybrid CMC-UHTC injectors (2x)

Whereas passive parts rely on internal convective fuel cooling only, active parts additionally include a transpiration cooled section at the leading edge being the most exposed region of the injector. For experimental testing, the CMC variants with increased oxidation resistance (2) had to be skipped due to geometrical mismatches after the coating process. Hence, only seven injectors were tested. 


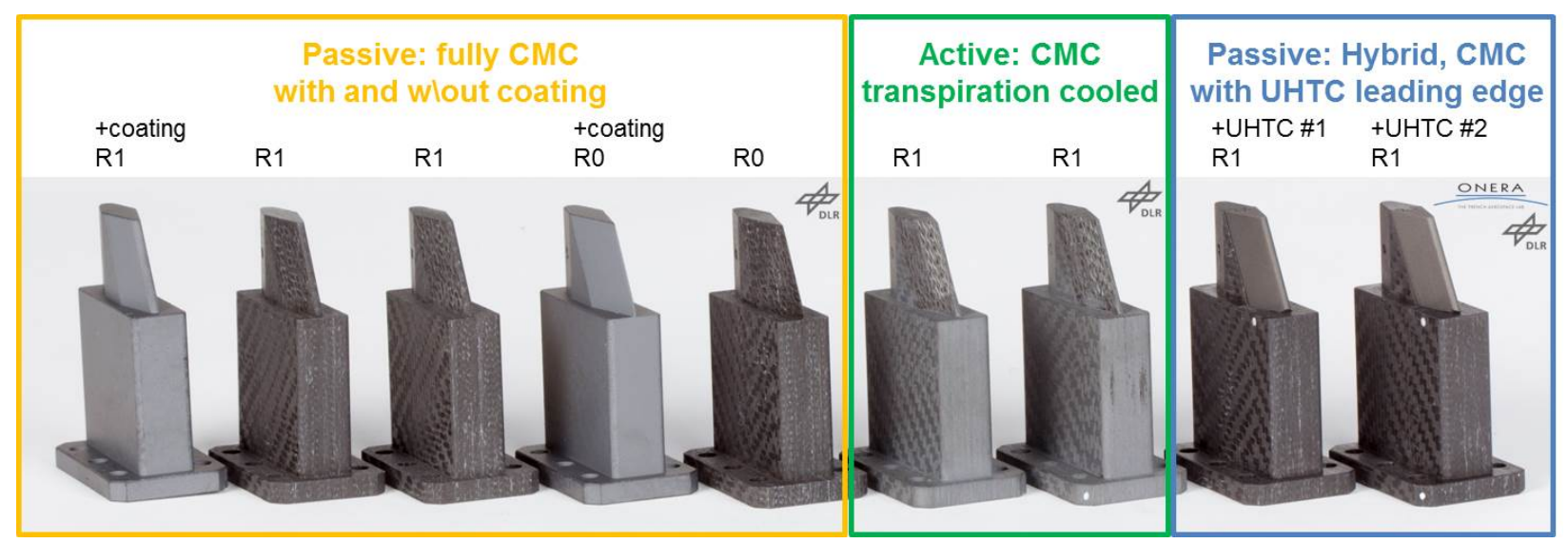

Figure 62: Generic ceramic injectors

A test campaign was performed in MBDA's dual-mode ramjet facility METHYLE which allowed for testing at operational relevant conditions. The performed tests simulated conditions of an equivalent ramjet/scramjet flight at Mach 6 for a long duration. The applied fuel consisted of a gaseous mixture of $20 \% \mathrm{H}_{2}$ and $80 \% \mathrm{CH}_{4}$ and was injected through the ceramic injectors with an equivalence ratio of 1.0. This corresponded to a mass flow of $12 \mathrm{~g} / \mathrm{s}$ for each strut injector. Figure 63 shows a photograph taken during the METHYLE test campaign. It shall be noticed that the incoming air has a recovery temperature of about $1600 \mathrm{~K}$, and that no cooling by radiation is possible: the dual-mode ramjet walls are water-cooled but covered with a thick thermal barrier coating, leading to nearly adiabatic wall temperatures.

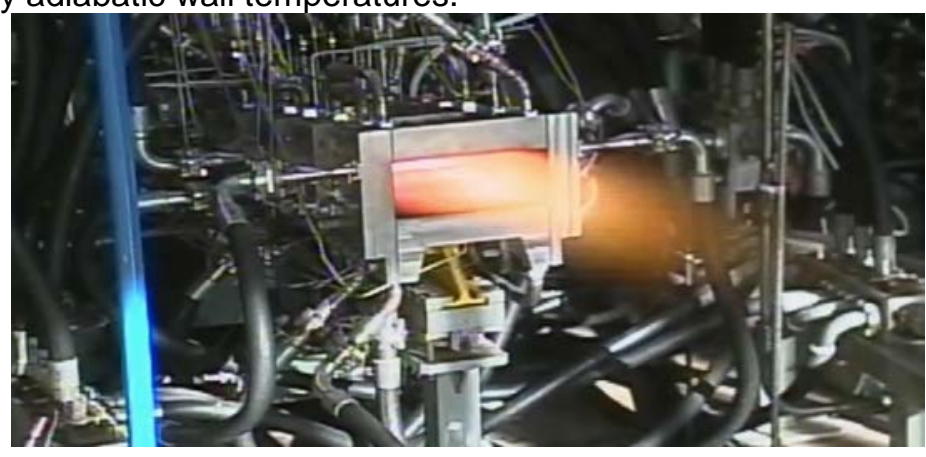

Figure 63: METHYLE test with project-built injectors

Within each of the experimental injector parts, thermocouples were integrated to get an indication of occurring temperatures (see Figure 64) for the different approaches. Thereby, steady-state conditions were reached for each of the injectors. Sharp-edged CMC injectors showed the highest temperatures with appr. $1500 \mathrm{~K}$. For the blunt CMC variants, temperatures were lowered by about $200 \mathrm{~K}$ compared to the sharp-edged case. Even lower temperature levels of appr. $800 \mathrm{~K}$ were achieved with the UHTC variants which can be explained by the tremendously increased thermal conductance of such materials. Transpiration cooling exhibited significantly lowered temperatures levels compared to all other configurations; however, a post-test simulation becomes necessary in order to directly compare the results. This cooling technology seems to be working very good indicating very high cooling efficiencies.

It can be stated that all tested injectors performed well and appeared undamaged after testing. A first visual post-analysis of the injectors was performed. Uncoated CMC injector showed local oxidation of carbon-fibres at the leading edge surface which was not detected for the transpiration-cooled CMC injector variants. The same findings could be stated for both UHTC variants; this material seems to be quite promising due to its extremely high oxidation resistance.

That means that the feasibility of all different injector types was successfully demonstrated for the applied testing conditions. This paved the way for future development efforts of ceramic airbreathing propulsion components like strut and wall injectors, flame-holders, inlets, combustors and bleeds.

At the end, the assessment of each different injector variant is depending on the envisaged application duration: uncoated materials proved to be suited for medium-termed applications in the minutes range, such as engine boosters for aerospace applications etc. More sophisticated approaches like transpiration-cooled or UHTC-based injectors are highly promising candidates for long-term applications. Hence, these solutions might be considered for future propulsion concepts of civil hypersonic cruisers. 


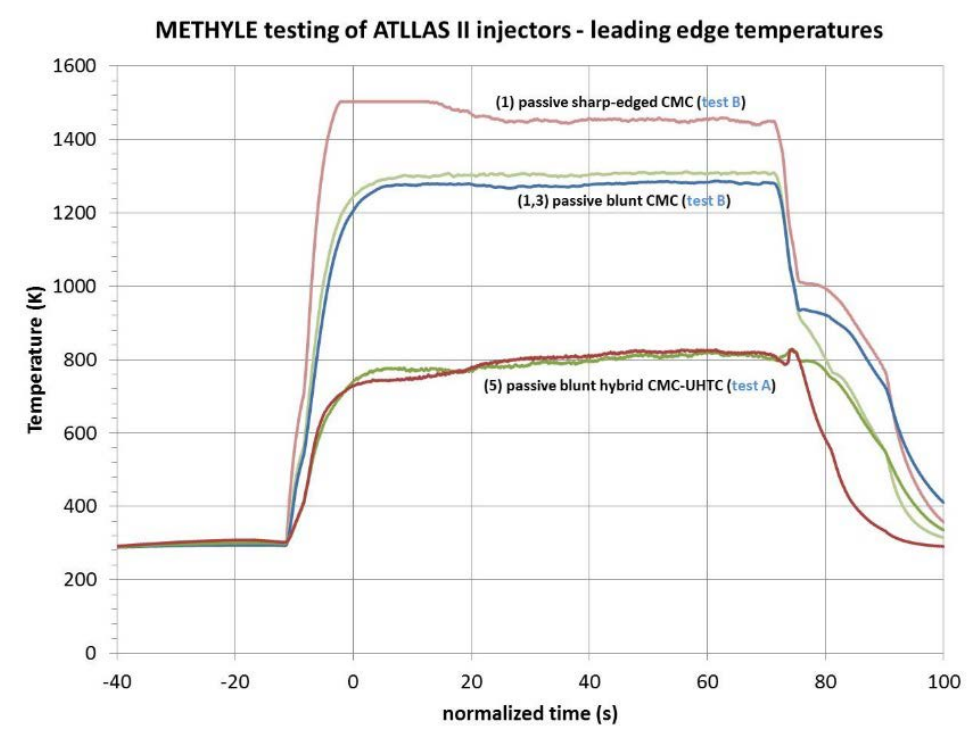

Figure 64: Measured injector leading edge temperatures during METHYLE tests

The following figure shows two post-test photographs of an active transpiration-cooled, blunt $\mathrm{CMC}$ injector (Figure $65 \mathrm{a}$ ) and a passive, blunt hybrid CMC-UHTC injector (Figure $65 \mathrm{~b}$ ).

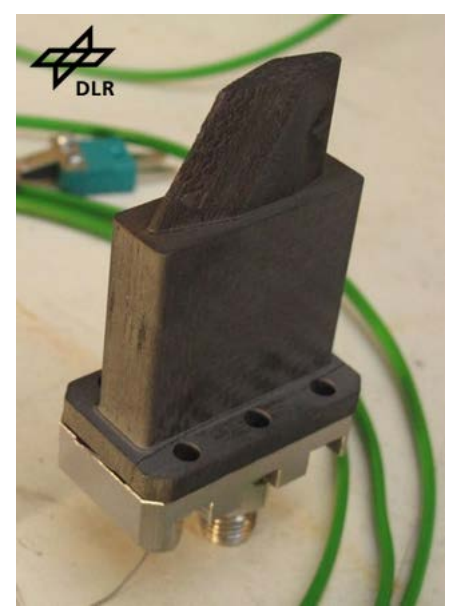

a) active transpiration-cooled CMC (R1)
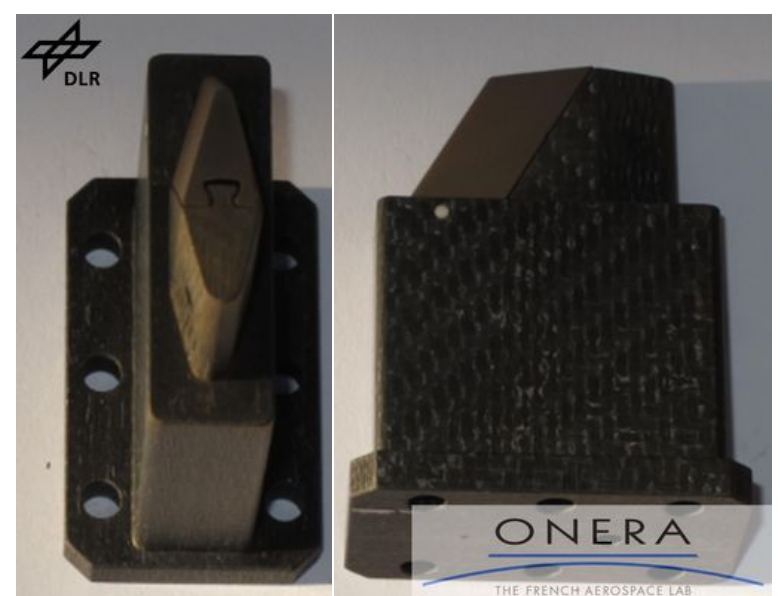

b) passive, blunt hybrid CMC with UHTC LE (R1)

Figure 65: post-test photographs of ceramic strut injectors

\section{IV.4 CMC characterization}

For high-speed aircraft, both the external and internal flowpath will be exposed to high-temperature and an oxidizing environment. Therefore, the use of CMC materials is possible and sometimes mandatory for the various components of a future high-speed airliner with cruise speed beyond Mach 4 (Figure 66). 


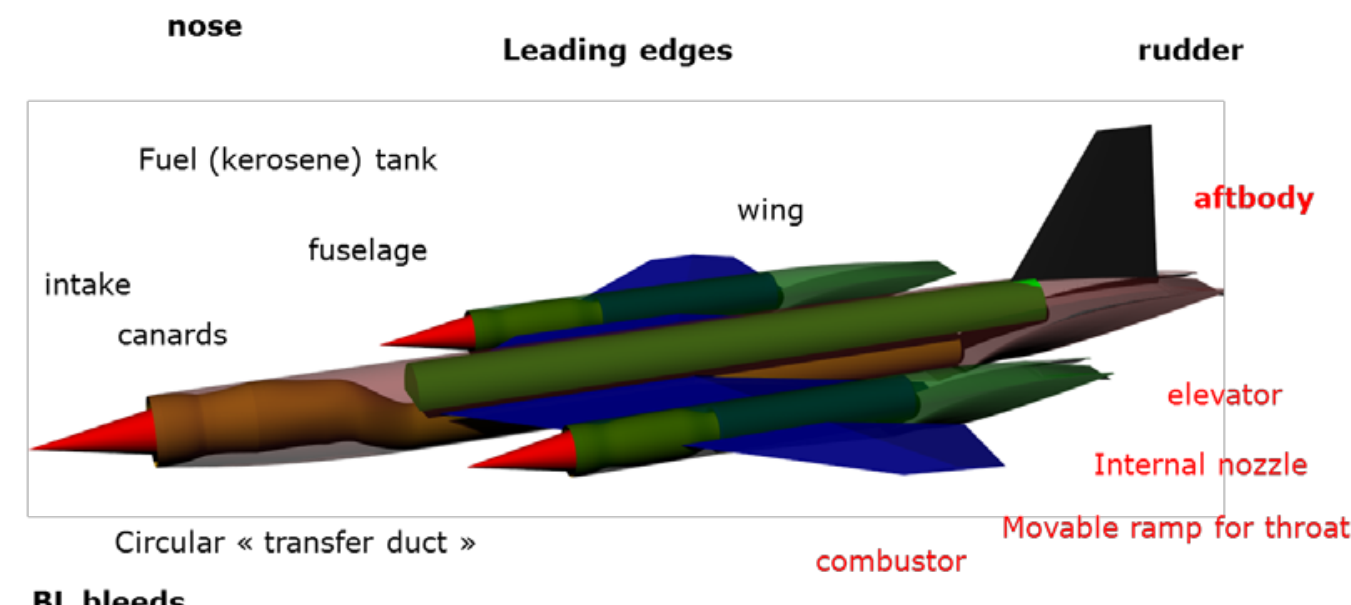

BL bleeds

-External diverter Flame Holder

-Porous bleed

-Internal bleed

-Air Pax cabin control

Injectors

CMC characterization

Figure 66: Synthesis view of possible CMC use on a high-speed airliner

Different activities were performed, leading to better understand CMC behaviour for high-speed oxidative environment (Figure 67):

- Erburig flat plates (AGI, DLR)

- Permeability in hot conditions (DLR)

- $\quad$ CMC uncooled panel in scramjet nozzle environment (DLR, MBDA)

- Injectors manufacturing (DLR).

Some of them were already described above, some others are presented here.
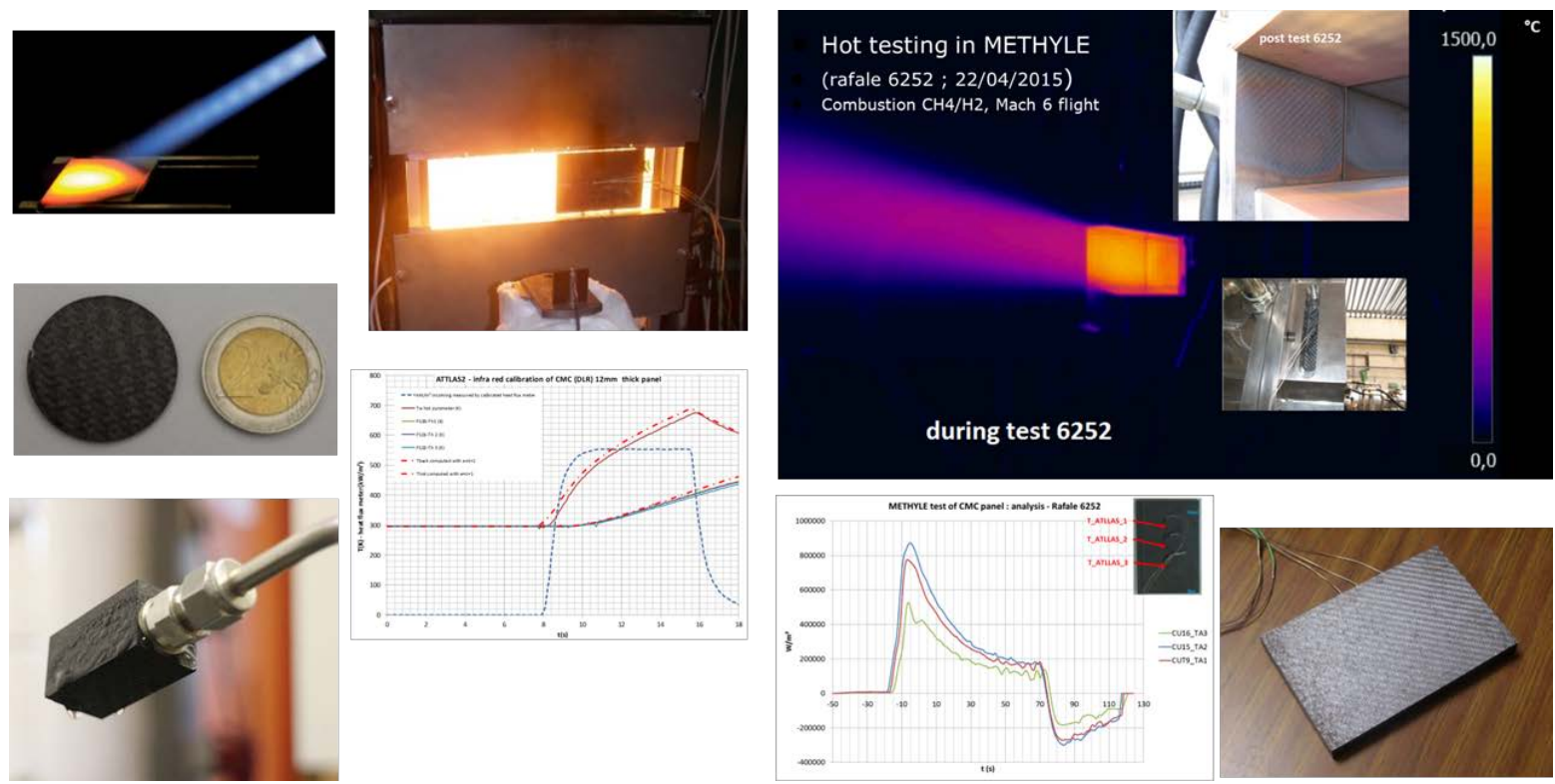

Figure 67: Overview of CMC activities in ATLLAS II

After developing the test plans and overall design of the CMC material samples, different CMC material samples were manufactured by DLR and Airbus and tested in ERBURIG-K (Figure 68). The testing was conducted in a temperature range from $1050-1700^{\circ} \mathrm{C}$ (Table 3). Post-test analysis of the tested flat $\mathrm{CMC}$ material samples was conducted by the manufacturer [58]. The experimental campaign was also used to benchmark multi-disciplinary numerical simulations of the ERBURIG tests considering chemistry, flow and conjugate heat transfer with radiation (Figure 69). 

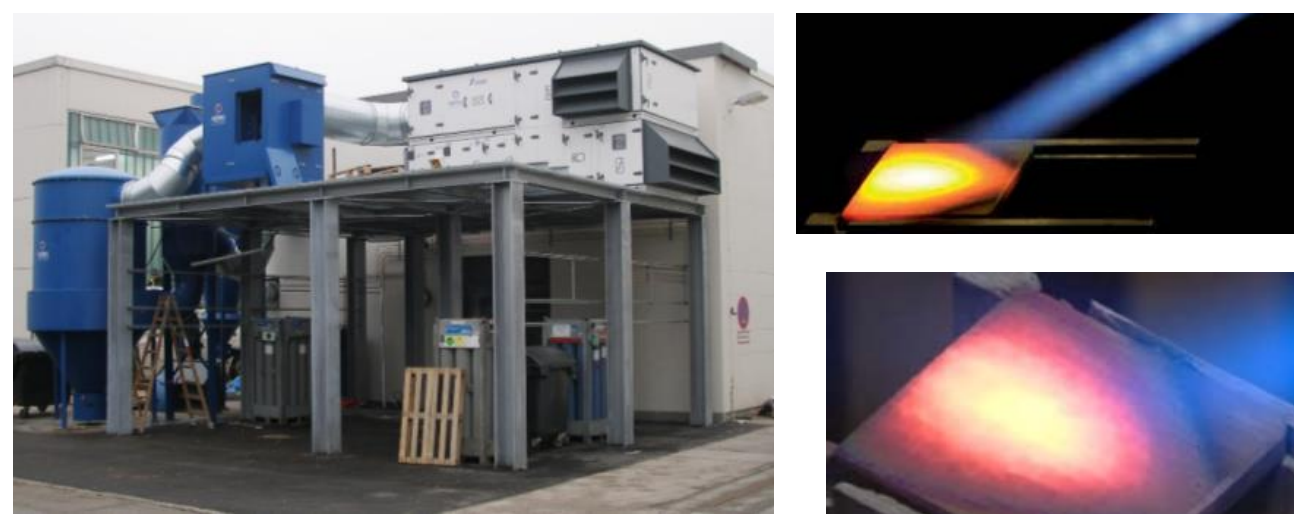

Figure 68 : flat sample testing at the ERBURIG ${ }^{\mathrm{K}}$ test facility

\begin{tabular}{|c|c|c|c|}
\hline System & Tradename & $\begin{array}{l}\text { Temperature }\left[{ }^{\circ} \mathrm{C}\right] \\
\text { | Time }[\mathrm{h}]\end{array}$ & $\begin{array}{l}\text { Amount } \\
\text { of Samples }\end{array}$ \\
\hline $\begin{array}{l}\text { C/C-SiC } \\
\text { W/o coating }\end{array}$ & --- & $\begin{array}{l}1500 / 1 \\
1700 / 1\end{array}$ & 2 \\
\hline $\begin{array}{l}\text { C/C-SiC } \\
\text { W/ CVD-SiC }\end{array}$ & --- & \begin{tabular}{|l}
$1500 / 4$ \\
$1700 / 1$
\end{tabular} & 2 \\
\hline SiC/SiCN (LaPO4) & |-- & \begin{tabular}{|l|}
$1300 / 4$ \\
$1500 / 4$ \\
$1700 / 1,5$
\end{tabular} & 3 \\
\hline $\operatorname{SiC} / \operatorname{SiCN}(P y C)$ & $\mid--$ & $\begin{array}{l}1300 / 4 \\
1500 / 4 \\
1700 / 4\end{array}$ & 3 \\
\hline $\begin{array}{l}\text { Ox./Ox. } \\
\text { (RBAO-SC) }\end{array}$ & WHIPOX & \begin{tabular}{|l|}
$1050 / 4$ \\
$1200 / 0,5$
\end{tabular} & 2 \\
\hline $\begin{array}{l}X x . / O x . \\
(R B A O-C F)\end{array}$ & WHIPOX & $\begin{array}{l}1050 / 4 \\
1200 / 0,5\end{array}$ & 2 \\
\hline Total & & \multicolumn{2}{|c|}{ 37,5 h (planned: 35h) } \\
\hline
\end{tabular}

Table 3: ERBURIGK ${ }^{\mathrm{K}}$ test plan for flat CMC material samples of DLR.
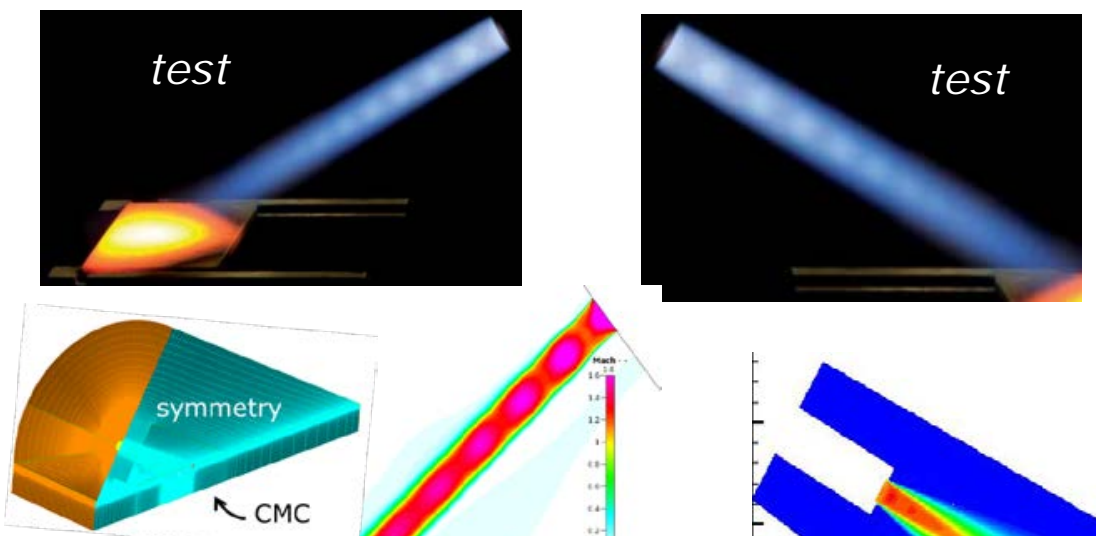

CFDACE (ESTEC)
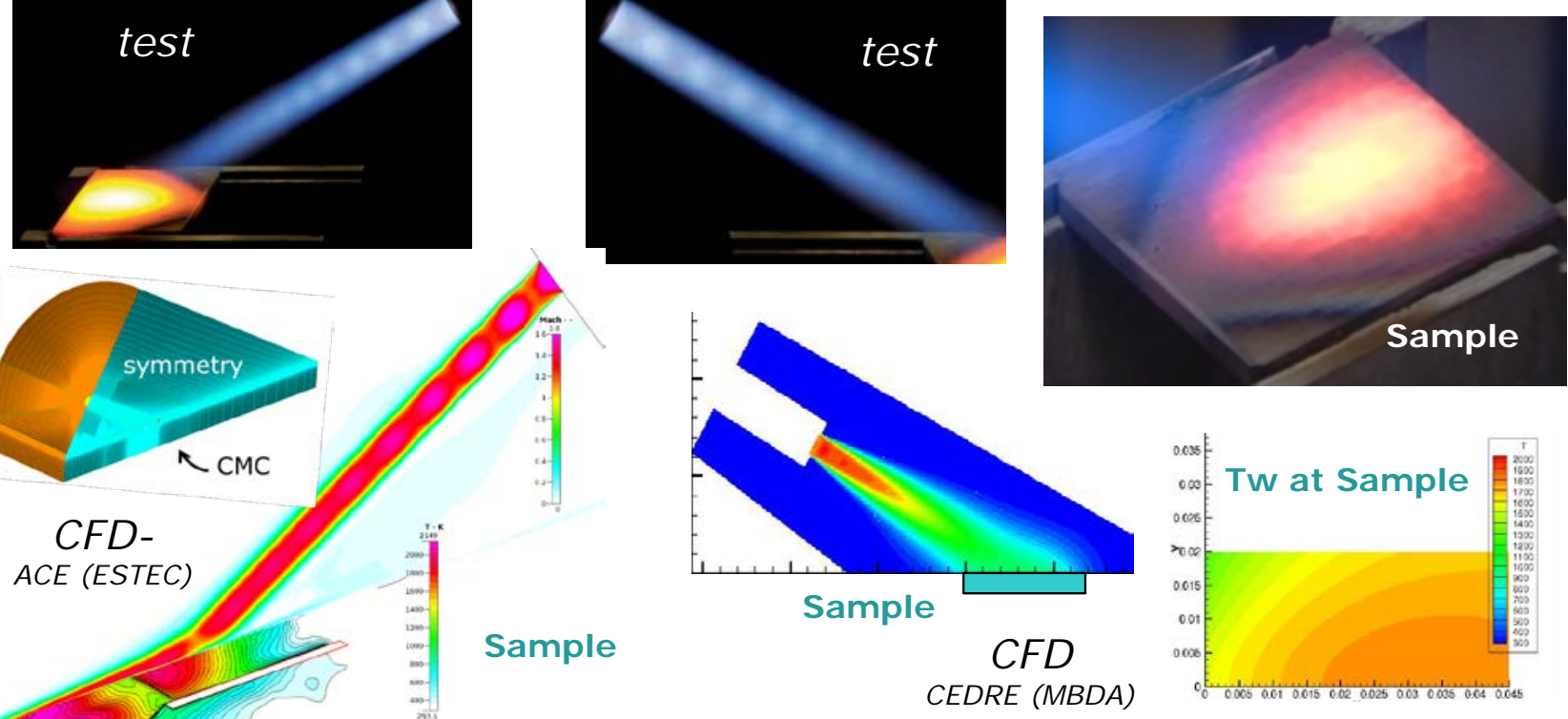

Figure 69 : Summary of 3D CFD simulations of the ERBURIG test 
The dependency of the permeability of porous materials on temperature and stress by performing various permeability tests was carried out on the DLR test bench P6.1. Approximately cylindrical test samples made of $\mathrm{C} / \mathrm{C}$ random $\left( \pm 15^{\circ}\right)$ and OXIPOL $3 x$ pyrolysed $\left(0 \mid 90^{\circ}\right)$ with two fibre designs (parallel and perpendicular penetration) have been used in the test campaign. Two approaches for the determination of the permeability parameters have been compared.

In comparison to the previously used ambient temperature permeability test set-up, the elevated temperature permeability test set-up used here additionally contains a test fluid heating system (Figure 70). This allows the derivation of the Darcy and Forcheimer permeabilities ( $\mathrm{Kd}$ and $\mathrm{Kf}$ ) for each sample from the "mass flow vs pressure drop" measurements (Figure 71).
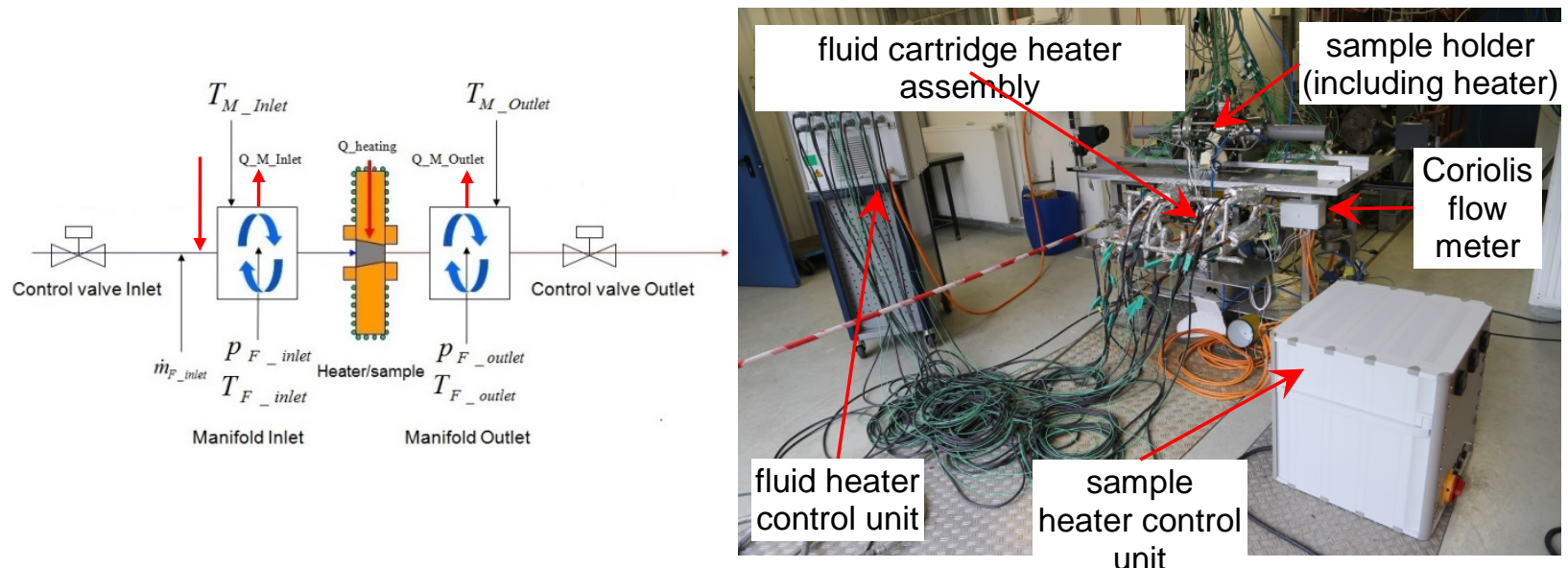

unit

Figure 70 : Flow scheme (left) and photograph (right) of the elevated temperature permeability measurement set-up.

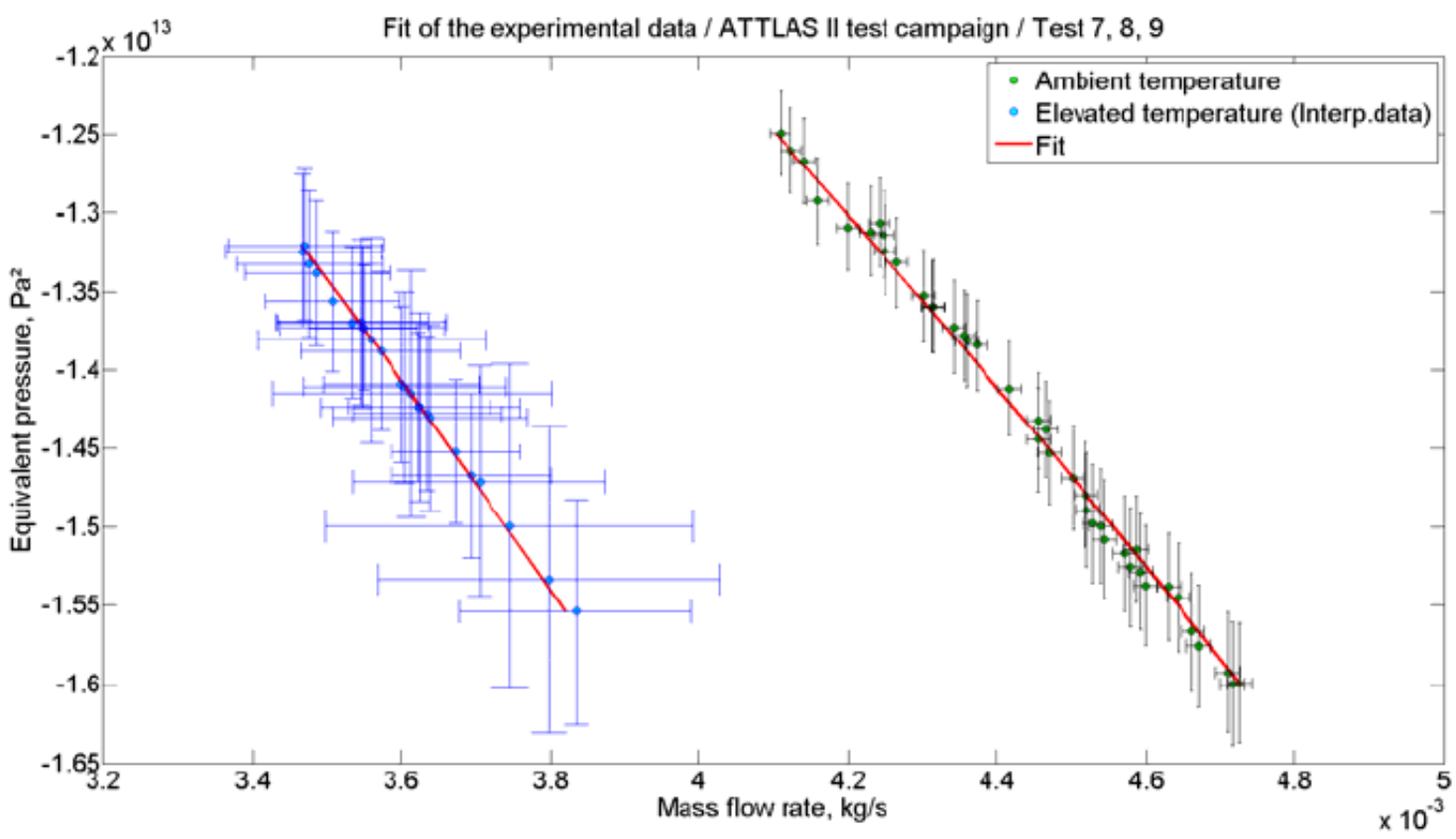

Figure 71 : Fit of the experimental data for the ATLLAS test sample $\mathrm{C} / \mathrm{C}$ random perpendicular at ambient temperature $(300 \mathrm{~K})$ and at "isothermal elevated" temperature $(360 \mathrm{~K})$

These results seem to show than the permeability decreases with (a rather small) temperature. The investigations imply that the permeability of a porous material is not only dependent on temperature but also on the stress [59][60]. Similarly, as with the HSS panel (see above), MBDA tested a DLR CMC panel under IR lamps and consecutively in the exit of the MBDA dual-mode ramjet, with stoichiometric combustion at Mach 6 flight conditions. The CMC panel did not have any coolant and was only radiative cooled through the flame (Figure 72). 


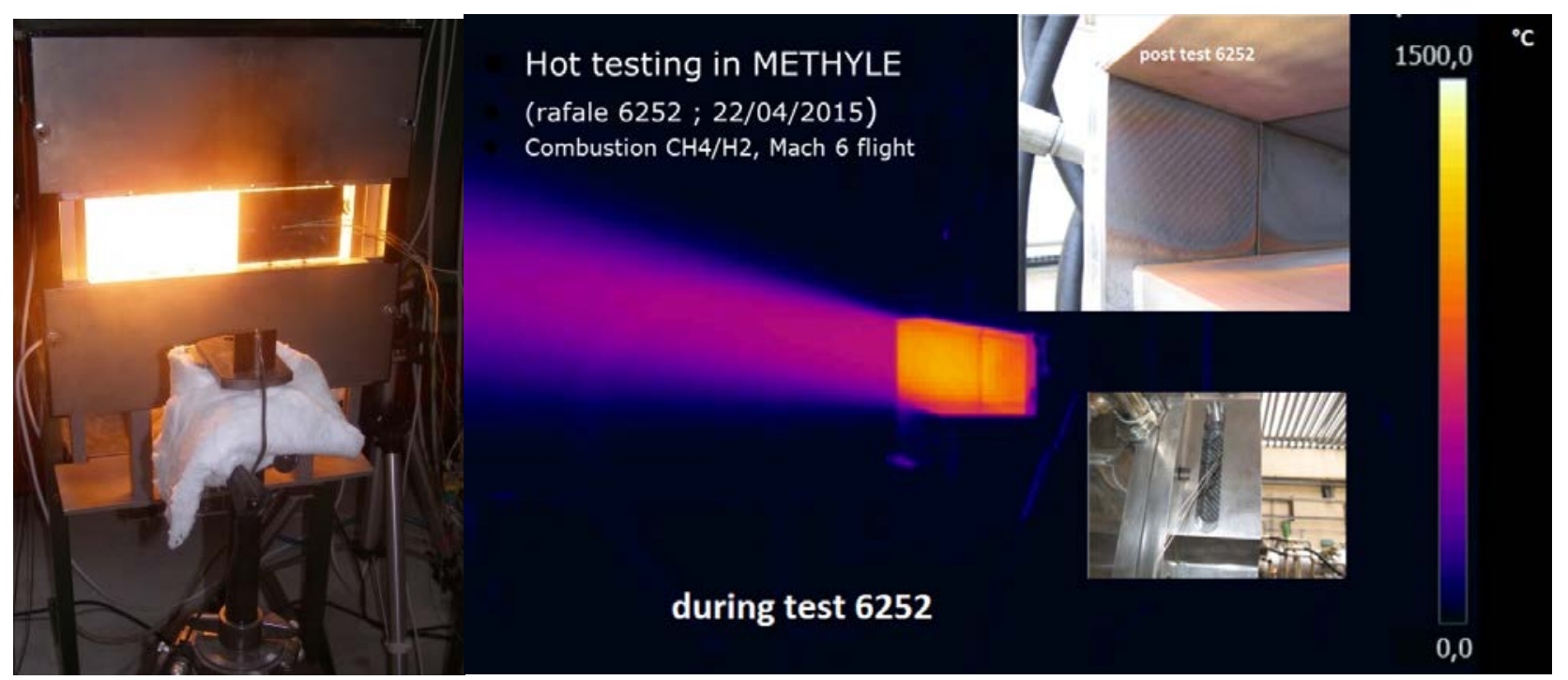

Figure 72: Hot testing of uncooled generic CMC panel with IR lamps (left) and at Mach 6 with combustion in METHYLE (right)

\section{IV.5 Discussion}

The design structures were tested with different levels of environment representability on one hand and instrumentation on the other hand. The test were prepared and analysed with design tools and with respect to possible use in high-speed combustion environment and integration.

This had led to an intensive design of generic components and relevant successful testing. Table 4 illustrates in a synthetic way the different systems and materials investigated.

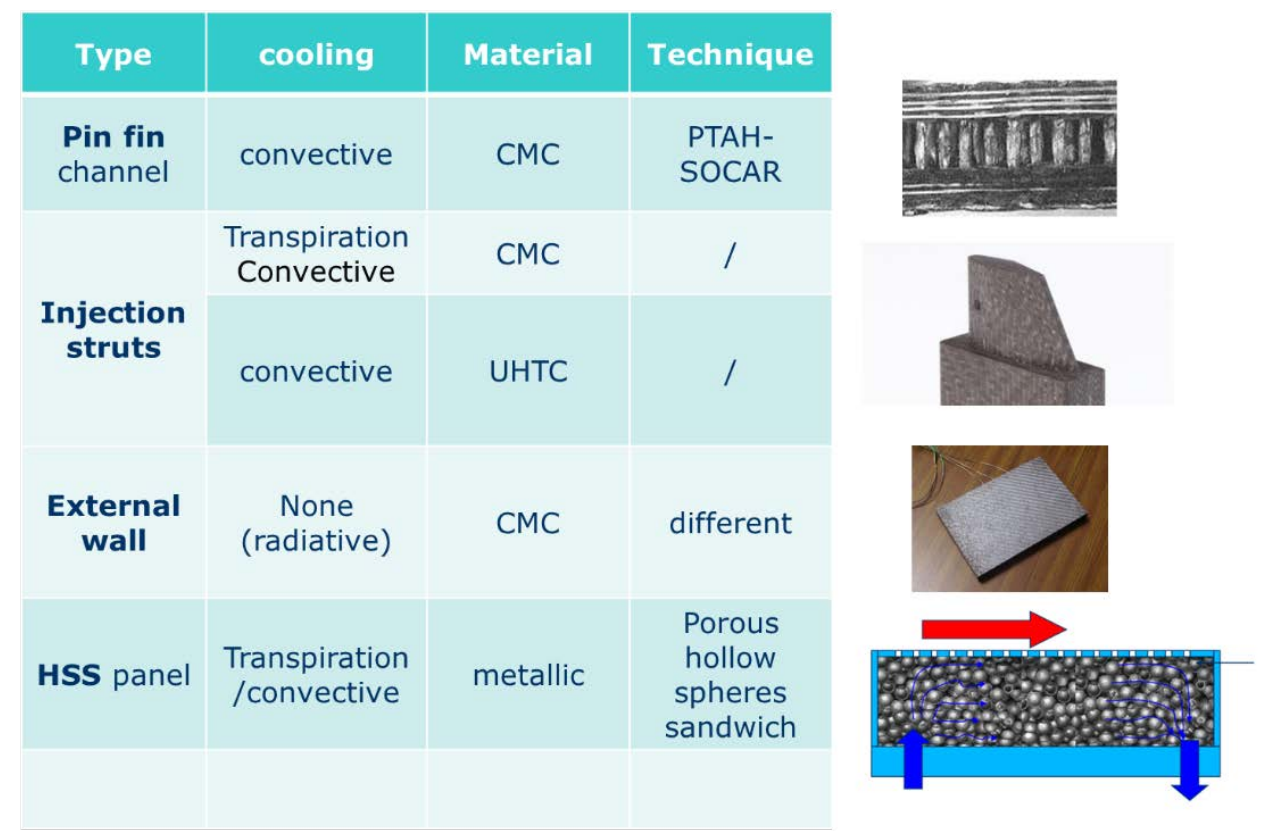

Table 4 : overview of material and structures successfully investigated 


\section{Aero-Thermal-Structural and High-Speed Transition Investigations for External Components}

The aero-thermal-structural design for a hypersonic vehicle is a very challenging task and depends on detailed knowledge of the loads (mechanical and thermal), which are significantly different from knowledge and observations coming from subsonic aircrafts. To address these aspects different experiments were setup during ATLLAS // using the experience from ATLLAS I, LAPCAT-I and LAPCAT-II [9][10]. In the High Enthalpy Shock Tunnel (HEG) at DLR Göttingen detailed SWBLI investigations addressing geometrical aspects as well as surface temperature effects on boundary layer transition were performed. High frequency instrumentation allowed analysing the intermittency behaviour from local heat flux data. The same approach was used for supersonic transition experiments at SITAEL with specific focus on roughness-induced transition for flat plates and cones. On the computational side, detailed Direct Numerical Simulation was applied by SOTON. These data were used for stability analysis methods by SOTON and FOI. Finally, improved RANS-modelling approaches have been developed by ESA-ESTEC for design analysis with respect to high-speed transition physics for pressure and heat loads on vehicle structures.

\section{V.1 Experimental Studies for Aero-Thermodynamics on Control Surfaces}

The experimental investigations on SWBLI using heated surfaces were performed in the High Enthalpy Shock Tunnel Göttingen (HEG) at DLR. Detailed CFD analysis was performed in advance at ESA-ESTEC to define the requirements for the test model as well as the operating conditions. The model specification followed several aspects, e.g. impact of boundary layer transition on SWBLI upstream of a flap at angle of attack considering surface temperature effects and the influence of open/closed gap [61]. Thereby high-frequency heat flux and pressure measurements were taken to obtain from the data analysis the intermittency distributions and turbulent spot production rates and to define the transition starting points and the transition lengths. The instrumented model is shown in Figure 73.

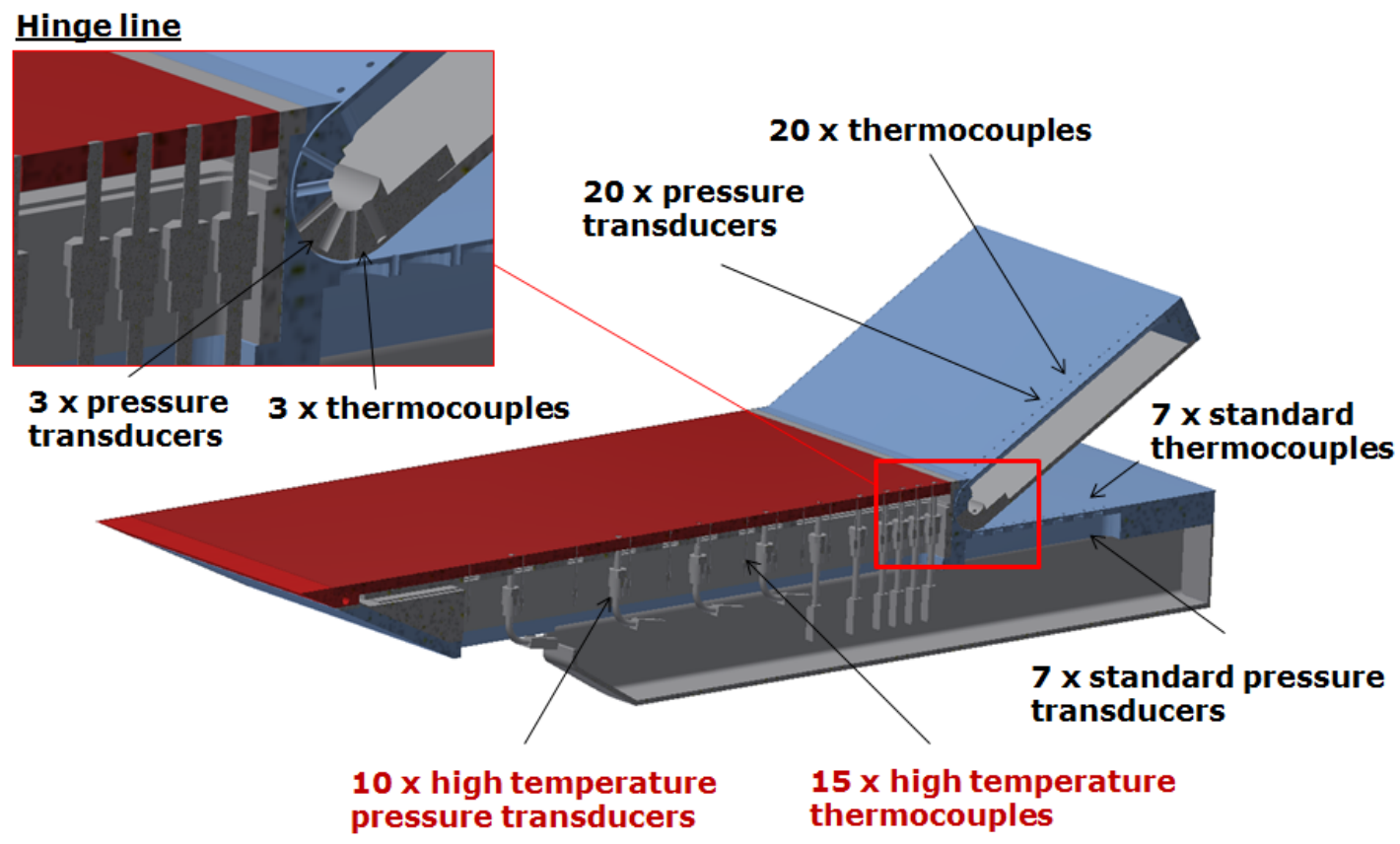

Figure 73: Instrumentation selected for SWBLI investigations in HEG

After several commissioning tests, the boundary layer intermittency behaviour was confirmed using the approach by Narasimha [62] based on the surface heat flux data for unheated and heated wall surface conditions on a flat plate (Figure 74). 


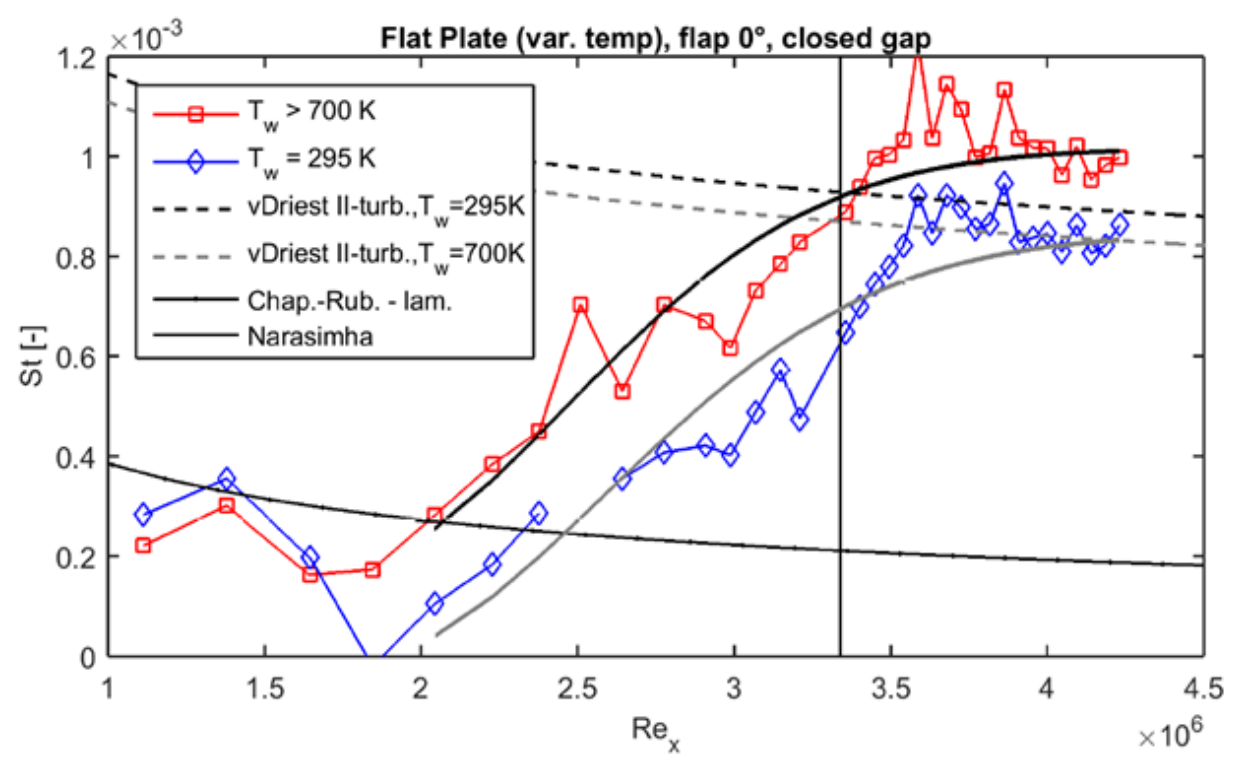

Figure 74: Intermittency according to Narasimha based on the measured heat flux distribution

The measured influence of surface wall temperature is well in line with the modelling by Narashima and slightly larger as the predictions by the well-known van Driest-correlation for a fully turbulent boundary layer. A detailed test matrix setting the different conditions according to the objectives and allowing possible intercomparisons was defined and all experiments performed accordingly. It has been shown, that the surface temperature has a significant effect on the investigated flow situations. The obtained database provides detailed information on this effect and design approaches for a hypersonic cruise vehicle should account for the surface temperature influences on the aero-thermodynamic behaviour on control surfaces.

\section{V.2 Experimental Studies of Roughness Effects on High-Speed Transition}

The effects of different roughness configurations was investigated in the Supersonic Transition Onset Experiments at SITAEL. Thereby the intermittency approach was used for data analysis as well. Table 5 provides the methodology used for the data analysis.

\begin{tabular}{|l|l|}
\hline Intermittency (q= heat flux) & $\gamma=\frac{q_{\text {meas }}-q_{\text {lam }}}{q_{\text {turb }}-q_{\text {lam }}}$ \\
\hline Spot production rate and transition starting point & $\gamma(x)=1-\exp \left[-\hat{n} \sigma\left(\operatorname{Re}_{x}-\operatorname{Re}_{x t}\right)^{2}\right]$ valid for $x \geq x_{t}$ \\
\hline Turbulence level & $1^{\text {st }}$ method) $\quad \operatorname{Re}_{\theta t}=420 \cdot T u^{-0.69}$ \\
& $2^{\text {nd }}$ method) $\quad \hat{n} \sigma=1.5 \cdot 10^{-11} \cdot T u^{7 / 4}$ \\
\hline Compressible-to-incompressible equation set & \multicolumn{1}{|c|}{$\operatorname{Re}_{\theta, \text { inc }}=0.664 \cdot \sqrt{\operatorname{Re}_{x t}}$} \\
& $\operatorname{Re}_{\theta, M}=\sqrt{1+0.38 M^{0.6}} \cdot \operatorname{Re}_{\theta, \text { inc }}$ \\
& $\hat{n} \sigma_{M}=\hat{n} \sigma_{\text {inc }} \cdot\left[1+0.58 M^{0.6}\right]^{-2}$ \\
\hline
\end{tabular}

Table 5: Equation set used during the post-process

For these studies a new Mach 6 nozzle has been manufactured and qualified in detail verifying, that the flow uniformity is excellent and close to the expected values from the design phase. A high frequency thin film heat transfer gauges system was developed and manufactured at SITAEL. The system was used very successfully to investigate the effects of several roughness configurations on hypersonic laminar-turbulent transition behaviour for flat plates and cones related to different structural parts for a hypersonic vehicle (see Figure 75). The tests provide a dedicated database and the associated analysis using intermittency modelling. 


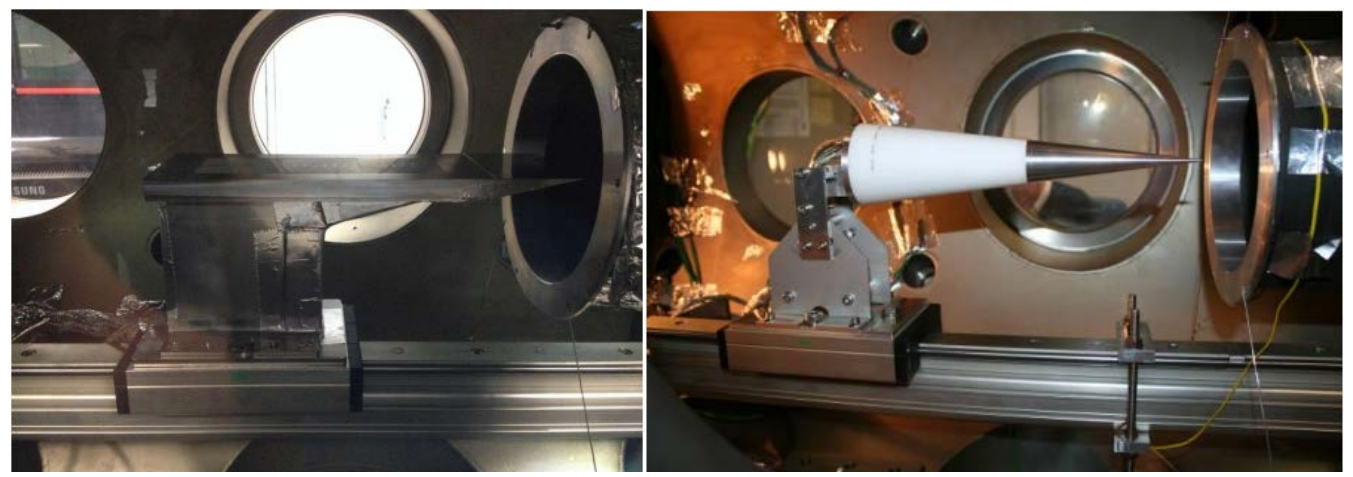

Figure 75: Plate and cone test articles installed in Mach 6 nozzle facility

At the end of the experimental test campaigns, post-processing of the data was performed. In particular, estimations of the intermittency distributions $(\gamma)$, spot production rates $(n \sigma)$ and turbulence level $(T u)$ were carried out and used to calculate the transition starting points $\left(x_{t}\right)$ and the transition lengths, both for the flat plate and the cone. An overview is given in Table 6.

\begin{tabular}{|c|c|c|c|c|c|c|c|c|c|c|c|c|}
\hline Test Article & \begin{tabular}{|c|} 
Leading \\
Edge Radius
\end{tabular} & $\begin{array}{c}\text { Total } \\
\text { Pressure }\end{array}$ & Twall & Unit Re & $\begin{array}{c}\text { Roughness } \\
\text { height }\end{array}$ & $x_{t}$ & no & $n \sigma_{\text {inc }}$ & $\operatorname{Re}_{M}$ & $\operatorname{Re} \theta_{\text {inc }}$ & $\begin{array}{c}\text { Tu1 } \\
\text { (Re-inc) }\end{array}$ & $\begin{array}{l}\text { Tu2 } \\
\text { (no) }\end{array}$ \\
\hline$[-]$ & [mm] & [bar] & [K] & {$\left[\mathrm{m}^{-1}\right]$} & [mm] & {$[\mathrm{m}]$} & {$[-]$} & {$[-]$} & {$[-]$} & {$[-]$} & [\%] & [\%] \\
\hline Flat Plate & 0 & 11.80 & 330 & $2.64 \mathrm{E}+07$ & 0 & 0.184 & $1.30 \mathrm{E}-13$ & $9.29 \mathrm{E}-13$ & $1.46 \mathrm{E}+03$ & $1.01 \mathrm{E}+03$ & 0.28 & 0.20 \\
\hline Cone & 0 & 5.24 & 293 & $1.35 \mathrm{E}+07$ & 0 & 0.2037 & $1.40 \mathrm{E}-13$ & $9.30 \mathrm{E}-13$ & $1.10 \mathrm{E}+03$ & $1.03 E+03$ & 0.27 & 0.20 \\
\hline Cone & 0 & 7.58 & 293 & $1.93 E+07$ & 0 & 0.1663 & $1.80 \mathrm{E}-13$ & $1.20 \mathrm{E}-12$ & $1.19 \mathrm{E}+03$ & $7.72 \mathrm{E}+02$ & 0.41 & 0.24 \\
\hline Cone & 0 & 9.76 & 294 & $2.51 \mathrm{E}+07$ & 0 & 0.14 & $2.70 \mathrm{E}-13$ & $1.79 \mathrm{E}-12$ & $1.24 E+03$ & $8.35 E+02$ & 0.37 & 0.30 \\
\hline Cone & 0 & 11.85 & 293 & $3.06 \mathrm{E}+07$ & 0 & 0.1325 & $6.70 \mathrm{E}-13$ & 4.45E-12 & $1.34 \mathrm{E}+03$ & $8.73 E+02$ & 0.35 & 0.50 \\
\hline Cone & 1 & 9.78 & 293 & $2.52 \mathrm{E}+07$ & 0 & 0.21 & $3.05 \mathrm{E}-13$ & $2.03 \mathrm{E}-12$ & $1.53 E+03$ & $9.37 E+02$ & 0.31 & 0.32 \\
\hline Cone & 1 & 11.91 & 293 & $3.06 \mathrm{E}+07$ & 0 & 0.205 & $4.35 \mathrm{E}-13$ & $2.89 \mathrm{E}-12$ & $1.66 \mathrm{E}+03$ & $1.07 E+03$ & 0.26 & 0.39 \\
\hline Flat Plate & 0 & 7.22 & 332 & $1.62 E+07$ & 1 & 0.168 & $7.05 \mathrm{E}-13$ & $5.04 \mathrm{E}-12$ & 1.09E +03 & $7.56 \mathrm{E}+02$ & 0.43 & 0.54 \\
\hline Flat Plate & 0 & 9.56 & 330 & $2.14 \mathrm{E}+07$ & 1 & 0.132 & $5.50 \mathrm{E}-13$ & $3.93 \mathrm{E}-12$ & $1.12 \mathrm{E}+03$ & $7.71 \mathrm{E}+02$ & 0.41 & 0.47 \\
\hline Flat Plate & 0 & 11.47 & 329 & $2.55 \mathrm{E}+07$ & 1 & 0.119 & $1.95 \mathrm{E}-13$ & $1.39 \mathrm{E}-12$ & $1.16 \mathrm{E}+03$ & $8.00 \mathrm{E}+02$ & 0.39 & 0.26 \\
\hline Flat Plate & 0 & 7.28 & 325 & $1.63 \mathrm{E}+07$ & 1.5 & 0.202 & $3.35 \mathrm{E}-13$ & $2.40 \mathrm{E}-12$ & $1.21 \mathrm{E}+03$ & $8.32 \mathrm{E}+02$ & 0.37 & 0.35 \\
\hline Cone & 0 & 5.31 & 293 & $1.36 \mathrm{E}+07$ & 0.5 & 0.2025 & 4.50E-12 & $2.99 \mathrm{E}-11$ & $1.10 E+03$ & $8.45 E+02$ & 0.36 & 1.48 \\
\hline Cone & 0 & 7.55 & 293 & $1.93 E+07$ & 0.5 & 0.1688 & $1.22 \mathrm{E}-11$ & $8.11 \mathrm{E}-11$ & $1.20 \mathrm{E}+03$ & $7.74 E+02$ & 0.41 & 2.62 \\
\hline Cone & 0 & 9.78 & 293 & $2.52 E+07$ & 0.5 & 0.145 & $3.33 \mathrm{E}-12$ & $2.21 \mathrm{E}-11$ & $1.27 E+03$ & $8.41 E+02$ & 0.37 & 1.25 \\
\hline
\end{tabular}

Table 6: Summary of the intermittency analysis results

\section{V.3 Numerical Investigations on High-Speed Transition}

Based on the developed methods and applications evaluated within ATLLAS-I by SOTON [63][64][65][66][67], additional aspects were investigated by Direct Numerical Simulations in close relation to the above experiments. Thereby the mechanisms involved in the receptivity and linear growth of disturbances in a Mach 6.0 boundary-layer in the presence of individual roughness elements have been analysed in a parametric study including the effect of roughness height, disturbance type, position with respect to the boundary layer, wall temperature and roughness shape.

The sharp-edged roughness induces a pair of counter-rotating streamwise vortices, which lead to the formation of a low velocity streak through the lift-up of low momentum fluid from the wall. The roughness wake is shows regions of highly detached shear, which are receptive and develop instability modes for a broad frequency range. The chosen computational domain for these studies is shown in Figure 76.

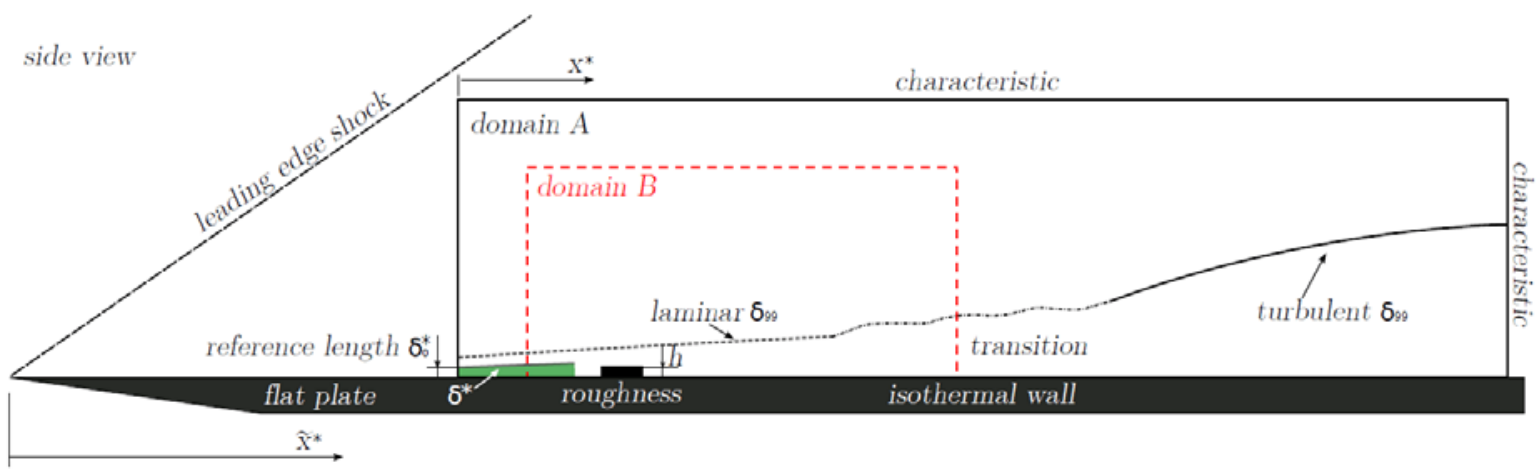

Figure 76: Numerical domain for DNS studies 
With these full-domain simulations, the whole transition process can be investigated. While a sharp-edged roughness element showed significant effects on disturbance growth rates, a smooth bump of similar height and frontal area has been found to have little effect. In accordance to the above experimental studies, it was determined, that there is a considerable difference between the "ramp-cases" (upward or downward see Figure 77). An upward ramp does not generate a more unstable wake than the similar roughness element without ramp. A downward ramp at the aft section of the roughness element damps strongly the wake modes and the generated wake is much less unstable. This is illustrated with the different growth rates for disturbance energy shown in Figure 78. These results are especially important as both configurations have the same values of Reynolds number based on height or frontal area, such that current empirical models based on these parameters would predict the same effect on transition.
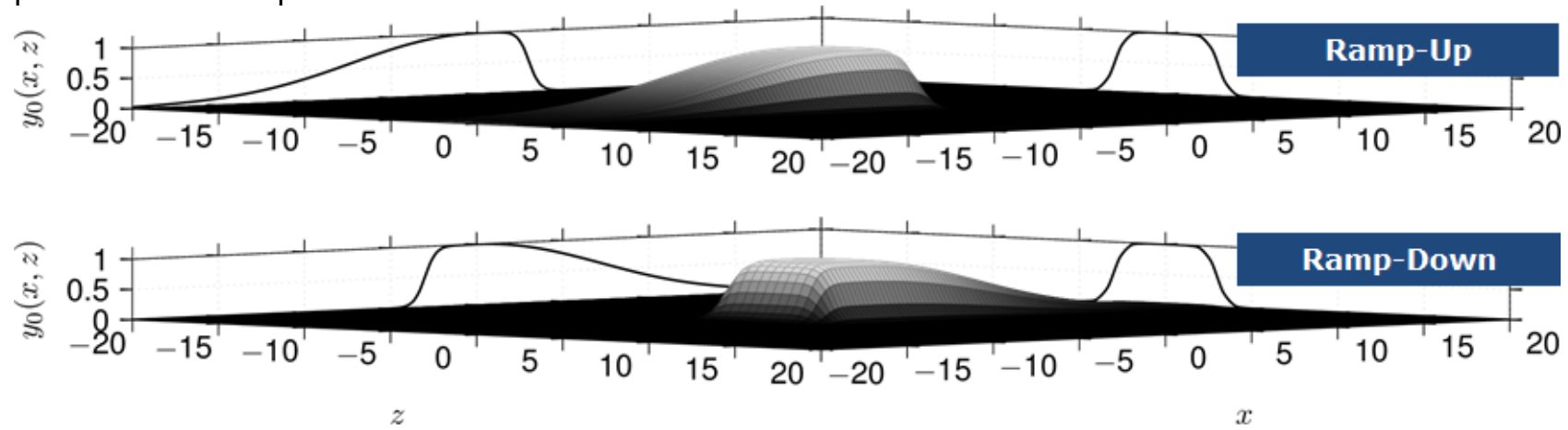

Figure 77: Ramp-Up and Ramp-Down configurations investigated

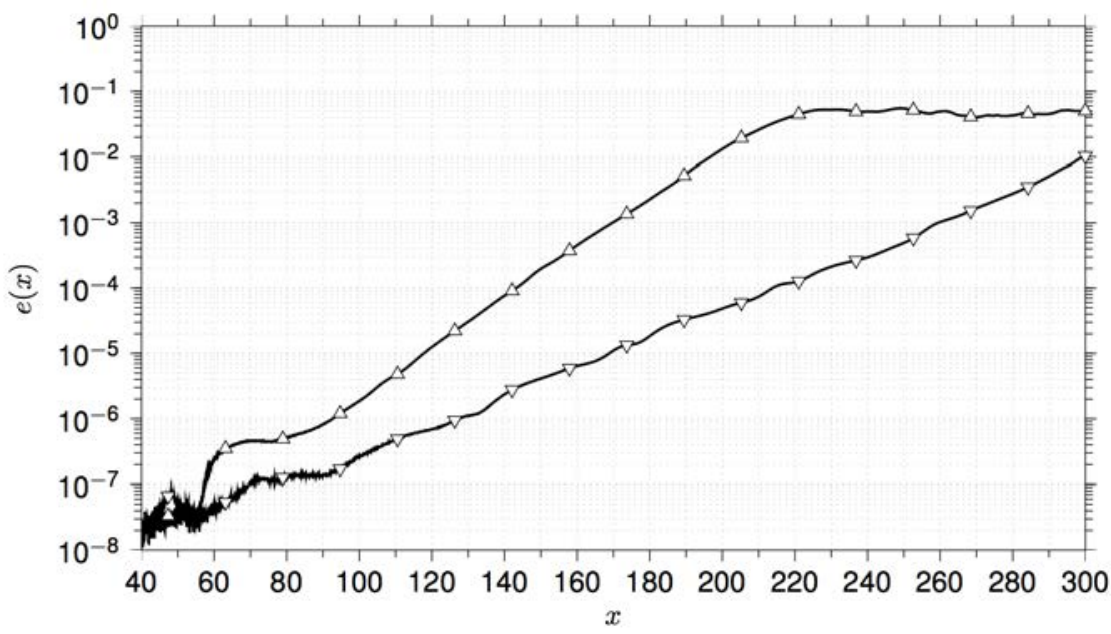

Figure 78: Growth of disturbance energy behind the ramp-up (triangle) and ramp-down (inverted triangle) roughness elements

Transition criteria for the flat plate and the cone were determined and compared with available criteria and the results obtained during ATLLAS I. Observed specific effects are very well in line with the detailed DNS-analysis of SOTON. The associated bi-local linear stability analysis showed the main characteristics regarding instability modes from DNS-data. Detected shortcomings at high Mach numbers were identified and possible improvements using e.g. PSE-3D methods analysed to guide further developments in this area.

The comprehensive experimental databases achieved in ATLLAS // at DLR and SITAEL with the associated intermittency based data analysis and reduction provided in combination with these detailed numerical simulations and physical understanding a new excellent base for the development and validation of engineering models applicable to general design aspects [69]. Furthermore, an intermittency based approach was followed by ESA-ESTEC for improved transition modelling in the TAU-code developed at DLR. Thereby, a decoupled approach between turbulence and transition modelling was decided, to allow considering various physical phenomena (e.g. compressibility, surface temperature, pressure gradients) by specific engineering correlations. These can be easily adopted without affecting the implementations of the available turbulence models. The developed overall model was successfully validated using well-defined literature test cases (see Figure 79). This approach and the achieved generic modelling are unique at present, especially for the aspects concerning supersonic-hypersonic flows [70]. 

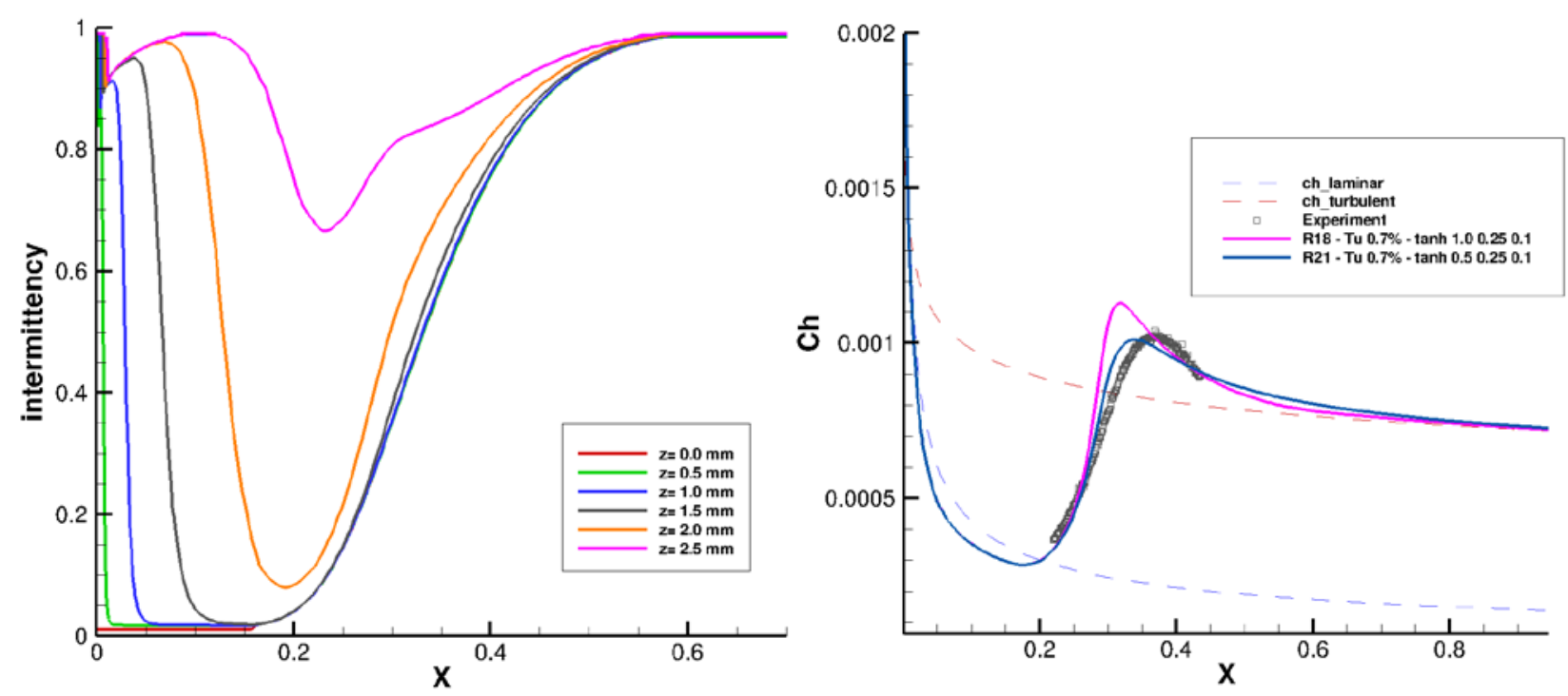

Figure 79: Example of results for the RWG Hypersonic case: intermittency evolution over the plate (left) and surface Stanton number (right)

\section{V.4 Shock Wave Boundary Layer and Fluid-Structure Interactions}

The experiments for the investigations on unsteady fluid-structure-interaction were undertaken in the trisonic test section (TMK) at DLR in Cologne (see Figure 80). The impact of dynamic loads on relatively thin metallic structures were analysed with high-speed schlieren and high-frequency pressure measurements. The structural response was measured with different deformation sensors (optical and capacitive) and strain gauges. The shocks of different strength were generated using a movable wedge structure above the test panels.

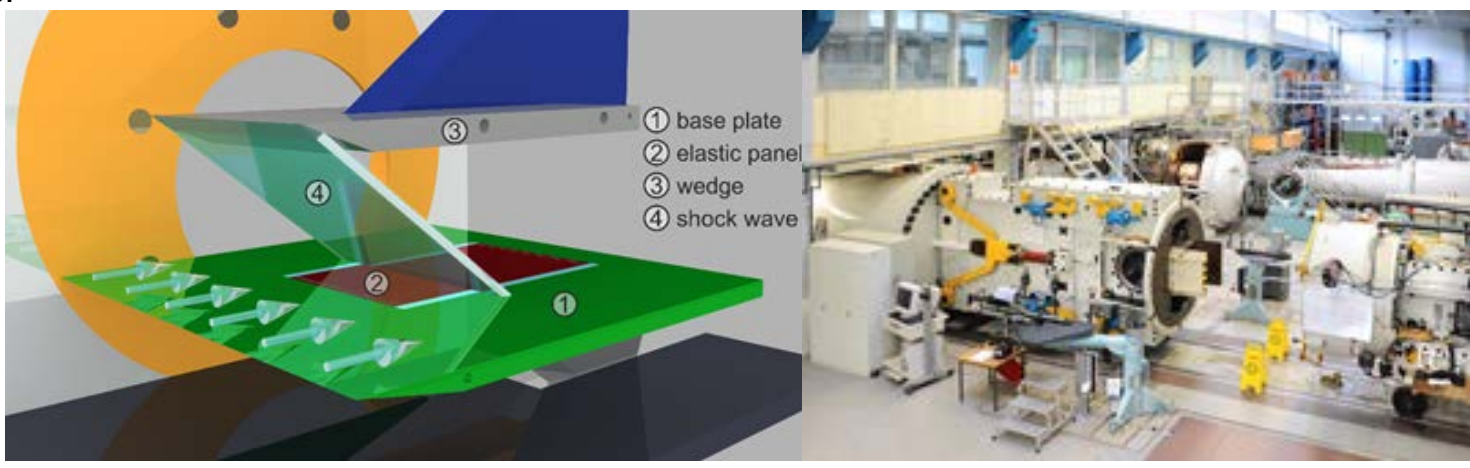

Figure 80: Sketch of model for shock induced FSI (left) used in TMK at DLR Cologne (right)

First, a SWBLI investigation on a rigid panel with static and dynamic pressure sensors was performed yielding detailed static pressure distributions for Mach numbers of 2.5, 3.0, 3.5 and 4.0. The frequency behaviour of the static pressures was investigated using dynamic pressure sensors.

Second, a combination of the SWBLI with fluid-structure interaction was set-up using an elastic panel. Therefore, CFD simulations were performed using a static aero-elastic coupling modal analysis based on a finite element (3D ANSYS FE) model built at DLR and applied at FOI. This structural finite element model was coupled to a CFD analysis using the CFD code "Edge" [29] at FOI.

Finally, additional excitation was imposed on the elastic panel using oscillating magnetic fields applied from underneath the panel. Figure 81 shows the elastic panel with the installed sensor configurations used for displacement measurements by laser sensors in the experiments without excitation (left) and the sensor configuration for the experiments with excitation (right). 


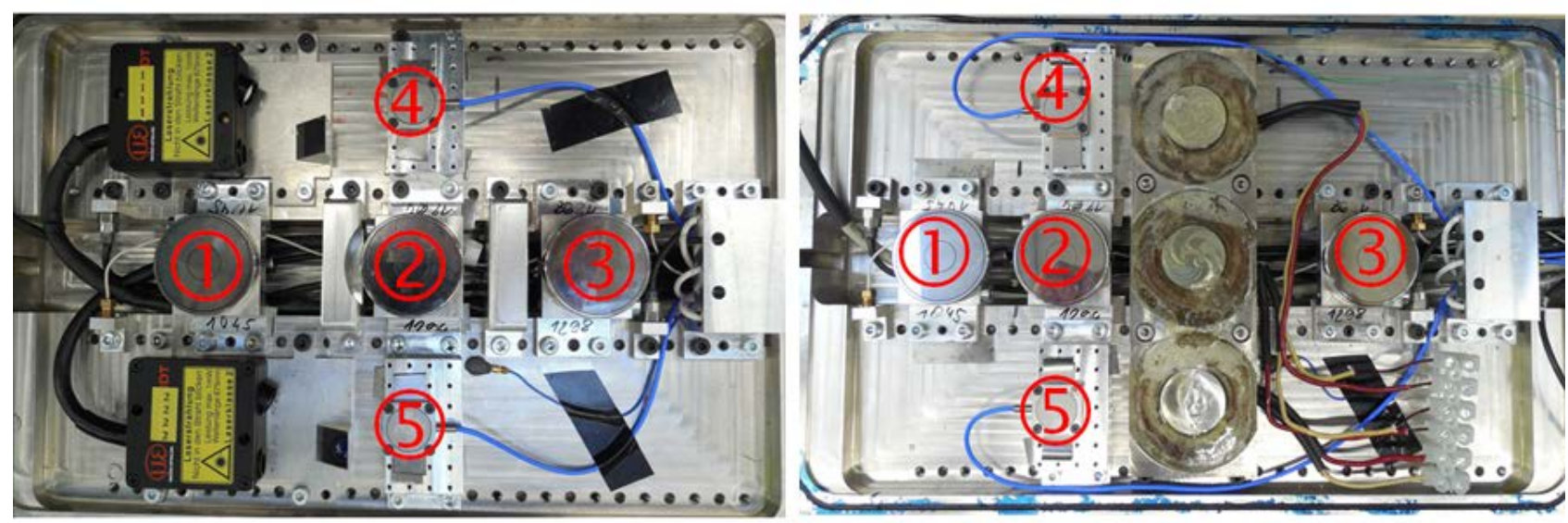

Figure 81: Instrumentation in the sensor pod underneath the elastic panel

The measured static pressure distributions for the rigid panel of the shock wave boundary layer interaction in this case for the Mach numbers investigated are shown in Figure 82. As expected the impinging shock wave leads to a steep pressure increase. The effect of the separation bubble with the separation shock upstream of the maximum pressure is well detected. It is also seen, that the size of the separation region decreases with an increasing Mach number.

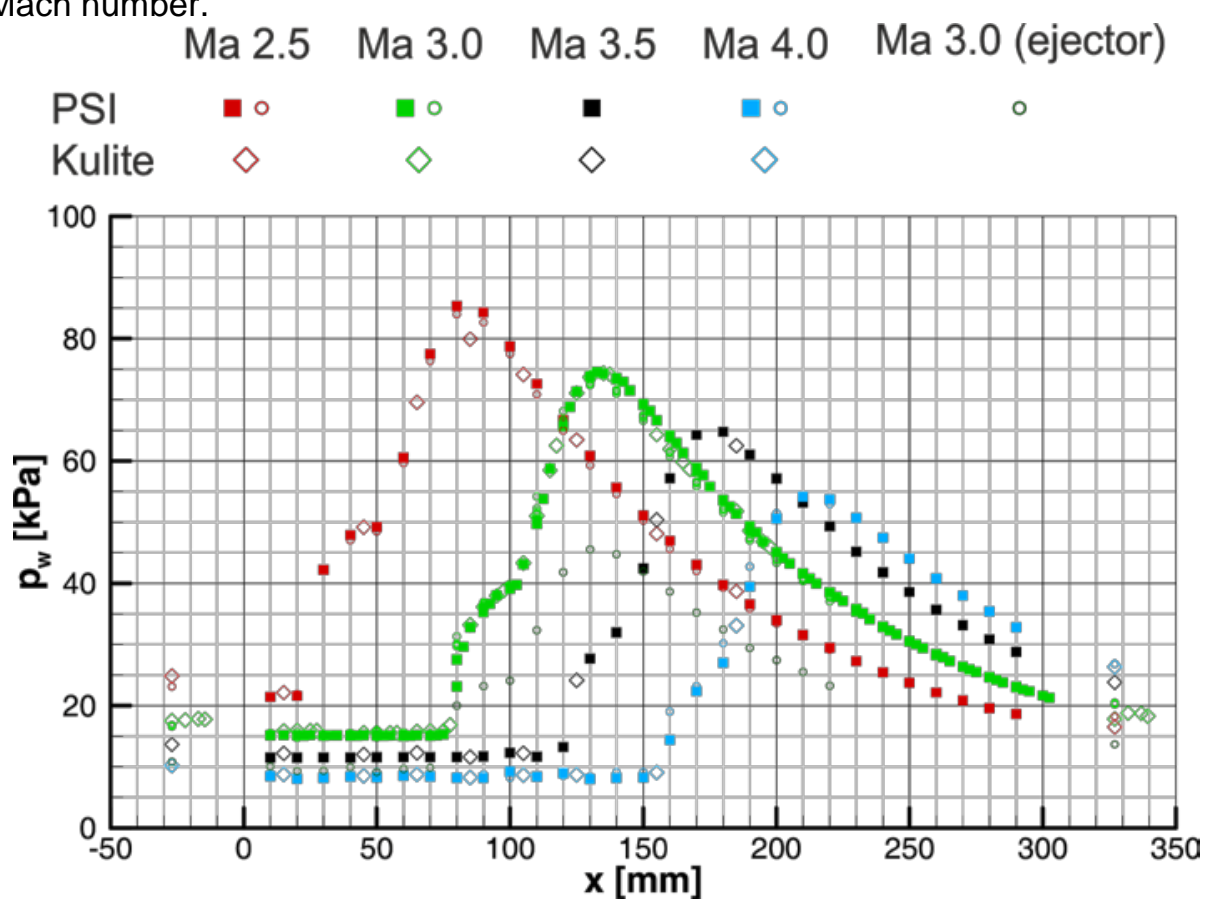

Figure 82: Static pressure distributions of the SWBLI on the rigid insert

From the high-frequency Kulite sensors, the power spectral density of the pressure could be obtained and analysed. Figure 83 shows exemplarily the oscillations on the rigid and elastic panel for $\mathrm{Ma}=3.0$.

This situation has been addressed with detailed DNS-analysis at SOTON for a Mach 4 boundary layer. Two different methods have been used to generate the turbulent boundary layer base flow: a synthetic turbulence (ST) approach simulating bypass transition and a digital filter (DF) approach. The base flows resulting from these two methods indicated to have the correct turbulence intensities and mean velocity profiles. The comparison of the results from the experimental and the numerical "pseudo- schlieren" is shown in Figure 84. These schlieren images show the shock system of impinging and reflected shocks. The instantaneous separation bubble is illustrated by the contour of zero streamwise velocity in the numerical results. The comparison with the CFD analysis at FOI is given in the bottom picture of Figure 84. Although of course very much "diffusive" due to the numerical methodology, the main features are also captured here. 


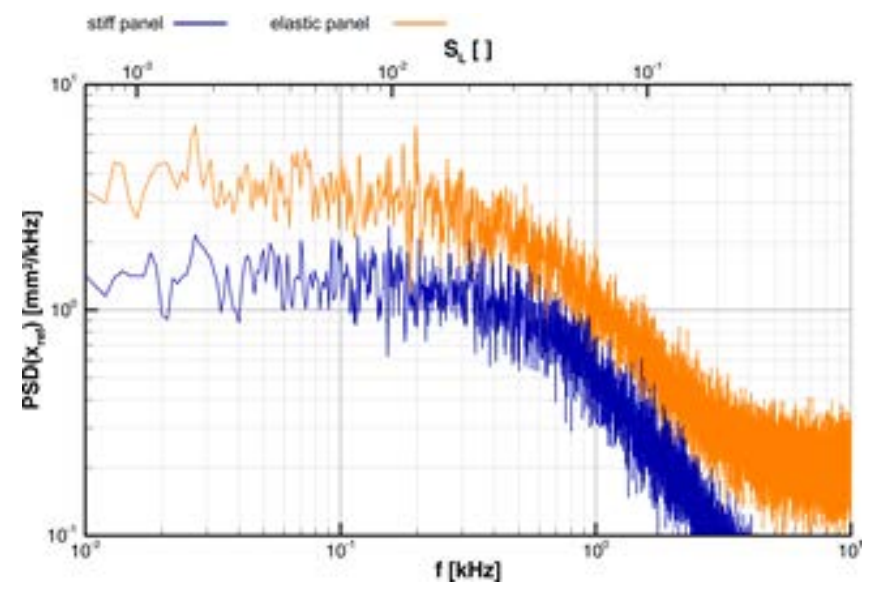

Figure 83: Oscillations of the reflected shock at $\mathrm{Ma}=3.0$ on the rigid and elastic panel

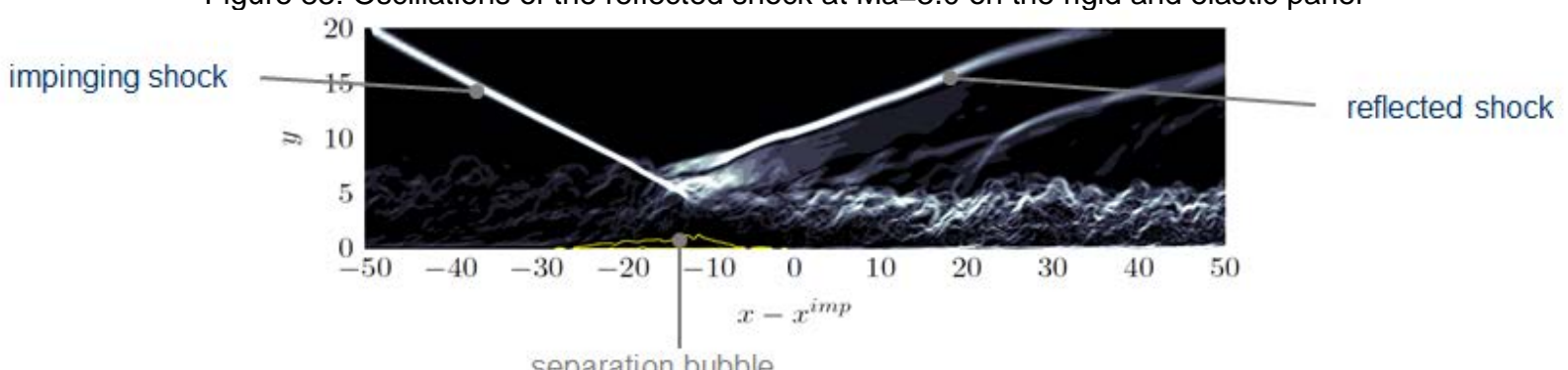

separation bubble

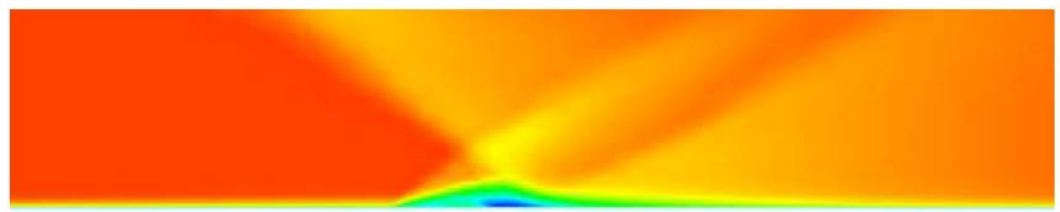

Figure 84: DNS simulation (upper), and CFD (bottom)

The second experimental investigation combined the SWBLI with FSI by applying it to an elastic panel. The deflection of the elastic panel showed a large static component and only a small dynamic component. The deflection is well two-dimensional with the measures along the centerline $(y=0)$ and offset. This is illustrated in Figure 85 for one shock generator position at $x=-160 \mathrm{~mm}$.

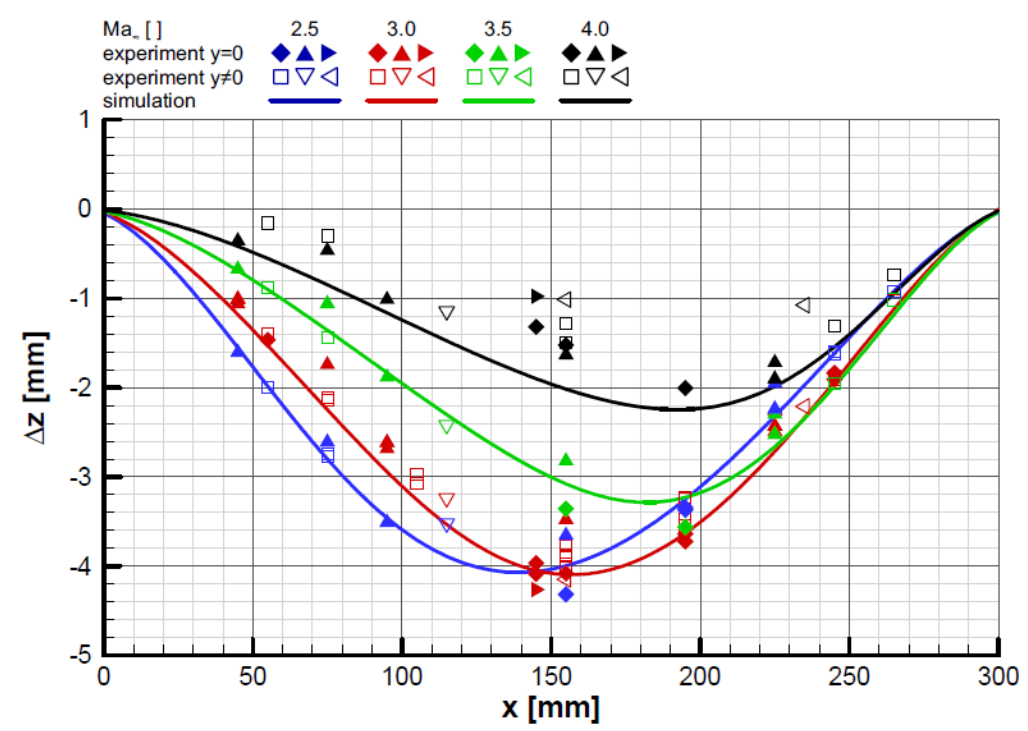

Figure 85: Static deflection of the elastic panel for different Mach numbers at $x=-160 \mathrm{~mm}$ 
From the dynamic components, several frequencies for the panel vibrations could be identified which correlate well with the eigenfrequencies of the elastic panel from structural analysis. An important aspect is thereby the adequate formulation of the structural boundary conditions in comparison between experiment and numerical analysis. With this, the approach of coupled CFD-FEM analysis at FOI has been qualitatively verified but showed still shortcomings for quantitative analysis. The interaction of experiments, detailed DNS and coupled CFD-FEM simulation provide a comprehensive assessment on the physical aspects as well on the needs for accurate engineering design models.

\section{V.5 Aero-Thermal Aspects for Cooling and High Heat Loads}

CFD-tools for detailed studies and industrial design are since many years applied to address cooling aspects for e.g. combustion chamber components experiencing high heat loads. The tools and models mainly apply RANS-approaches with different turbulence modelling approaches. They differ between the software packages applied in these terms. Therefore, validation work for single jet impingement heat transfer and cooling has been performed by the three partners, ESA, USTUTT and MBDA using a common benchmark case from the ERCOFTAC-database. The best suited models for each partner for this comparison has been applied for the regenerative cooling path featuring the PTAH-SOCAR technology from MBDA as generic pin-fin channel cooling investigated at USTUTT. Application of the chosen models to the experiments for the hot impingement compressible jet investigations at EADS-IW revealed further needed corrections including conjugate analysis of flow, heat transfer, conduction and radiation.

\section{V.5.1 Benchmark Study for Single Impingement Jet}

The case of a single round impinging jet has been selected as test case, since impinging flows are difficult to predict by means of CFD due to the complex flow physics. The validation data is available from an ERCOFTAC test case "C.25 Normally-Impinging Jet from a Circular Nozzle" (mainly based on the experimental results by Cooper et al. [68]). This common test case was investigated by the partners with three different flow solvers CFD-ACE (ESA-ESTEC), CEDRE (MBDA) and ANSYS-CFX (USTUTT) with respect to results obtained from different CFD-solvers and implemented turbulence models. From the available database of this test case and similar studies in literature one specific case $(R e=23,000, H / D=2)$ has been investigated in several independent studies and the data analysed in form of Nusselt numbers for heat transfer and flow field variables. Due to the symmetry of the physical situation using RANS, the geometrical domain to be analysed was simplified and a "quasi"-two-dimensional mesh was applied with different grid resolutions to assess grid independency. All partners used the same mesh regarding spatial discretization of the computational domain and identical boundary conditions (Figure 86).

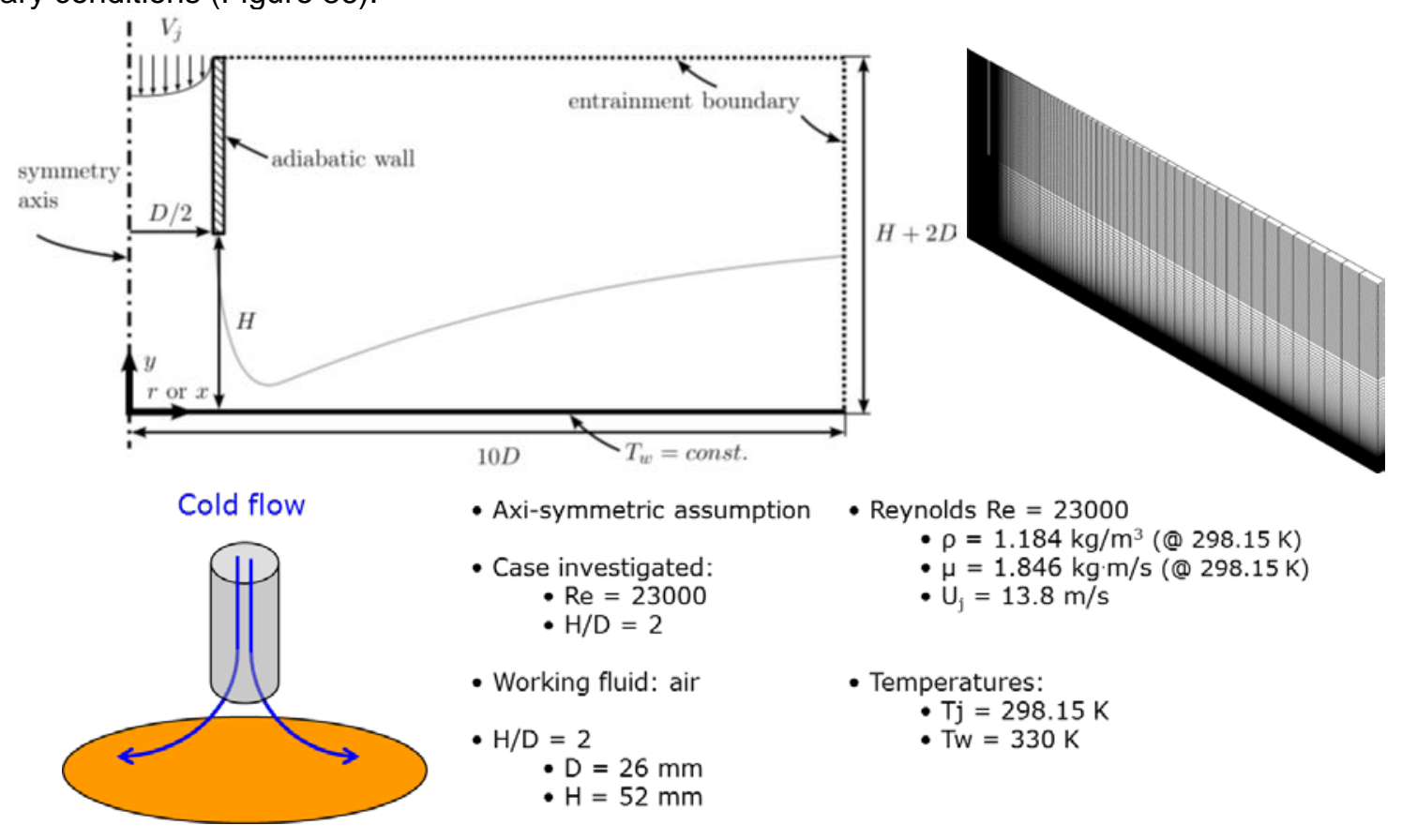

Figure 86: Domain and boundary conditions simulated (upper left) and mesh structure (upper right) and boundary conditions (lower) 
Figure 87 shows exemplarily the results for the radial Nusselt number distributions in comparison to experimental data for the different codes and turbulence modelling applied. As can be seen a "best modelling" approach" is difficult to define. In view of industrial applications, the use of implemented Reynolds Stress Models (RSM) as used by USTUTT seems not to provide better results than the less expensive k- $\omega-$ SST model. The $\mathrm{k}-\omega-\mathrm{SST}$ model was chosen by USTUTT and MBDA for the further heat transfer studies described below, whereas for ESA-ESTEC the two-layer-k- $\varepsilon$ and the realizable- $k-\varepsilon$ performed better especially in the stagnation point region for heat transfer.
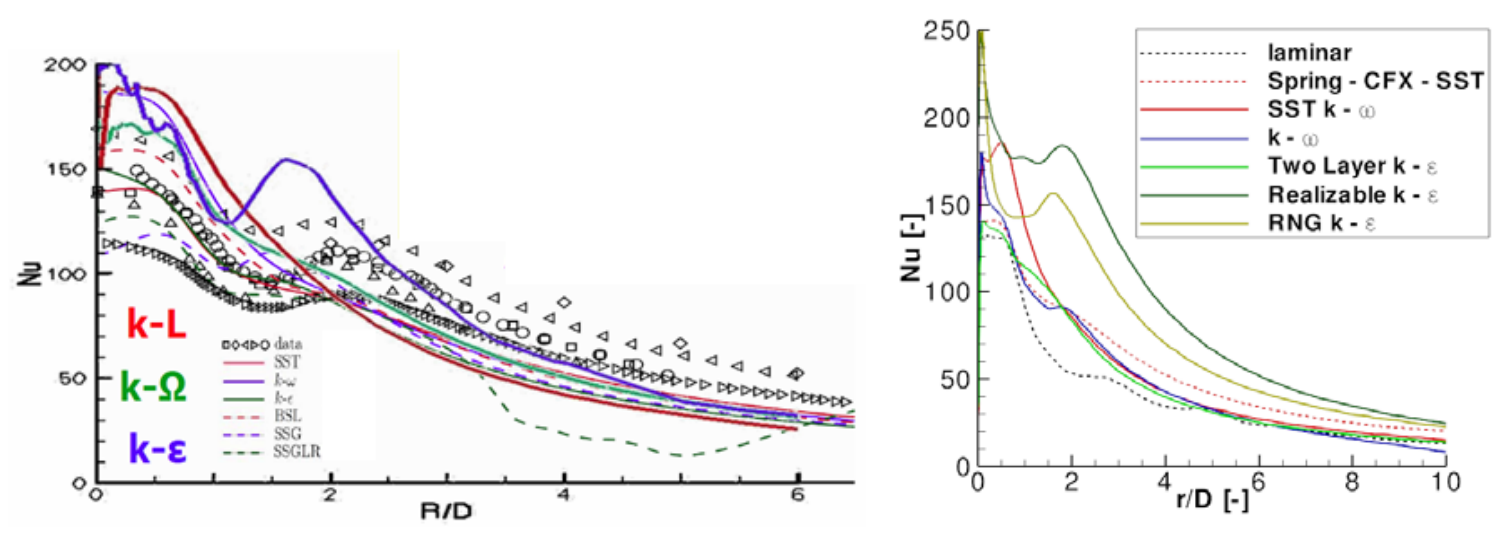

Figure 87: Nusselt number distributions. USTUTT and MBDA (full lines) - left; ESA-ESTEC-right

\section{V.5.2 Pin Fin Channel Cooling}

Pin fin channel cooling is one technology well known from gas turbine cooling. The regenerative cooling technology PTAH-SOCAR experimentally investigated (see above) for a generic configuration for this cooling technology has been numerically addressed by MBDA and USTUTT. In accordance to the experimental test program numerical simulatoins were performed for the specific configurations in a Reynolds number range from 5,000 to 25,000 using the k- $\omega-$ SST model at USTUTT and MBDA. As the parameter ranges with respect to pin spacings in stream-wise and lateral directions and height $\left(\mathrm{S}_{\mathrm{x}}, \mathrm{S}_{\mathrm{y}}, \mathrm{H}\right)$ normalized by the pin diameter $\mathrm{D}$ differ from most studies available in literature, several cases have been investigated (see Figure 88).

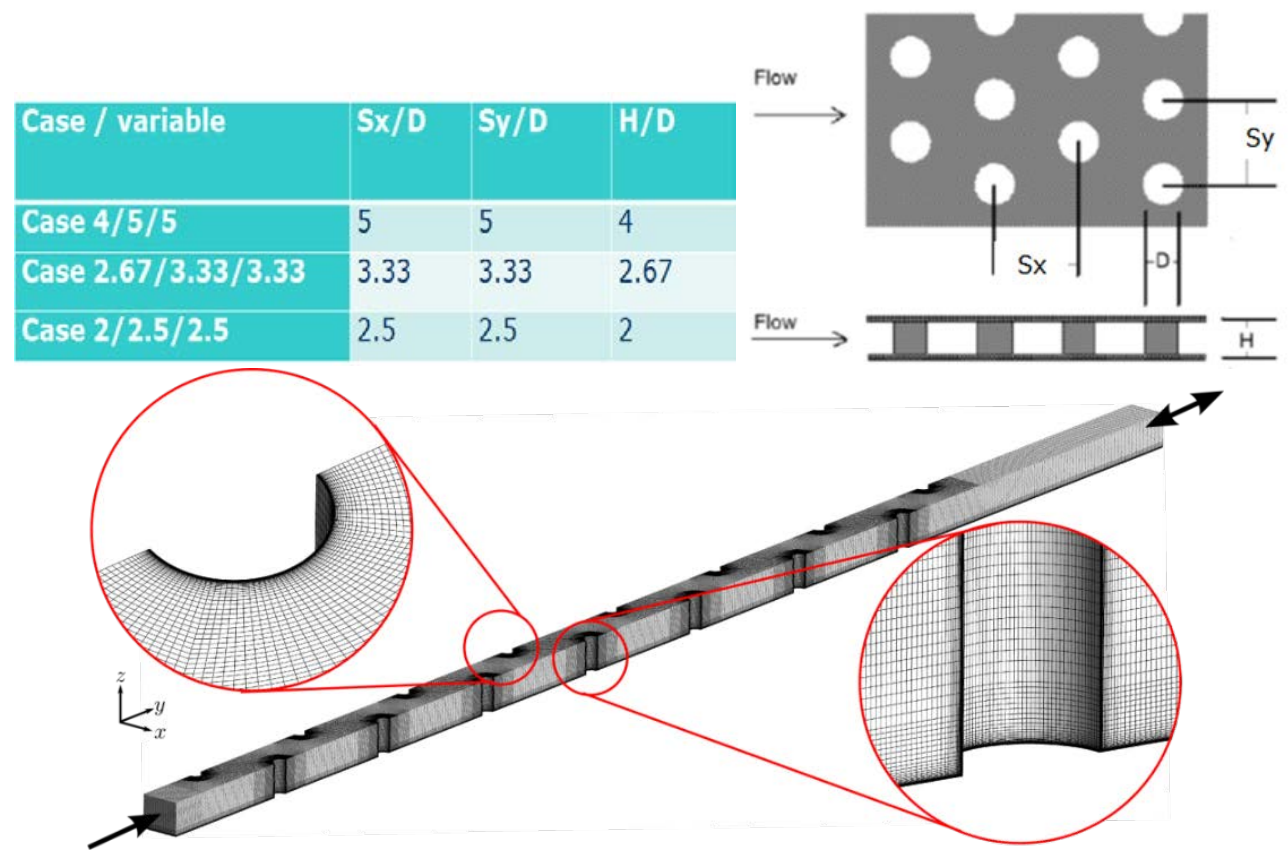

Figure 88: Test matrix (upper-left), Parameter definitions (upper-right) and mesh (bottom) 
All meshes were constructed as block-structured meshes with hexahedral elements. The reduced computational domain allowed for resolving all walls with very fine mesh scales $\left(\mathrm{y}^{+}<2\right)$ so that a low-Reynolds wall treatment could be used important for accurate heat transfer predicitions. From this modelling analysis, a computational approach has been identified, that can be considered appropriate and computationally efficient at the same time for industrial tool design work. It is based on a half-height channel using periodic boundary conditions as given in Figure 89 on the upper right. Further studies showed that adaptions of modelling parameters and modifications regarding e.g. transitional turbulence and curvature correction modification improve the simulation results in comparison to the experimental data for both heat transfer and pressure losses. Thereby also the importance of appropriate boundary conditions as in the experimental investigations has been addressed.

Symmetry

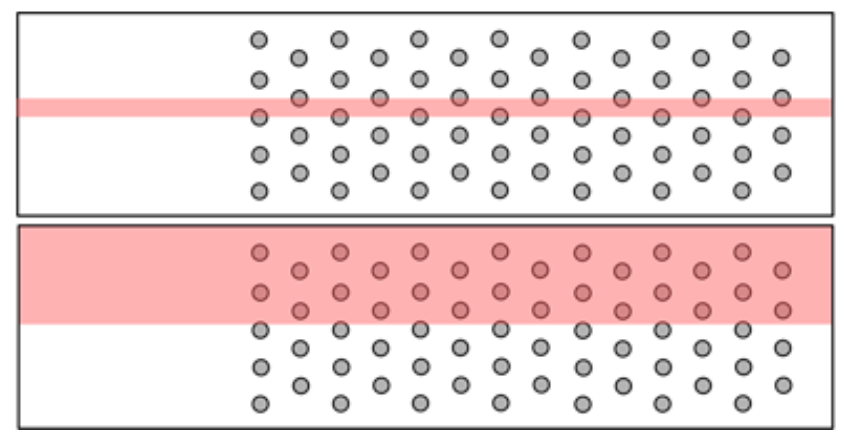

\section{Periodic / Symmetry}

\begin{tabular}{|lllllllllllllll|}
\hline & 0 & 0 & 0 & 0 & 0 & 0 & 0 & 0 & 0 & 0 & 0 & 0 & 0 & 0 \\
0 & 0 & 0 & 0 & 0 & 0 & 0 & 0 & 0 & 0 & 0 & 0 & 0 & 0 \\
0 & 0 & 0 & 0 & 0 & 0 & 0 & 0 & 0 & 0 & 0 & 0 & 0 & 0 \\
0 & 0 & 0 & 0 & 0 & 0 & 0 & 0 & 0 & 0 & 0 & 0 & 0 & 0 \\
0 & 0 & 0 & 0 & 0 & 0 & 0 & 0 & 0 & 0 & 0 & 0 & 0 & 0 \\
\hline \hline & 0 & 0 & 0 & 0 & 0 & 0 & 0 & 0 & 0 & 0 & 0 & 0 & 0 & 0 \\
0 & 0 & 0 & 0 & 0 & 0 & 0 & 0 & 0 & 0 & 0 & 0 & 0 & 0 \\
0 & 0 & 0 & 0 & 0 & 0 & 0 & 0 & 0 & 0 & 0 & 0 & 0 & 0 \\
0 & 0 & 0 & 0 & 0 & 0 & 0 & 0 & 0 & 0 & 0 & 0 & 0 & 0 \\
0 & 0 & 0 & 0 & 0 & 0 & 0 & 0 & 0 & 0 & 0 & 0 & 0 & 0 \\
\hline
\end{tabular}

Figure 89: Domain modelling approaches using symmetry and periodic conditions for half and full channel heights

Similar findings can be reported form the extensive detailed study of MBDA on the pin-fin channel cooling in comparison to the same experimental results and additional to data from literature as e.g. overall heat transfer characteristics reported in Metzger et al. [54]. Using extensive parameter variations it was found, that the pressure losses for all cases could be sufficiently accurate for engenerring applications predicted. Both partners found always an under-prediction of the heat transfer on the side- respective end-walls of the pin-fin channel but an over-prediction of the average heat transfer (as measured) on the pin-fins themselves. This might explain the results from MBDA, that the overall heat transfer also in comparison to the literature data from is generally satisfactorily for industrial design assessments but the row-wise distribution differs as shown in Figure 90 for the simulation of the Metzger et al. pin-fin experiments [68] for two operating conditions. For the higher Reynolds number it has not been possible to obtain converged results for two of the three turbulence models tested $(k-\omega$ and $k-\varepsilon)$. This might be due to compressibility effects in a strongly confined flow.
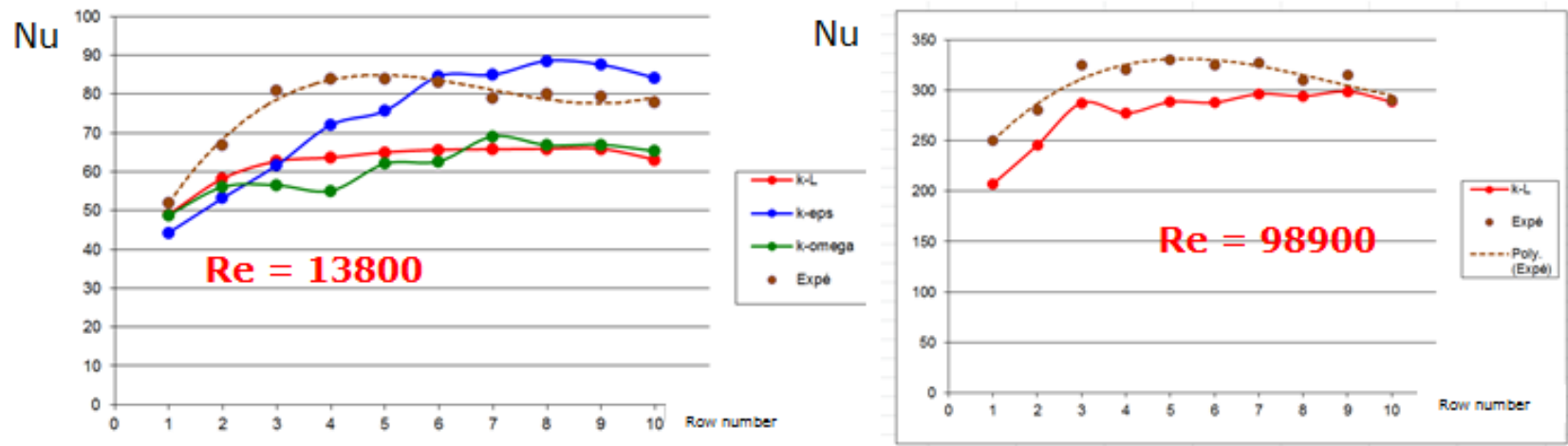

Figure 90: Results from MBDA-analysis using CEDRE for Metzger et al. [54] test case

\section{V.5.3 Hot Compressible Jet Impingement}

All the findings, assessments, modelling approaches and modifications and made hypotheses described above have to be taken into account for the investigations of the numerical studies on the hot compressible jet impingement case studied experimentally at EADS-IW using the ERBURIGK-test facility. An oblique high temperature jet impinges on a solid anisotropic plate sample (CMC-material) and heats up the sample with time. Experimental data was obtained with transient local thermocouple and pyrometer data on top of the test sample and on the sidewalls for assessing appropriate boundary conditions as well as the numerical domain (see Figure 91). 

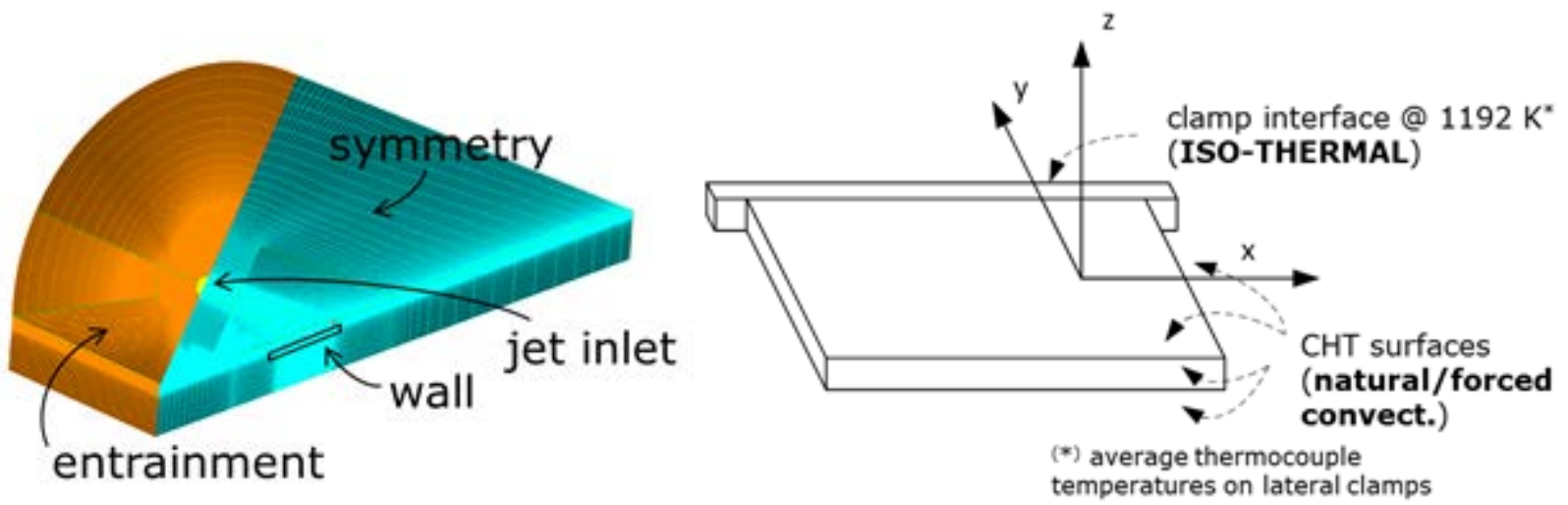

Figure 91: Domain modelling and boundary settings

After several investigations the ESTEC analysis using CFD-ACE revealed, that the turbulent viscosity had to be strongly limited to describe the Mach number contours as observed visually in the experiments. With this, a good agreement was found for the local temperature measurements in comparison to the experiments. The heat transfer distribution on the solid wall did not well correspond to the numerical results with CEDRE at MBDA. This is shown in Figure 92. From the modelling at MBDA it was recognized, that for this situation with high compressibility effects an adaptation had to be applied to the chosen turbulence model. This was achieved with a correction model developed by Aupoix [71]. With this compressibility correction, CEDRE brought satisfactory results. Further a "quasi-conjugate modelling was applied by interpolating the heat transfer data from the flow solution as boundary conditions for a transient solid conduction analysis of the sample. The major challenges, approaches and achievements are summarized in Table 7.

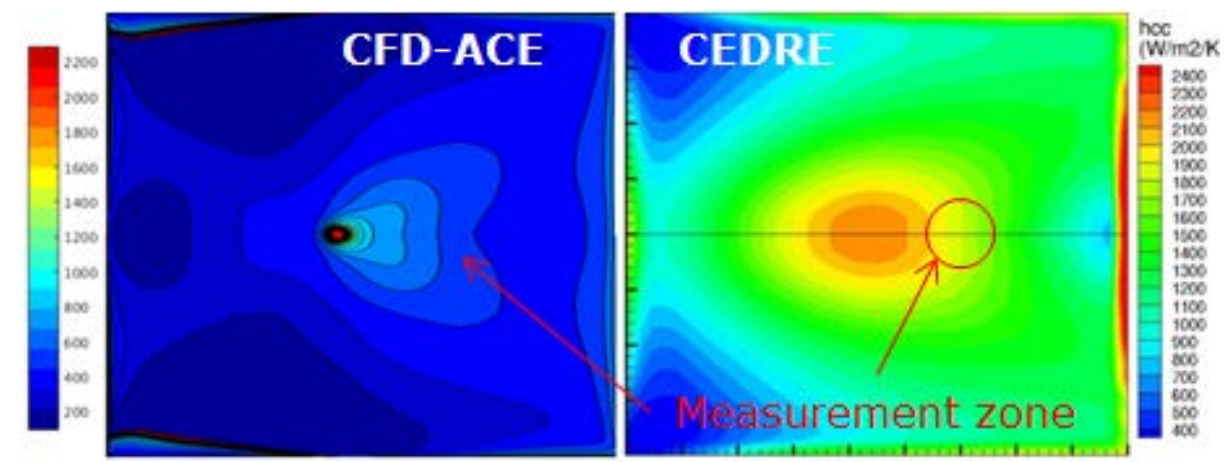

Figure 92: Heat transfer distributions as predicted by CFD-ACE and CEDRE indication the measurement locations

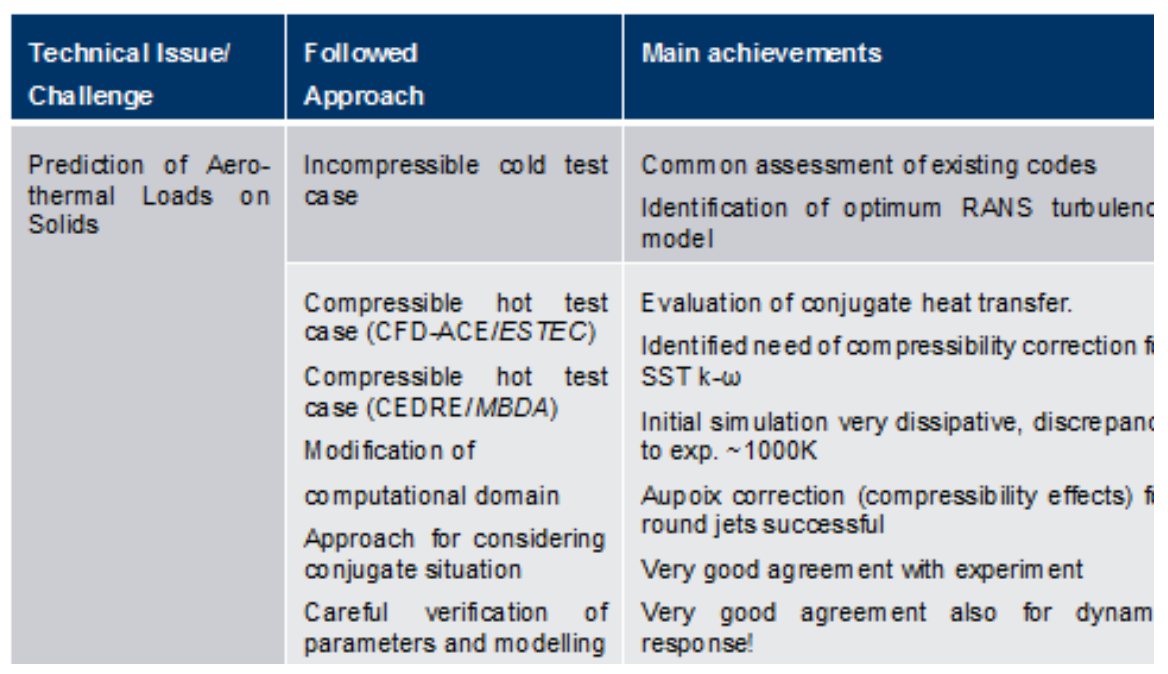

Table 7: Major findings for the hot compressible jet impingement study 


\section{V.6 Summary}

The activities ATLLAS // with close interaction between experimental investigations addressing significant areas of aero-thermal-structural interactions for high-speed vehicle concepts, and detailed physical analysis and design tools has been successfully completed.

The investigations on Aero-Thermal-Structural and High-Speed Transition for External Components provided comprehensive databases for SWBLI at relevant flight conditions.

The wind tunnel model designed and integrated in the High Enthalpy Shock Tunnel Göttingen (HEG) allowed for tests at elevated surface temperatures of up to $800 \mathrm{~K}$ and to study flow phenomena such as boundary layer transition or shock wave boundary layer interactions. The conducted tests revealed a boundary layer transition promoting effect of the heated model surface compared to the cold reference case. Furthermore, an impact on the surface pressure and heat transfer distribution on the flap was found.

The experiments in TMK provided a large database for the investigation of pure SWBLI at Ma $\in\{2.5,3.0,3.5$, $4.0\}$ and in combination with a FSI on an elastic panel. The flow leads to a large static deflection and has a significant effect on the panel vibrations and the deflection has a significant effect onto the shock positions and oscillations. Additional excitation with magnetic fields enhances these effects. The detailed numerical analysis by DNS provided in depth results for low frequency loads in SWBLI conditions. The developed FSI engineering modelling using engineering-design coupled approaches were applied and shown to be able to predict the basic qualitative behaviour for the response of an elastic panel but revealed at the same times shortcomings in the current modelling.

A comprehensive approach was taken to investigate high-speed transition effects on drag and heat loads from experimental and numerical analysis side and allowed to develop and calibrate engineering laminar-toturbulent boundary layer transition models including intermittency based ones through detailed DNS [72][73][74], experiments and RANS-CFD. A new and unique database for high-speed laminar-turbulent transition on plates and cones with different roughness elements has been developed. A general frame was setup to allow straightforward implementation of transition model ling into CFD-RANS tools. This approach and the achieved generic modelling are unique at present, especially for the design aspects concerning supersonic-hypersonic flows.

The investigations on Aero-Thermal Aspects for Cooling and High Heat Loads focused on the further development of thermal design tools. Considering the results obtained with respect to turbulence modelling has shown, that a choice depends on how the model is implemented in a specific code and also on the problem to be addressed (compressibility, high or low Mach number, conjugate situation). The SST k- $\omega$ model is recommended for MBDA and for USTUTT, while it is not following ESTEC conclusions, where the two-layer k$\varepsilon$ and realizable $k-\varepsilon$ models are preferred. Hereby the importance of close interactions between experiment and simulation to define the appropriate boundary conditions for dedicated assessment and corrections has been shown.

This is especially to be considered for very complex physical situations as e.g., the hot compressible jet impingement case. Here, both simulations by MBDA and ESTEC have initially led to a large overspreading of the jet, and consequently a large under-estimate for heat flux and temperature distributions on the CMC sample. The simulations could significantly improve by considering the compressibility effects present in jets in the turbulence modelling. Several further development approaches have been identified in the scope of an enhancement of industrial tools. In CEDRE, non-isotropic conductivity and emissivity function of the temperature could be of interest. In CFD-ACE, a specific correction for compressible round jets seems to be essential for future applications.

\section{Conclusions and Overall Research Achievements}

The two consecutive ATLLAS I and I/ projects [6][11] aimed to foster technologies enabling civil high-speed transportation with an emphasis on the development of lightweight high-temperature materials and related structures. To well define the general material requirements and their applicability, the study was centred on a multi-disciplinary conceptual design of a 200 passengers' aircraft with an optimal cruise Mach number of 5 to 6. To assure realizability and involvement of other dimensioning disciplines also other related study topics were covered. In overall, the following elements were addressed:

- Conceptual design of a high-speed civil aircraft including multi-disciplinary optimization

- High-temperature, low-weight materials: Titanium and Ceramic Matrix Composites, Ultra HighTemperature Composites, Hollow-Sphere and Tube Stacking components,

- Thermal Protection System: heat transfer control to passengers' cabin, engines components (combustor, nozzles...), airframe structures, control surfaces (ailerons, canards...)

- High-Speed aerodynamics: control surfaces, fluid-structure interaction, gaps, transition

- Environmental impact: sonic boom and high-altitude emissions 
The study indicated that a kerosene fuelled high-speed transport vehicle for 200 passengers with a cruise at Mach number of 5-6 is technically feasible: the achievable range is $9,800 \mathrm{~km}$, the GTOW 465tons with a 200 passenger capacity. This compares to a hydrogen-fuelled vehicle at the same speed respectively with $19,600 \mathrm{~km}, 400$ tons and 300PAX. The overall characteristics of the ATLLAS-II vehicle after several multidisciplinary optimization loops are given in the table below. Its performance was assessed both numerically and experimentally in design and off-design conditions.

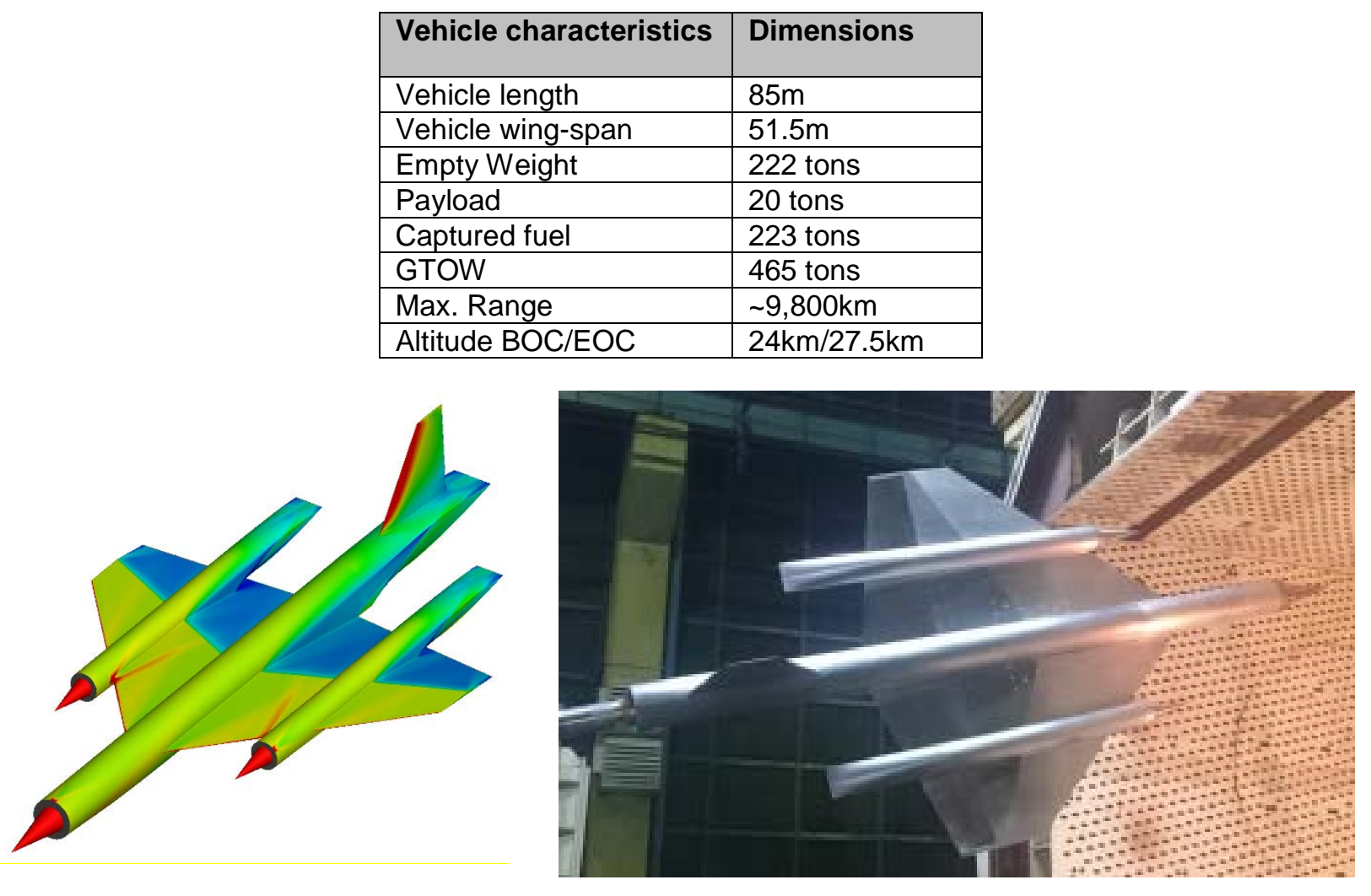

Figure 93: General layout of the vehicle with fuselage and nacelles shielded behind the air intakes; left: numerical nose-to-tail verification (pressure field), right: experimental model in supersonic wind tunnel.

Advanced lightweight and high-temperature materials for hypersonic cruiser airframe structures were thoroughly investigated with respect to their long-term behaviour at high heat flux and high mechanical loading environment.

Limits of TMC materials were pushed further by taking active cooling into account which was proved at sample and component level. TMCs could be considered as supporting material for CMC-based TPS systems but also for stand-alone systems demanding for different means of enhanced thermal protection and internal cooling. HSS and TSS materials were further characterised focussing on their creep behaviour which allowed an enhanced prediction of such structures. New TSS architectures in form of sandwich like structures were achieved. Applying rather regular than random oriented structures enabled to better predict and tune the materials to the requirements.

CMC materials SiC/SiCN and WHIPOX proved to be quite damage-tolerant and oxidation-resistant. Extensive fatigue and creep tests allowed estimating the materials long-term behaviour. However, SiC/SiCN demands for an EBC to improve its overall oxidation resistance in the HT range. WHIPOX proved to be applicable for long-term applications in the medium temperature range up to $1200^{\circ} \mathrm{C}$.

The development of $\mathrm{ZrB}_{2}$ - and $\mathrm{HfB}_{2}$-based UHTC materials resulted in increased production dimensions, which enable component-like tests in future. Oxidation tests proved the brilliant HT oxidation characteristics of these materials. Nevertheless, the material needs to be reinforced to obtain both a better damage tolerance behaviour and an increased operational capability.

Dynamic shaker tests with a CMC-based TPS panel successfully proved the feasibility for an accumulated Mach 6 flight of 100 hours flight time which corresponds to 25 flights of 4 hours duration each. Yet for realistic hypersonic cruiser vehicle lengths, bigger panels may become necessary which come along with thermal expansion effects and manufacturing issues to be solved for prospective hypersonic cruisers. 
The development of the various high-temperature materials were based upon their applicability and need for the various components of the vehicle. The identified structures can be cooled or uncooled based on metallic or ceramic materials. Promising technologies were tested in ATLLAS-I with moderate durations (up to several minutes) though a few hours of cruise flight would demand thousands of hours in cumulative times for survivability at actual operational conditions. ATLLAS-II allowed testing the high-temperature materials and structures under relevant chemical and aero-thermal conditions with test time from minutes to hours. This resulted in a unique and vast material database with dependencies of temperature and lifetime considerations accrued over these two projects.

The various test series were prepared and analysed with design tools and with respect to possible use in highspeed combustion environment and integration. The design structures were tested with different levels of environment representability on one hand and instrumentation on the other hand, from lab to industry engine, from isolated phenomena to fully complex ones.

Some unique new results were obtained, including:

- Pin fin channels heat transfer experimental detailed documentation (high scale, pressure drop and local heat transfer, with warm air under a large range of Reynolds numbers)

- 3 hours testing of cooled CMC subscale hydrocarbon subsonic combustion chamber (compared to some minutes of similar testing in ATLLAS I)

- Development and testing of a multifunctional metallic generic sandwich panels; the final testing was made at the exit of a scramjet combustor at Mach 6 flight conditions

- Development of CMC and hybrid CMC/UHTC generic injection struts tested in a ramjet/scramjet combustor at flight conditions of Mach 6

Possible applications of these structures on a future high-speed airliner were pointed out, and the generic design of tested hardware (cooling channels, advanced materials, multifunctional sandwiches, advanced CMC or hybrid injectors) may allow adapting the ATLLAS // results to different engines and high-speed vehicles.

Perspective of future research include further development and testing of advanced structures, development of associated multidisciplinary modelling and design capabilities, extension of still one or two orders of magnitudes of hot test durations, associated fatigue characterization and modelling.

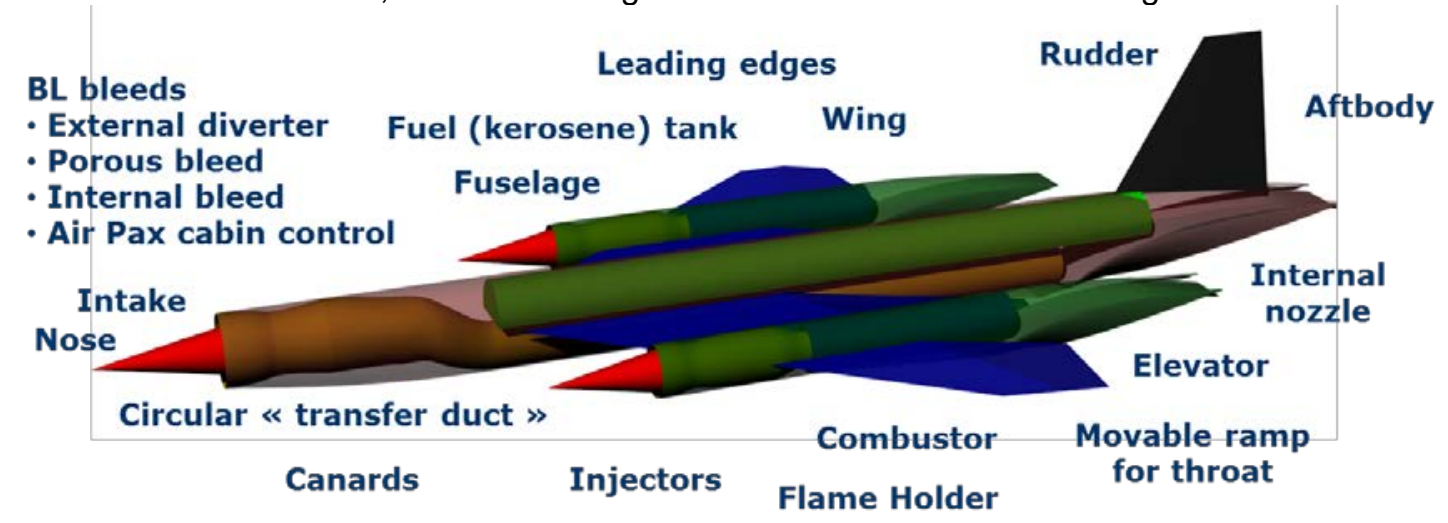

Figure 94: Materials and structures investigated to benefit the airframe and propulsion elements

The aero-thermal-structural design of hypersonic vehicles largely depends on the knowledge of the loads which are of a completely different nature than for subsonic aircraft. Generally, heat loads and shock wave boundary layer interactions have an important impact on the overall vehicle dimensioning. Therefore, particular loads presently difficult to predict were investigated:

- transitional effects under high speed conditions at high wall temperatures with and without roughness have been thoroughly evaluated experimentally.

- aero-frame structures and control surfaces trigger unsteady loads accompanied by high heat loads. Experimental and numerical investigations quantified these aero-thermal loadings and the response of the structural surfaces.

- the intake, combustor and nozzle loadings demand for advanced cooling techniques. The prediction and design capabilities were improved and validated for transpiration and regenerative cooled structures where effects of heat radiation were included.

The vehicle design concurrently with material and structural development allowed the consortium to work out a roadmap for future material development (e.g. life-cycle...) and cooling capabilities including experimental flights. 


\section{References}

[1] Recherche Aéronautique sur le Supersonique, Enjeux Scientifiques, Axes de Recherche, Structuration de la Recherche, Rapport du Comité d'Orientation Supersonique, September 2000.

[2] Commercial Viability of the High-Speed Civil Transport (HSCT), Saounatsos, Yorgos E., 1997.

[3] Margaretic P. and Steelant J., 'Economical Assessment of Commercial High-Speed Transport', 5 $^{\text {th }}$ CEAS Air \& Space Conference, 7-11/09/2015, TU Delft, Netherlands.

[4] Barbaux Y., Guedra-Degeorges D., Lapassat G., The Materials Challenge for the Future SCT, 7th European Aerospace Conference, Toulouse, France, Oct. 1994.

[5] Stephens J.R., Materials/Coatings Requirements for the HSCT Propulsion System, presentation to the Committee on Coatings for High-Temperature Structural Materials, National materials Advisory Board, National Research Council, San Antonio, Texas, Dec. 13-14, 1993.

[6] Steelant J., "ATLLAS: Aero-Thermal Loaded Material Investigations for High-Speed Vehicles", 15 ${ }^{\text {th }}$ AIAA International Space Planes and Hypersonic Systems and Technologies Conference, 28/04-01/05-2008, Dayton, Ohio, USA, AIAA-2008-2582.

[7] Bouchez M. , Dufour E., Cheuret F., Steelant J., Sandham N., Redford J., Roberts G., Passaro A. and Baccarella D., 'Material-Aero-Thermal Interaction Computations in the ATLLAS European Programme', 44th AIAA Joint Propulsion Conference and Exhibit, 20-23/07 2008, Hartford, Connecticut, USA, AIAA2008-4670.

[8] Steelant J.: 'Achievements obtained on Aero-Thermal Loaded Materials for High-Speed Atmospheric Vehicles within ATLLAS', AIAA-2009-7225, 16th AIAA/DLR/DGLR International Space Planes and Hypersonic Systems and Technologies Conference, Bremen, Germany, October 19th-22nd, 2009.

[9] Steelant J., 'Achievements Obtained for Sustained Hypersonic Flight within the LAPCAT project', 15th AIAA International Space Planes and Hypersonic Systems and Technologies Conference, AIAA-20082578, Dayton, Ohio, USA, AIAA, 28/04-01/05/2008.

[10] Steelant J., Varvill R., Defoort S., Hanneman K. and Marini M., 'Achievements Obtained for Sustained Hypersonic Flight within the LAPCAT-II Project', 20th AIAA International Space Planes and Hypersonic Systems and Technologies Conference, 06-09 July 2015, AIAA-2015-3677, Glasgow (UK).

[11] Steelant J., "European Activities on High-Speed Vehicles: Feasibility Studies and Technological Challenges for Hypersonic Cruisers", Aerothermodynamics Conference ATD7, ATD7-215019, May 2011, Bruges, Belgium.

[12] Steelant J., 'Evolutionary Technology Developments for High-Speed Transportation', Aerodays 2015, 2023/10/2015, London, UK.

[13] Cain T., Zanchetta M. and Walton C., 'Aerodynamic Design of the ATLLAS Mach 3 Transport', CEAS 2009 European Air and Space Conference, Manchester, UK, 2009

[14] Kopp A., Garbers N., Jarlas R., Rabia H., "Parametric Structural Analysis for the SpaceLiner", AIAA-20125944, 18th AIAA International Space Planes and Hypersonic Systems and Technologies Conference, Tours, France, September 2012

[15] Fernández-Villacé V. and Steelant J., 'The Thermal Paradox of Hypersonic Cruisers', 20th AIAA International Space Planes and Hypersonic Systems and Technologies Conference. Glasgow, Scotland: AIAA 2015, July 2015.

[16] Steelant J., Fernández-Villacé V., M. Dalenbring and G.-S. Wang, 'The Thermal and Structural Paradox for Hypersonic Cruisers', Aerothermodynamics Conference ATD8, ATD8-90155, March 2015, Lisbon, Portugal

[17] Mizuno M., Zhu S., Nagano Y., Sakaida Y., Kagawa Y. \& Watanabe M., "Cyclic-Fatigue Behavior of SiC/SiC Composites at Room and High Temperatures", J. of American Ceramic Society. 79(12), 306577,1996

[18] Hodgkinson J., "Aircraft Handling Qualities", Blackwell Science Ltd, ISBN 0-632-03816-0, 1999.

[19] MIL-F8785C, "Military Specification Flying Qualities of Piloted Airplanes", November 1980.

[20] Flight global, 23 Mar 2011, 747-8 Limit Cycle Oscillation.

[21] Ginn S. R., 'Sofia 747-SP, Structural Dynamics Overview', ISBN: 9781289075231, 2013.

[22] Carlson, "Design and Testing of Flexible Aircraft Structures", TRITA-AVE 2004:14

[23] Chevalier et al., "An analytical method for predicting the stability and control characteristics of large elastic airplanes at subsonic and supersonic speeds", AGARD-CP-46.

[24] Luquet D., Marchiano R., Coulouvrat F., Salah El Din I. and Loseille A., 'Sonic Boom Assessment of a Hypersonic Transport Vehicle with Advanced Numerical Methods', 21st AIAA/CEAS Aeroacoustics Conference, AIAA-2015-268522-26 June 2015, AIAA, Dallas, USA

[25] Loubeau $A$. and Coulouvrat $F$., 'Effects of meteorological variability on sonic boom propagation from hypersonic aircraft', AIAA J., 47(11), 2632-2641, 2009 
[26] Luquet D., Coulouvrat F. and Marchiano R., '3D Non-Linear Acoustic Propagation through the Atmosphere', 15th International Symposium on Long Range Sound Propagation, Oct. 2014.

[27] Luquet D., Coulouvrat F. and Marchiano R., '3D Numerical Simulation of the Long Range Propagation of Acoustical Shock Waves through a Heterogeneous and Moving Medium', 20th International Symposium Nonlinear Acoustics, 29 June-3 July 2015, AIP Conf. Proc. 1685 070010(1-4) (2015).

[28] Coulouvrat F., Luquet D. and Marchiano R., 'Numerical model of sonic boom in 3D kinematic turbulence', 20th International Symposium Nonlinear Acoustics/2 ${ }^{\text {nd }}$ International Sonic Boom Forum, 29 June-3 July 2015, AIP Conf. Proc. 1685 070015(1-4).

[29] Eliasson P., "EDGE, a Navier-Stokes Solver for Unstructured Grids", Proceeding to Finite Volumes for Complex Applications III, ISBN 190399634 1, 2002, pp 527-54.

[30] Kyle-Henney S., 'Silicon carbide monofilament reinforced titanium com[29]posites', 2nd European Titanium Conference, NAMTEC, 27-Mar-2012, UK.

[31] Kyle-Henney S., Flitcroft S., Shatwell R., Gibbon D., Voss G. and Harkness P., 'Silicon carbide monofilament reinforced titanium composites for space structures; a new material option', Proc. 12th European Conference on Space Structures, Materials and Environmental Testing, 20-23 March 2012, ESA, Netherlands.

[32] Davoine C., Götzfried A., Mercier S., Popoff F., Rafray A., Thomas M. and Marcadon V.: 'Metallic hollow sphere structures manufacturing process', Material Research Society Spring meeting, San Francisco, USA, 13-17 April 2009

[33] Marcadon V., Roques E. and Feyel F., 'Modelling of Mechanical Behaviours of Metal Hollow Sphere Regular Packing under Compression Loadings', 11 $11^{\text {th }}$ Euromech-Mecamat, Turing Italy, March 2008.

[34] Davoine C., Popoff F., Rafray A., 'Mechanical Strength of Oxidized Multi-channelled Metallic Structure Made with Brazed Hollow Tubes', 8th International Symposium on High-Temperature Corrosion and Protection of Materials, 20 - 25 May 2012, Les Embiez, France

[35] Davoine C., Popoff F., Rafray A., Passilly B. and Marcadon V., " Effect of Brazing on Mechanical Properties of Hollow Tubes Stacking', CellMat 2012 Conference, 7-9th November 2012, Dresden, Germany.

[36] Davoine C., Marcadon V., Popoff F., Rafray A., Passilly B., Ponse E. and Boivin D., 'Architectured Materials for High Temperature Applications', HETMAT group, October 11-12, 2012, Prague, Czech Republic

[37] Davoine C., Popoff F., Guyon A., Pinson S. and Dendievel R., 'Aluminized Superalloy Foams for Transpiration Cooling', METFOAM 2015 9th International Conference on Porous Metals and Metallic Foams, 31/08-02/09/2015, Barcelona, Spain.

[38] Kuhn M., Hald H., Ortelt M., Kirchberger C., Schlieben G. and Kau H.-P.: CMC Materials for Combustion Chamber Applications, EUCASS2009-224, 3rd European Conference for Aerospace Sciences, Versailles, France, 05-09 July 2009.

[39] Justin J.-F., 'Investigations of High Temperature Ceramics for Sharp Leading Edges or Air Intakes of Hypersonic Vehicles', EUCASS 2009-511, European conference of Aerospace Sciences, Versailles, France, 6-9 July 2009.

[40] Justin J.F. and Jankowiak A., "Ultra-High temperature Ceramics: Densification, Properties and Thermal Stability"; AerospaceLab, issue 3-November 2011

[41] Reimer T. and Kuhn M., 'Lifetime Testing of a CMC TPS under Vibration Load', 20th AIAA International SpacePlanes and Hypersonic Systems and Technologies Conference, AIAA 2015-3351, 6-9 July 2015, Glasgow (UK)

[42] Soller S., Kirchberger C., Kuhn M., Langener T., Bouchez M. and Steelant J., Experimental Investigation of Cooling Techniques and Materials for High Speed Flight Propulsion Systems, AIAA-2009-7374, 16th AIAA/DLR/DGLR International Space Planes and Hypersonic

[43] Kirchberger C., Wagner R., Kau H.-P., Soller S., Martin P., Bouchez M. and Bonzom C., 'Prediction and Analysis of Heat Transfer in Small Rocket Chambers', 46 ${ }^{\text {th }}$ AIAA Aerospace Sciences meeting and Exhibit, AIAA-2008-1260, Reno (NV), USA, 07-11/01 2008.

[44] Kirchberger C., Schlieben G., Hupfer A., Kau H.-P., Martin P. and Soller S.: 'Investigation on Film Cooling in a Kerosene/ GOX Combustion Chamber', AIAA-2009-5406, 45th AIAA/ASME/SAE/ASEE Joint Propulsion Conference \& Exhibit, Denver, CO, USA, August 2nd-5th 2009

[45] Bouchez M. and Beyer S., 'PTAH-SOCAR Fuel-Cooled Composite Material Structure', 15th AIAA International Space Planes and Hypersonic Systems and Technologies Conference, AIAA-2008-2626, Dayton, Ohio, USA, AIAA, 28/04-01/05/2008.

[46] Langener T., von Wolfersdorf J., Cheuret F. and Steelant J., 'Experimental and Numerical Study on Transpiration Cooling with Supersonic Flow', 19th Int. Symp. on Air Breathing Engines, ISABE, Montreal, Canada, 2009 
[47] Bouchez M., Dufour E., Benezech L., Cheuret F., Steelant J., Grenard P., Redford J.A., Sandham N.D., Roberts G.T., Passaro A., Baccarella D., Dalenbring M., Smith J. and Cavagna L., 'Multi-level Coupled Simulations of Cooled Structures in the ATLLAS European Programme', AIAA-2009-7374, 16th AIAA/DLR/DGLR International Space Planes and Hypersonic Systems and Technologies Conference, Bremen, Germany, 19-22 October, 2009

[48] Cheuret F., Steelant J., Langener T., von Wolfersdorf J.: Simulations on Transpiration Cooling for Supersonic Flow, CEAS 2009 European Air and Space Conference, Manchester, UK, 2009.

[49] Cheuret F., Steelant J., Langener T. and von Wolfersdorf J., , Transpiration Cooling Modelling for Ceramic Combustion Chambers', 20th ISABE Conference, ISABE-2011-1126, September 12-16, 2011, Gothenburg, Sweden.

[50] Bouchez M., Crampon F., Le Naour B., Wilhelmi C., Bubenheim K., Kuhn M., Mainzer B., Riccius J., Davoine C., Jean-Francois Justin, von Wolfersdorf J., Abdelmoula M., Villace V. and Steelant J., 'Combustor and Material Integration for High Speed Aircraft in the European Research Program ATLLASII', 19th AIAA Hypersonic Space Plane Conference, AIAA 2014-2950, Atlanta, GA, USA.

[51] Bouchez M., Dufour E., Le Naour B., Wilhelmi C., Bubenheim K., Kuhn M., Mainzer B., Riccius J., Davoine C., Justin J.-F., von Wolfersdorf J., Abdelmoula M., Spring S., Villace V. and Steelant J., 'Combustor Materials Research Studies for High Speed Aircraft in the European Program ATLLAS II', 20th AIAA International Space Planes and Hypersonic Systems and Technologies Conference, 06-09 July 2015, AIAA-2015-3639, Glasgow (UK).

[52] Poser R., J. von Wolfersdorf, 'Transient liquid crystal thermography in complex internal cooling systems', VKI Lecture Series 2010-05, Internal Cooling in Turbomachinery, von Karman Institute for Fluid Dynamics, Rhode-Saint-Genèse, Belgium, 2010.

[53] Axtmann M., J. von Wolfersdorf and Meyer G., 'Application of The Transient Heat Transfer Measurement Technique in a Low Aspect Ratio Pin Fin Cooling Channel', ASME J. Turbomachinery , (2015); doi: 10.1115/1.4031267

[54] Metzger D. E., Berry R. A. and Bronson J. P., "Developing Heat Transfer in Rectangular Ducts with Staggered Arrays of Short Pin Fins", Transactions of the ASME, J. of Heat Transfer, vol. 104, pp. 700706, 1982.

[55] Jacob M., "Heat transfer and flow resistance in cross flow of gases over tube banks," Trans. ASME 59, pp. 384-386, 1938

[56] Ashby M.F., Evans A.G., Fleck N.A., Gibson L.J., Hutchinson J.W. and Wadley H.N.G., 'Metal Foams: A Design Guide', Elsevier, 2000, ISBN-13:978-0-7506-7219-1 / ISBN-10:0-7506-7219-6

[57] Kuhn M., Bouchez M., Dufour E., Le Naour B., Justin J.-F. and Steelant J., 'Ceramic Strut Injection Technologies for High-Speed Flight', 20th AIAA International Space Planes and Hypersonic Systems and Technologies Conference, 06-09 July 2015, AIAA-2015-xxxx, Glasgow (UK).

[58] Schmidt-Wimmer S., Beyer S., Wigger F., Quering K., Bubenheim K., and Wilhelmi, C., 'Evaluation of Ultra High Temperature Ceramics and Coating-Systems for their Application in Orbital and Air-Breathing Propulsion', 18th International Space Planes and Hypersonic Systems and Technologies Conference, Tours, France. 09/2012

[59] Bouajila W. and Riccius J., 'Investigation of the influence of temperature and stress on the permeability of porous continuous fiber-reinforced composite materials through experiment and simulation', 6th European Conference for Aeronautics and Space Sciences, 29 June - 03 July 2015, EUCASS, Kraków $(\mathrm{PL})$.

[60] Bouajila W. and Riccius J., 'Determination of the temperature and stress dependency of porous continuous fiber-reinforced composite materials permeability through experiment and simulation', Space Propulsion 2016, 2-6/05/2016, Rome, Italy, 2016.

[61] Wagner A., Martinez Schramm J. and Hannemann K., 'Experimental Hypersonic Shock Wave Boundary Layer Interaction Studies on a Flat Plate at Elevated Surface Temperature', 20th AIAA International Space Planes and Hypersonic Systems and Technologies Conference, 06-09 July 2015, AIAA-2015xxxx, Glasgow (UK).

[62] Narasimha R., 'On the distribution of intermittency in the transition region of a boundary layer', Journal of Aeronautical Science, 24:711-712, 1957.

[63] Krishnan L. and Sandham N. D., 'Effect of Mach Number on the Structure of Turbulent Spots', Journal of Fluid Mechanics, Vol. 566, pp 225-234, 2006.

[64] Redford J. A., Sandham N. D. and Roberts G. T., 'Numerical simulations of turbulent spots in supersonic boundary layers: Effects of Mach number and wall temperature', Progress in Aerospace Sciences, Jul. 2012, Vol. 52, pp 67-79, doi 10.1016/j.paerosci.2011.08.002. 
[65] Redford J. A., Sandham N. D. and Roberts G. T., Direct numerical simulation of transitional flow at high Mach number coupled with a thermal wall model, Computers and Fluids, June 2011, Vol. 45:1, pp 37-46, doi 10.1016/j.compfluid.2010.11.024

[66] Redford J.A., Sandham N.D. and Roberts G.T., 'Roughness-induced transition of compressible laminar boundary layers', Seventh IUTAM Symposium on Laminar-Turbulent Transition, KTH, Stockholm, Sweden, June 23-26, 2009.

[67] Redford J.A., Sandham N.D. and Roberts G.T., 'Compressibility Effects on Boundary-Layer Transition Induced by an Isolated Roughness Element', AIAA J., Dec. 2010, vol. 48:12, pp 2818-2830, doi: 10.2514/1.J050186

[68] Cooper D., Jackson D., Launder B., and Liao G., "Impinging jet studies for turbulence model assessment-l. Flow-field experiments“, International Journal of Heat and Mass Transfer, vol. 36, no. 10, pp. 2675-2684, 1993.

[69] Steelant J., Passaro A., Fernandez-Villace V., Gubanov A., Ivayushkin D., Shvalev Y., Voevodenko N., Marini M. and di Benedetto S., 'Boundary Layer Transition Assessment on a Slender High-Speed Vehicle', 21st Int. Space Planes and Hypersonic Systems and Technology Conference, AIAA-2017-XXXX, 6-9 March 2017, Xiamen, China.

[70] Van den Eynde J., Steelant J. and Passaro A., 'Local Correlation-based Transition Model with Phenomenological Intermittency Behaviour', 21st Int. Space Planes and Hypersonic Systems and Technology Conference, AIAA-2017-xxxx, 6-9 March 2017, Xiamen, China.

[71] Aupoix B., "Modeling of Compressibility Effects in Mixing Layers", J. of Turbulence, Vol. 5, 2004.

[72] Van den Eynde J.P.J.P. and Sandham N.D., 'Numerical Simulations of Transition due to Isolated Roughness Elements at Mach 6', AIAA Journal, 23 July 2015, http://dx.doi.org/10.2514/1.J054139

[73] Van den Eynde J.P.J.P. and Sandham N.D., 'Numerical Investigation of Roughness-induced Transition at Mach 6 in the European ATLLAS // Programme', 8th European Symposium on Aerothermodynamics for Space Vehicles, 2-6 March 2015, Lisbon, Portugal.

[74] Van den Eynde J.P.J.P. and Sandham N.D., 'Numerical Simulation of Roughness-Induced Instability Growth and Transition at Mach 6', 7th AIAA Theoretical Fluid Mechanics Conference, 17 June 2014, Atlanta, GA, USA.

\section{Acknowledgments}

This work was performed within the 'Aero-Thermodynamic Loads on Lightweight Advanced Structures II' project investigating high-speed transport. ATLLAS II, coordinated by ESA-ESTEC, is supported by the European Union within the 7th Framework Programme Theme 7 Transport, Contract no.: ACP0-GA-2010263913. Further info on ATLLAS II can be found on http://www.esa.int/techresources/atllas II.

The authors want to thank all the colleagues that participate to the results presented in the present overview.

Consortium Beneficiaries:

\begin{tabular}{|l|l|l|l|}
\hline $\mathbf{N r}$ & Beneficiary name & $\begin{array}{l}\text { Beneficiary } \\
\text { short name }\end{array}$ & Country \\
\hline 1 & $\begin{array}{l}\text { European Space Agency - } \\
\text { European Space Research and Technology Centre }\end{array}$ & ESA-ESTEC & $\begin{array}{l}\text { France - } \\
\text { Netherlands }\end{array}$ \\
\hline 2 & $\begin{array}{l}\text { EADS Deutschland GmbH: European Aeronautic Defence } \\
\text { and Space - Innovation Work }\end{array}$ & EADS-IW & Germany \\
\hline 3 & MBDA-France & MBDA & France \\
\hline 4 & Deutsches Zentrum für Luft- und Raumfahrt & DLR & Germany \\
\hline 5 & Office National d'Etudes et de Recherches Aérospatiales & ONERA & France \\
\hline 6 & Totalförsvarets Forskningsinstitut & FOI & Sweden \\
\hline 7 & SITAEL S.p.A. & ALTA & Italy \\
\hline 8 & Gas-Dynamics Limited & GDL & UK \\
\hline 9 & National Institute of Aerospace Research 'Elie Carafoli' & INCAS & Rumenia \\
\hline 10 & TISICS: Titanium Composites & TISICS & UK \\
\hline 11 & University of Southampton & SOTON & UK \\
\hline 12 & University of Stuttgart & USTUTT & Germany \\
\hline 13 & Université Pierre et Marie Curie & UPMC & France \\
\hline
\end{tabular}

